\title{
Access to Health Care in Sierra Leone: The Experience of Poor, Rural Women
}

\author{
by
}

\author{
Clare Levin
}

B.A. (Hons), University of Manitoba, 2003

\begin{abstract}
A thesis submitted to the Faculty of Graduate and Postdoctoral Affairs in partial fulfilment of the requirements for the degree of

Master of Arts

in

International Affairs
\end{abstract}

Carleton University

Ottawa, Ontario

(C) 2010, Clare Levin 


$\begin{array}{ll}\begin{array}{l}\text { Library and Archives } \\ \text { Canada }\end{array} & \begin{array}{l}\text { Bibliothèque et } \\ \text { Archives Canada }\end{array} \\ \begin{array}{l}\text { Published Heritage } \\ \text { Branch }\end{array} & \begin{array}{l}\text { Direction du } \\ \text { Patrimoine de l'édition }\end{array} \\ \begin{array}{l}\text { 395 Wellington Street } \\ \text { Ottawa ON K1A ON4 } \\ \text { Canada }\end{array} & \begin{array}{l}\text { 395, rue Wellington } \\ \text { Ottawa ON K1A ON4 } \\ \text { Canada }\end{array}\end{array}$

Your file Votre référence

ISBN: 978-0-494-71683-0

Our file Notre référence

ISBN: 978-0-494-71683-0

NOTICE:

AVIS:

The author has granted a nonexclusive license allowing Library and Archives Canada to reproduce, publish, archive, preserve, conserve, communicate to the public by telecommunication or on the Internet, loan, distribute and sell theses worldwide, for commercial or noncommercial purposes, in microform, paper, electronic and/or any other formats.

The author retains copyright ownership and moral rights in this thesis. Neither the thesis nor substantial extracts from it may be printed or otherwise reproduced without the author's permission.

L'auteur a accordé une licence non exclusive permettant à la Bibliothèque et Archives Canada de reproduire, publier, archiver, sauvegarder, conserver, transmettre au public par télécommunication ou par l'Internet, prêter, distribuer et vendre des thèses partout dans le monde, à des fins commerciales ou autres, sur support microforme, papier, électronique et/ou autres formats.

L'auteur conserve la propriété du droit d'auteur et des droits moraux qui protège cette thèse. $\mathrm{Ni}$ la thèse ni des extraits substantiels de celle-ci ne doivent être imprimés ou autrement reproduits sans son autorisation.

In compliance with the Canadian Privacy Act some supporting forms may have been removed from this thesis.

While these forms may be included in the document page count, their removal does not represent any loss of content from the thesis.
Conformément à la loi canadienne sur la protection de la vie privée, quelques formulaires secondaires ont été enlevés de cette thèse.

Bien que ces formulaires aient inclus dans la pagination, il n'y aura aucun contenu manquant.

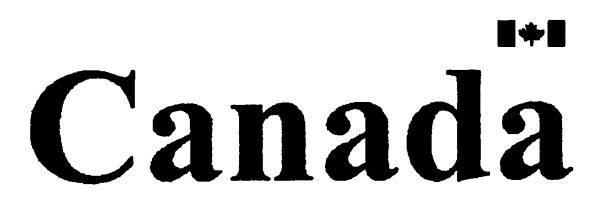




\begin{abstract}
This thesis examines barriers to accessing health care and their effects on health service utilization for poor women, using Sierra Leone as a case study. Literature on access to health often focuses on one factor, such as financial barriers, and does not examine the range of socio-economic and health system factors that affect access to health services. This thesis analyses access from the perspective of women utilizing these services, examining the interface between women, their socio-economic context, and the health system. It develops a new analytical framework that illustrates this interface, enabling the development of solutions that more effectively improve access. This research found evidence of barriers related to availability, acceptability, geographic accessibility, financial accessibility and gender that prevented women from accessing care in Sierra Leone. Policy recommendations for reducing these barriers are based on the framework and address both the immediate and distal factors that influence access to health services.
\end{abstract}




\section{Acknowledgements}

This research could not have taken place without the support and assistance of many people, including family, friends, other researchers, and colleagues. The guidance and suggestions I received from both my supervisors, Dr. Valerie Percival and Dr. James Ron, was invaluable. I would like to especially thank Dr. Percival, who continuously offered constructive critiques of my work, pushed me to engage deeply with the issues, and encouraged me when I found the process frustrating.

I would like to extend thanks to all the people in Sierra Leone who assisted me with this work: the interview respondents who gave their time to participate in this study; the staff and volunteers of the Centre for Development and Peace Education (cdpeace) who assisted me with logistics and making connections in the community; the leaders and community members in Mapaki, especially Chief Masa Paki Kebombor II, Sallay Conteh, Kouame Maxime, and Mabinty Kamara, who all made me feel so welcome and took such good care of me while I was in Sierra Leone; and many other friends and colleagues, both Sierra Leoneans and expatriates, who offered their thoughts, time, and friendship. I would like to thank the translators who worked with me, Mabinty Kamara and Michael Kalokoh, for their time and energy, especially Mabinty, who translated most of the interviews and helped me with selection of participants.

I was fortunate to receive financial support from two organizations that assisted me in carrying out this work: a Canada Graduate Scholarship from the Social Sciences and Humanities Research Council, which supported my studies; and a Students for Development internship from the Canadian International Development Agency that facilitated my travel to and stay in Sierra Leone. I very much appreciate this support.

Finally, I would like to thank my family and friends, who acted as sounding boards and shoulders to lean on, and who offered me encouragement, support, guidance and inspiration as I worked on this project. I especially want to express my deep gratitude to my husband, Chris Poulain for his patience with endless weekends spent writing and field work that took me half way around the world, and for the love, support, and encouragement he gave me as I took this journey. 


\section{Table of Contents}

Abstract $\quad$ ii

Acknowledgements iii

Table of Contents iv

List of Tables vi vi

List of Figures vii

List of Acronyms viii

CHAPTER 1: Introduction 1

1.1 Statement of the Problem 1

1.2 Research Questions 5

1.3 Argument 5

1.4 Chapter Outline $\quad 13$

CHAPTER 2: Methodology 15

2.1 Sampling: key informants and individual interviews $\quad 17$

$\begin{array}{ll}2.2 \text { Research instruments and data collection } & 20\end{array}$

$\begin{array}{ll}2.3 \text { Data coding and analysis } & 21\end{array}$

CHAPTER 3: A framework for assessing access to care: a review of the literature 22

3.1 Access to health care: the evolution of a definition 22

3.2 Geographic accessibility 24

$\begin{array}{ll}3.3 \text { Financial accessibility } & 27\end{array}$

3.4 Availability 31

3.5 Acceptability $\quad 32$

3.6 Conclusion $\quad 34$

CHAPTER 4: Sierra Leone - the economic, social, political, and health context 36

$\begin{array}{ll}4.1 \text { Economic and social conditions } & 37\end{array}$

4.2 Political context $\quad 42$

4.3 The health context $\quad 47$

4.4 Conclusion $\quad 54$

CHAPTER 5: Sierra Leone's health system $\quad 55$

$\begin{array}{ll}5.1 \text { Policy \& governance } & 57\end{array}$

$\begin{array}{ll}5.2 \text { Financing } & 63\end{array}$

$\begin{array}{ll}5.3 \text { Payments } & 67\end{array}$

$\begin{array}{ll}5.4 \text { Service delivery } & 67\end{array}$

$\begin{array}{ll}5.5 \text { Human Resources } & 70\end{array}$

5.6 Traditional health care $\quad 74$

$\begin{array}{ll}5.7 \text { Conclusion } & 75\end{array}$

CHAPTER 6: Gender and access to care $\quad 76$

CHAPTER 7: Geographic accessibility barriers $\quad 82$

$\begin{array}{ll}7.1 \text { Distance to a health facility } & 83\end{array}$

$\begin{array}{ll}7.2 \text { Access to transportation } & 83\end{array}$

7.3 Geographic barriers and choice of health provider 86

$\begin{array}{ll}7.4 \text { Conclusion } & 87\end{array}$

CHAPTER 8: Financial accessibility barriers $\quad 89$

8.1 Financial resources $\quad 91$ 
8.2 Knowledge and information about fees and costs 92

$\begin{array}{ll}8.3 \text { Methods of payment } & 93\end{array}$

8.4 Financial barriers and choice of health provider 96

$\begin{array}{ll}8.5 \text { Conclusion } & 97\end{array}$

CHAPTER 9: Availability barriers to access $\quad 98$

9.1 Staff availability and skill level $\quad 99$

$\begin{array}{ll}\text { 9.2 Availability of medications and equipment } & 101\end{array}$

$\begin{array}{ll}9.3 \text { Conclusion } & 103\end{array}$

CHAPTER 10: Acceptability barriers to access $\quad 104$

$\begin{array}{ll}10.1 \text { Traditional and cultural beliefs } & 106\end{array}$

$\begin{array}{ll}\text { 10.2 Social and community norms } & 109\end{array}$

$\begin{array}{ll}10.3 \text { Trust } & 110\end{array}$

10.4 Other acceptability barriers $\quad 111$

\begin{tabular}{ll}
10.5 Conclusion & 112 \\
\hline
\end{tabular}

CHAPTER 11: Conclusion and policy recommendations $\quad 114$

11.1 Barriers to accessing health care and their impact on health service $\quad 115$ utilization

$\begin{array}{ll}11.2 \text { Policy responses } & 118\end{array}$

$\begin{array}{ll}11.3 \text { Recommendations for future research } & 125\end{array}$

$\begin{array}{ll}11.4 \text { Conclusion } & 126\end{array}$

APPENDIX 1: Map of Sierra Leone $\quad 128$

APPENDIX 2: Consent Materials $\quad 129$

APPENDIX 3: Sample Interview Questions $\quad 132$

APPENDIX 4: Coding Structure $\quad 137$

BIBLIOGRAPHY 139 


\section{List of Tables}

Table 1: Characteristics of individual interview respondents..................................... 18

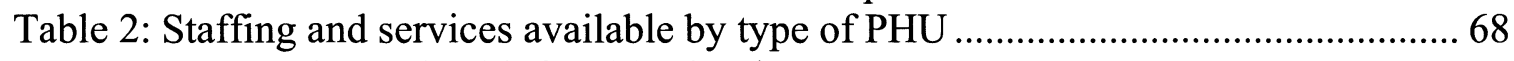

Table 3: Distribution of health facilities in Sierra Leone ...............................................69

Table 4: Health workforce distribution by category and region .................................. 72 


\section{List of Figures}

Figure 1: Areas where barriers to accessing health services may exist ......................... 6

Figure 2: Analytical framework ......................................................................... 10

Figure 3: Economic social and political context in the analytical framework.................. 36

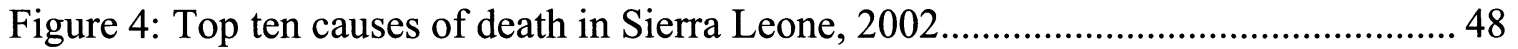

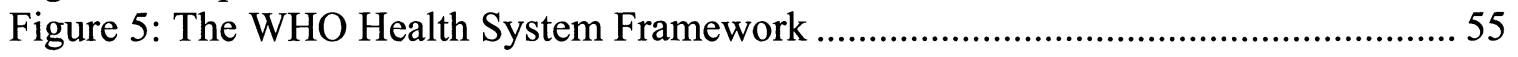

Figure 6: The health system in the analytical framework .......................................... 56

Figure 7: Diagram of health sector responsibilities, by level ..................................... 58

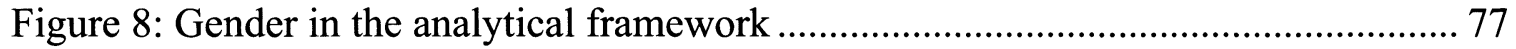

Figure 9: Geographic accessibility barriers in the analytical framework ....................... 82

Figure 10: Financial accessibility barriers in the analytical framework ......................... 89

Figure 11: Availability barriers in the analytical framework...................................... 98

Figure 12: Acceptability barriers in the analytical framework ................................... 105

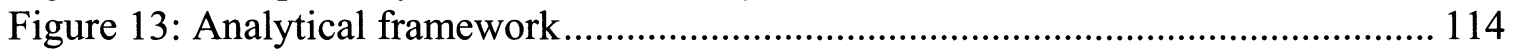




\section{List of Acronyms}

\begin{tabular}{|l|l|}
\hline AIDS & Acquired Immune Deficiency Syndrome \\
\hline AFRC & Armed Forces Revolutionary Council \\
\hline APC & All People's Congress \\
\hline ARI & Acute Respiratory Infection \\
\hline BPEHS & Basic Package of Essential Health Services \\
\hline cdpeace & Centre for Development and Peace Education \\
\hline CHC & Community Health Centre \\
\hline CHO & Community Health Officer \\
\hline CHP & Community Health Post \\
\hline CHW & Community Health Worker \\
\hline DHMT & District Health Management Team \\
\hline DMO & District Medical Officer \\
\hline ECOWAS & Economic Community of West African States \\
\hline EPI & Expanded Programme on Immunization \\
\hline GAVI & The Global Alliance for Vaccines and Immunisation \\
\hline GNI & Gross National Income \\
\hline GoSL & Government of Sierra Leone \\
\hline HIV & Human Immunodeficiency Virus \\
\hline HSCC & Health Sector Coordinating Committee \\
\hline IEC & Information, Education and Communication \\
\hline IFIs & International Financial Institutions \\
\hline MCH Aide & Maternal and Child Health Aide \\
\hline MCHP & Maternal and Child Health Post \\
\hline MDG & Millennium Development Goal \\
\hline MoHS & Ministry of Health and Sanitation \\
\hline MSF & Médecins Sans Frontières \\
\hline NPRC & National Provisional Ruling Council \\
\hline NGO & Non-governmental Organization \\
\hline NHSSP & National Health Sector Strategic Plan \\
\hline OB/GYN & Obstetrician/Gynecologist \\
\hline PHU & Peripheral Health Unit \\
\hline PRSP & Poverty Reduction Strategy Paper \\
\hline RUF & Revolutionary United Front \\
\hline SECHN & State Enrolled Community Health Nurse \\
\hline SLDHS & Sierra Leone Demographic and Health Survey \\
\hline SLPP & Sierra Leone People's Party \\
\hline STIs & Sexually Transmitted Infections \\
\hline SWAp & Sector Wide Approach \\
\hline TBA & Traditional Birth Attendant \\
\hline UN & United Nations \\
\hline UNAMSIL & United Nations Mission in Sierra Leone \\
\hline WHO & World Health Organization \\
\hline
\end{tabular}




\section{CHAPTER 1: Introduction}

\subsection{Statement of the Problem}

Several new articles examining maternal mortality have recently been published in The Lancet. ${ }^{1}$ These articles review the current levels and trends in maternal mortality and assess progress towards the fifth Millennium Development Goal (MDG) of reducing the maternal mortality ratio by three quarters by 2015 . This research finds that although some progress has been made, maternal morbidity and mortality remain extremely high throughout much of the developing world, and progress remains stubbornly slow. ${ }^{2}$

High rates of maternal mortality can act as an indicator that a country faces challenges in ensuring adequate health for all of its citizens. It can indicate that there are problems with the functioning of the health system, or that broader systemic issues such as poverty or gender inequality exist that are having a negative impact on health outcomes. The inter-relationship between health and development is clear: "The healthier people are, the less likely they are to be poor - the more entrenched poverty is, the more likely people are to become ill and die." ${ }^{, 3}$ However, most developing countries are not able to meet the health needs of their populations - while these countries account for 90 percent of the global disease burden, they represent only 12 percent of global health

\footnotetext{
${ }^{1}$ See for example: Margaret C Hogan et al., "Maternal Mortality for 181 Countries, 1980-2008: A Systematic Analysis of Progress Towards Millennium Development Goal 5," The Lancet 375, no. 9726 (April 12, 2010). Badara Samb, "Reforming Country Health Systems for Women's Health," The Lancet 375, no. 9712 (January 30, 2010). Zulfiqar A. Bhutta et al., "Countdown to 2015 Decade Report (200010): Taking Stock of Maternal, Newborn, and Child Survival," The Lancet 375, no. 9730 (June 5, 2010). ${ }^{2}$ Hogan et al., "Maternal Mortality for 181 Countries," 1622. Bhutta et al., "Countdown to 2015 Decade Report," 2043.

${ }^{3}$ Department for International Development (DFID), Working Together for Better Health: Department for International Development (DFID), 2007), http://www.dfid.gov.uk/Documents/publications/healthstrategy07.pdf (accessed June 18, 2009), 2.
} 
expenditures. ${ }^{4}$ For women around the world, protecting and maintaining their health and accessing health care ${ }^{5}$ is an ongoing challenge.

Maternal health has been the subject of much recent attention from the policy community, partly due to the lack of progress in reducing maternal mortality rates. The Canadian government made a major maternal and child health initiative the focus of the G8 meeting held in Canada in June $2010,{ }^{6}$ drawing significant political and media interest. Maternal health is also at the top of the health agenda in Sierra Leone. In September 2009, Amnesty International launched a campaign to end maternal mortality in Sierra Leone, declaring the high number of maternal deaths in the country a "human rights emergency."7 Partly in response to this campaign, a new national initiative providing free health care for pregnant and lactating women and young children was launched in April 2010 in an attempt to reduce child and maternal mortality. ${ }^{8}$

Many factors affect women's health outcomes, including the socio-economic and political context, gender roles and norms, the functioning of the health system, and women's ability to access the health services they need. While improving health outcomes for women requires addressing each of these factors, increasing women's ability to access proven and effective health interventions is an important area of work.

\footnotetext{
${ }^{4}$ Pablo Gottret and George Schieber, Health Financing Revisited: A Practitioner's Guide (Washington, D.C.: The International Bank for Reconstruction and Development/The World Bank, 2006), 23.

5 "Health care" is defined as the prevention, treatment, and management of illness and the preservation of mental and physical well-being through the services offered by the medical and allied health professions (standard definition). For the purposes of this research, I also include untrained and traditional sources of care, for example, village healers or traditional birth attendants under "allied health professions".

${ }^{6}$ Office of the Prime Minister of Canada, "Canada's G8 Priorities," http://pm.gc.ca/eng/media.asp?id=3093 (accessed March 28, 2010).

7 Amnesty International, "Maternal Death Rate in Sierra Leone Is A "Human Rights Emergency"," $\mathrm{http} / / / \mathrm{www} . a m n e s t y . o r g /$ en/news-and-updates/report/maternal-death-rate-sierra-leone-quothuman-rightsemergencyquot-20090921 (accessed October 15, 2009).

${ }^{8}$ Government of Sierra Leone, Free Healthcare Services for Pregnant and Lactating Women and Young Children in Sierra Leone (Freetown, Sierra Leone: Government of Sierra Leone, 2009), http://www.sierraleoneconference2009.org/docs/free_services_framewk_nov09.pdf (accessed November 29, 2009).
} 
Research that explains why women do or do not use health services can help to reduce barriers to accessing those services, resulting in improved health outcomes for women.

Access to health care is defined in different ways, but is usually linked to the "timely use of services according to need." Much of the research on access to health to date has focused on technical and supply side factors: strengthening specific components of health systems, building health infrastructure, and examining medical solutions. The literature on barriers to care has tended to look primarily at constraints faced by the user, such as financial and geographic barriers.

Absent in much of the existing work on access to health is the inclusion of the perspective of the user of health services. This is a critical omission. Even if effective health care interventions are readily available, users may still choose not to access these interventions because of their perceptions about health services. Studies have shown that patient behaviour may be influenced as much by perceptions and beliefs about health care as by the objective reality of barriers that exist. ${ }^{10}$ For example, although exemptions from fees for health services may be available, if women are not aware of this, or if they are afraid the exemption will not be honoured, the perceived cost of care will still act as a deterrent.

As Priscilla Ulin et al. state, “[m]any problems central to public health research and practice are deeply embedded in their cultural contexts," and "research in public health must have the capacity to uncover multiple perspectives and understand their

\footnotetext{
${ }^{9}$ A more comprehensive definition of access used for the purposes of my research is developed in the literature review. David H. Peters et al., "Poverty and Access to Health Care in Developing Countries," Annals of the New York Academy of Sciences 1136, no. Reducing the Impact of Poverty on Health and Human Development: Scientific Approaches (June 2008): 162.

${ }^{10} \mathrm{~J}$. William Thomas and Roy Penchansky, "Relating Satisfaction with Access to Utilization of Services," Medical Care 22, no. 6 (June 1984): 554. Also, patients' perception of the quality of care has been found to be a more important determinant of health care utilization than other aspects of access. Peters et al., "Poverty and Access to Health Care in Developing Countries," 166.
} 
implications for health decision-making." ${ }^{11}$ Barriers to accessing health care must be understood within the broader context - the interface between women, the health system, and social, economic and political factors. Using Sierra Leone as a case study, my thesis examines how barriers to accessing care, both actual and perceived, affect women's utilization of health services. I focus on poor, rural women as this population has received little attention in the literature.

The qualitative, single case study approach of my research allowed me not only to examine existing barriers and their effects, but also to develop a new analytical framework for understanding the interactions among these various barriers. This framework (found in Figure 2, p. 10) provides a better understanding of these interactions, facilitating the development of more effective solutions to barriers. The qualitative nature of my work is particularly useful for better understanding barriers around the acceptability of care, where user opinions are especially important.

This study also helps to fill a knowledge gap on women and access to health care. Most studies that examine the issue of gender in the context of health focus on genderspecific medical problems. ${ }^{12}$ Little work has been carried out on the relationship between gender and access, and even less on the perspectives of women in developing countries as users of the health system. However, women's position in society can have a significant effect on the health status of women and on their ability to access health care. ${ }^{13}$ Barriers to care for women can be influenced by gender differences in levels of education or the ability to earn or access income. Gender role stereotypes and expectations may mean that

\footnotetext{
${ }^{11}$ Priscilla R. Ulin, Elizabeth T. Robinson, and Elizabeth T. Tolley, Qualitative Methods in Public Health: A Field Guide for Applied Research (San Francisco, CA: Jossey-Bass, 2005), 5.

${ }^{12}$ Marta Gil-Lacruz and Ana I. Gil-Lacruz, "Health Perception and Health Care Access: Sex Differences in Behaviors and Attitudes," The American Journal of Economics and Sociology 69, no. 2: 784.

${ }^{13}$ Editorial, "Gender Equity Is the Key to Maternal and Child Health," The Lancet 375, no. 9730 (June 5, 2010): 1939.
} 
women lack information and decision-making power about their health, or need to keep health choices secret from family members. An analysis of access to health from the perspective of women is therefore critical in improving women's health.

\subsection{Research Questions}

This research is guided by the following research questions:

1. What are the actual or real barriers to accessing health care for poor rural women in Sierra Leone?

2. What do women perceive as major barriers to accessing health care?

3. Are there differences between the real and perceived barriers?

4. How do these barriers influence choices about health care utilization?

\subsection{Argument}

\section{Literature}

I carried out an extensive review of the literature, assessing factors that influence a woman's ability to access health care services. My literature review was guided by the David H. Peters et al. framework of access to health care services (Figure 1 below), and I focused on literature specific to developing countries, primarily in sub-Saharan Africa. Specific components of access identified by Peters et al. include geographic accessibility (the relationship between the location of the user and the location of health services), financial accessibility (the relationship between the user's willingness/ability to pay and the cost of services), availability (the relationship between the type and quantity of care needed by users and the type and quantity of care that is available) and acceptability (the 
relationship between the user's preferences and expectations about health services and the characteristics of health services provided). ${ }^{14}$ Quality is placed at the centre of all dimensions of access. The literature review examines each component of access and identifies potential barriers that might exist in Sierra Leone, as well as their possible impact on health service utilization.

\section{Figure 1: Areas where barriers to accessing health services may exist}

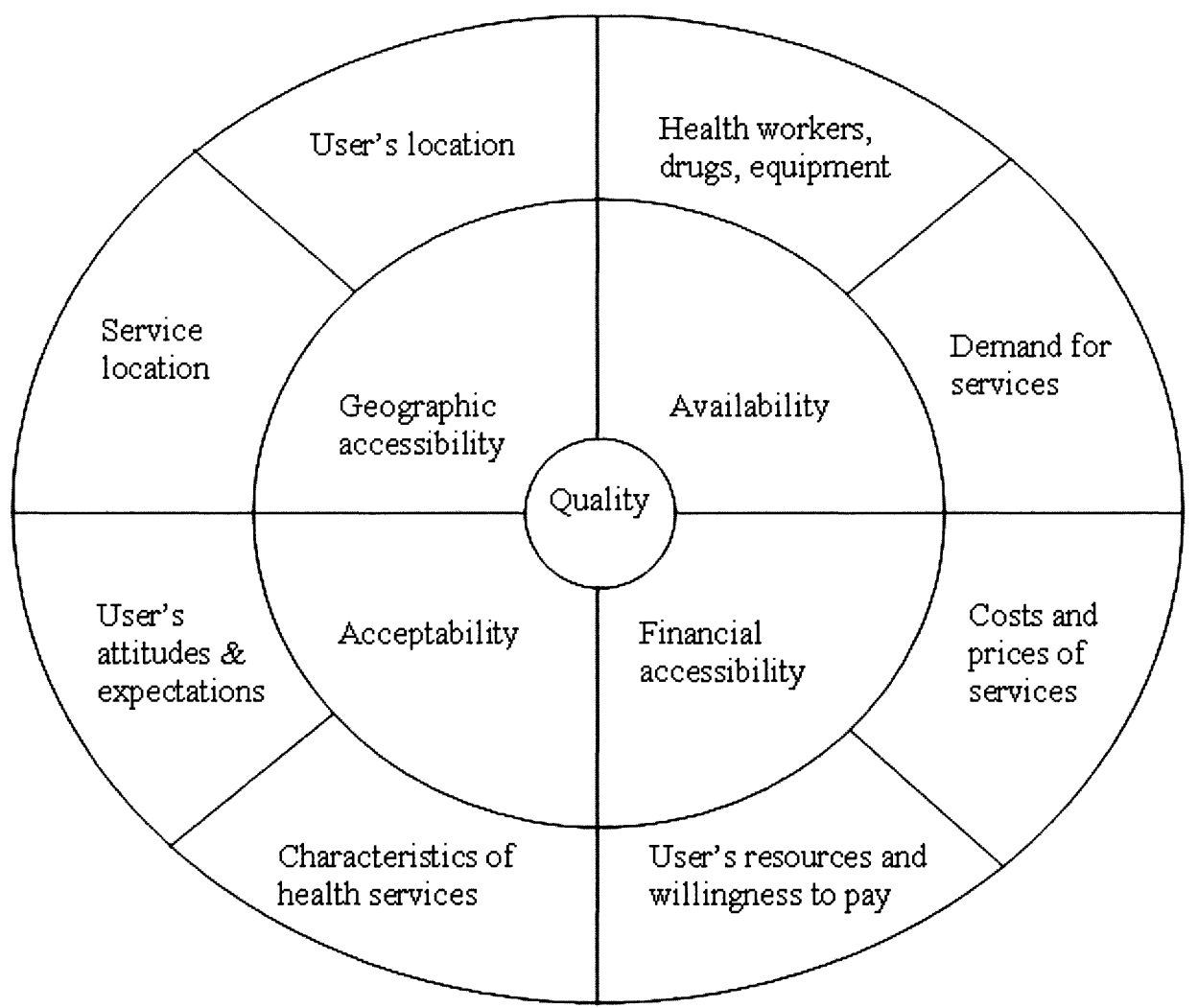

Source: David H. Peters et al., "Poverty and Access to Health Care in Developing Countries," Annals of the New York Academy of Sciences 1136, no. Reducing the Impact of Poverty on Health and Human Development: Scientific Approaches (June 2008): 162.

While the Peters et al. framework was useful for outlining potential barriers, it does not have significant power to explain why and how women access health services. Its predictive power in shaping policy interventions is therefore limited. In addition, it

\footnotetext{
${ }^{14}$ Peters et al., "Poverty and Access to Health Care in Developing Countries," 162.
} 
gives the issue of gender only a passing mention, ${ }^{15}$ and does not explore how potential barriers may affect men and women differently. My literature review also includes an examination of each component of access through the lens of gender.

\section{Argument}

Through semi-structured interviews with 18 women and 7 key informants in one community in Sierra Leone, I examined whether or not the following factors identified in current research were present in Sierra Leone and how they affected a woman's utilization of health care:

- Geographic accessibility of health care services, including the distance to those services, women's access to transportation, and the quality of the road network.

- Financial accessibility of health care services, including the existence of risk pooling, and the resources women have available to pay the costs associated with seeking care, including formal, informal, and indirect costs. ${ }^{16}$

- Availability of health care for women, including the opening hours of clinics and the availability of health workers and medications.

- Acceptability of services to women, including the level of trust in care providers and cultural or social practices that influence health decision-making.

- Gender roles and norms, including women's ability to make decisions about their own health care and access the resources they need to obtain health care.

- A woman's knowledge of the causes and treatment of ill health, of available health care services, costs and possible methods of payment.

\footnotetext{
${ }^{15}$ Gender inequity in access to health is mentioned only once in the paper, on page $166 . ـ$, "Poverty and Access to Health Care in Developing Countries."

${ }^{16}$ For the purposes of this study, formal fees are defined as official charges to patients for health care goods and services as published in the health facility or in an official policy document. Informal fees are defined as other payments made by users not formally sanctioned in policy, but required in order to receive care (e.g. gifts or bribes). Indirect costs are defined as costs associated with seeking health care, but are not direct costs at the point of service (e.g. the cost of transportation, lodging or meals; the opportunity cost of lost time, etc.). It is important to note here that as there were no published or official fee schedules in Sierra Leone, it was very difficult for interview respondents to differentiate between formal and informal costs.
} 
Summary of results

My research produced clear evidence that both financial and geographic barriers exist in Sierra Leone, and both types of barriers deterred women from seeking health care. In the case of both acceptability and availability barriers, the evidence demonstrated that the reduction of barriers in these areas (for example, improvements in the availability of health services and increased acceptability due to trust in the health staff) contributed to increased utilization.

There was evidence that in some cases women may be deterred from seeking care by their perceptions of barriers rather than the actual barriers that exist. For example, some respondents indicated they would not try to seek health care because they believed that they would not be provided with care if they did not have cash available to pay the costs. In fact, other payment options were available, such as paying in-kind or paying in cash at a later date, that would have allowed women to get the care they needed had they been aware of these options.

While this case study focuses on barriers to accessing health services, these services are obviously located within a wider context. My case study of Sierra Leone demonstrates that barriers to accessing health services are also affected by the health system and the broader social, political and economic circumstances. I found evidence of the impact of these distal factors on barriers to care in my research. For example, the economic circumstances of a woman and her family affect her ability to earn income to pay the costs of care. The functioning of the health system is also a critical component weak supply chains and poor working conditions for staff can result in greater availability, financial accessibility and acceptability barriers. 
This case study facilitated the development of an analytical framework, shown in the figure below, that illustrates the interactions between all the factors that influence health care utilization. The outcome of interest, utilization, is in pink. The contextual factors (social, economic, and political) are identified in green. These distal factors affect utilization more indirectly, influencing the effectiveness of the health system and the general socio-economic circumstances in which women live.

The health system factors (policy and governance, service delivery, financing, and payments) are in blue. In the model, service delivery includes all service providers (government, private for-profit, and private non-profit), and encompasses factors such as human resources, medical products and technologies, pharmaceuticals, and the number and location of health facilities. While the World Health Organization (WHO) does not make a clear distinction between financing and payments, ${ }^{17}$ the way in which money is paid out creates, "powerful incentives that influence the actions of all the organizations and individuals in the health system." 18 Financing and payments are therefore separated out in my framework.

Weak health systems have been a major factor limiting progress on meeting the MDGs, ${ }^{19}$ illustrating the important role that health systems play in improving health outcomes. The functioning of the health system is affected by the external factors highlighted in green in the framework. The health system in turn affects the different

\footnotetext{
${ }^{17}$ World Health Organization, Everybody's Business: Strengthening Health Systems to Improve Health Outcomes: WHO's Framework for Action (Geneva: World Health Organization, 2007), http://www.who.int/healthsystems/strategy/everybodys_business.pdf (accessed June 26, 2010), 3. ${ }^{18}$ Marc J. Roberts et al., Getting Health Reform Right: $\bar{A}$ Guide to Improving Performance and Equity (Oxford: Oxford University Press, 2004), 190.

${ }^{19}$ Robert Fryatt, Anne Mills, and Anders Nordstrom, "Financing of Health Systems to Achieve the Health Millennium Development Goals in Low-Income Countries," The Lancet 375, no. 9712 (January 30, 2010): 419.
} 
components of access to health from the supply side (i.e. supply of medications and staff, locations of health facilities, cost of care, payment options, etc.).

The demand side factors, the circumstances in which women live, that affect the different components of access are highlighted in purple. The accessibility issues identified in both health systems and access literature are in yellow. It is the interactions between these demand side factors (influenced by the context) and the accessibility issues (influenced directly by the health system factors and indirectly by the context) that determine health care utilization.

Figure 2: Analytical framework

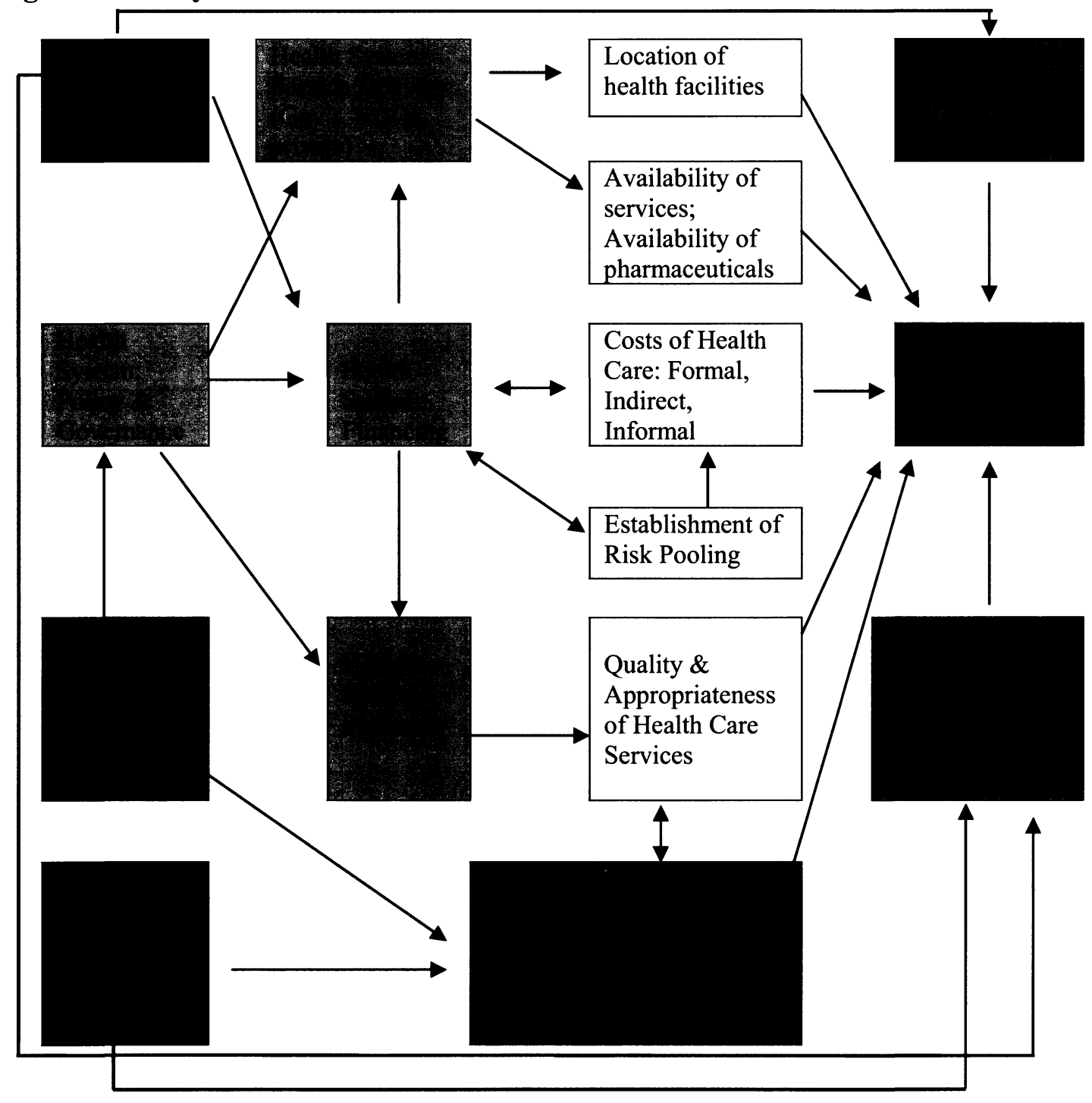


I developed and used this analytical framework because the existing literature did not adequately capture the interface between women and the health system, and the relationship between the political, economic and social context and the situation of women and the health system. This framework, in my single case study, better explains the multitude of factors that shape women's ability to access health care. It is more useful for policy makers because it has predictive power, clearly showing the different policy levers that can be used to improve accessibility. Because my field work was based in only one small community, the framework I developed needs to be tested in other communities and countries. This is an important recommendation for future research.

\section{Policy recommendations}

A range of policy recommendations follow as a result of my research. Since financial accessibility emerges as one of the most important barriers deterring the use of health services, many of the recommendations focus on improving financial accessibility. In order to reduce formal costs, a community based insurance program to facilitate local risk pooling could be implemented in Sierra Leone as a short to medium term solution (until national health insurance is available). Posting a standardised fee schedule in all health facilities so that patients know what they are supposed to pay will help to reduce informal costs (gifts, bribes, etc.).

Strengthening several components of the health system, especially in relation to human resources and service delivery, will reduce barriers related to availability as well as improving financial accessibility. Improving supply chains for pharmaceuticals and improving pay and working conditions for staff will increase the availability of services. 
It will also reduce the likelihood of informal charges for health care because staff are supplementing low salaries, or because clinics lack the drugs they need and staff have to re-supply drugs from their own incomes.

Geographic accessibility is another area in which barriers were a significant deterrent of use of health care. One way of addressing this barrier would be to hire and train community health workers that could provide basic preventative services in their home villages. Improving Sierra Leone's road network and developing an ambulance system would also help to improve geographic accessibility.

Sensitization of the public (both men and women) about the importance of using conventional health care will help to reduce acceptability barriers. This sensitization already takes place in Sierra Leone, but could be increased. Sensitization usually takes place through community meetings, radio programs, posters, and performance (e.g. skits and songs). Providing sensitization and training for conventional health workers on techniques for working more closely with traditional healers could also help to build trust in conventional care and improve utilization rates.

These interventions all address the proximal causes of barriers to accessing health care, but distal causes must also be addressed. Improving development in Sierra Leone, and addressing issues such as gender inequality and agricultural productivity will also help to reduce barriers and increase utilization. External support from donors, both for health and for development more generally, will remain critical until the Government of Sierra Leone (GoSL) has greater capacity for own-source revenue generation.

While access to health services is an important component of improving women's health, there are factors other than health services that affect health outcomes for women. 
For example, increasing gender equality can improve women's education levels, their access to financial resources, and their ability to act autonomously, all of which can contribute to reducing maternal mortality. ${ }^{20}$ Addressing the distal issues that influence access will therefore not only improve access to health services, but will also help to reduce women's health problems such as high rates of maternal mortality in other ways.

\subsection{Chapter Outline}

This thesis consists of eleven chapters. Following this introductory chapter, the second chapter reviews the methodology of my study in more detail. The third chapter, the literature review on access to health care, examines the potential barriers to access identified in the literature for each component in the Peters et al. framework (geographic, financial, acceptability, availability) as well as for gender.

The fourth and fifth chapters begin the analysis of the existing barriers to access in Sierra Leone. In the fourth chapter, I explore the current political, social and economic, and health environment in Sierra Leone. This chapter also provides a brief overview of the civil war and its aftermath, including its health-related effects. The fifth chapter focuses on Sierra Leone's health system, looking at components of the system such as governance, infrastructure, financing, and staffing, and assessing where barriers to access may exist.

Chapters six through ten analyse the findings from my interviews, examining in turn gender-related, geographic, financial, availability, and acceptability barriers to access. All these chapters include results from key informant interviews and individual

\footnotetext{
${ }^{20}$ Oona M R Campbell and Wendy J Graham, "Strategies for Reducing Maternal Mortality: Getting on with What Works," The Lancet 368, no. 9543: 61.
} 
interviews. These chapters address the second, third and fourth research questions, looking at what poor rural women in Sierra Leone think are the biggest barriers to accessing health care, the differences between these perceptions and the reality of existing barriers, and how these barriers influence choices about health care utilization. The eleventh and final chapter offers further discussion of the findings of the research, makes policy recommendations for improving access to health care for women in rural Sierra Leone, and discusses possibilities for future research. 


\section{CHAPTER 2: Methodology}

Qualitative methods, combined with documentary research, provided the best approach to answering my research questions. This approach also allowed me to expand the framework developed by Peters et al. and examine the problem from a more holistic perspective, taking into account how the health system and the social, cultural, economic, political, and physical environments interact to create barriers to access.

My research uses an interpretivist perspective to help identify the barriers to utilization of health care services that exist for poor rural women in Sierra Leone. Interpretive research "focuses not only on objectively verifiable facts but also on the many subjective meanings that people attach to them. ${ }^{21}$ This means understanding both the objective barriers that actually exist and also how a woman's subjective understanding of barriers affects her choices about whether and how to use health care.

I selected Sierra Leone as a case study for my research in part because I had the opportunity to live there for four months while working for a local NGO based in rural Sierra Leone. Sierra Leone is an appropriate choice for a case study for two reasons: its poor performance on women's health indicators, especially maternal mortality, and its status as a post-conflict country, still recovering from a long and brutal civil war. ${ }^{22}$ Violent conflict remains one of the most serious barriers to development facing many countries, ${ }^{23}$ so gaining a better understanding of health in the post-war context is critical.

\footnotetext{
${ }^{21}$ Ulin, Robinson, and Tolley, Qualitative Methods in Public Health, 18.

${ }^{22} \mathrm{~A}$ brief overview of the war is included in Chapter 4.

${ }^{23}$ Of the 34 countries the farthest from reaching the Millennium Development Goals, 22 of them are in or emerging from conflict. United Nations Millennium Project, "Chapter 12: Strategies for Countries Affected by Conflict," in Investing in Development: A Practical Plan to Achieve the Millennium Development Goals (London: Earthscan, 2005), 183.
} 
Sierra Leone's poor performance on women's health ${ }^{24}$ demonstrates that the country needs to improve access to proven health interventions. Although other factors also influence women's health outcomes (as identified in my framework - economic context, gender inequality, cultural expectations, etc.), a better understanding of the barriers that prevent women from getting health care will help to design more effective interventions to increase utilization. This research therefore has the potential to make a significant difference in health outcomes in Sierra Leone.

Sierra Leone is a small country geographically, approximately 72,000 square kilometres in size, with Guinea, Liberia, and the ocean along its borders. Its population is estimated to be around 5.5 million. ${ }^{25}$ The major urban centres are the capital, Freetown, and the cities of Bo, Makeni, and Kenema, but the majority of Sierra Leoneans live in rural areas. ${ }^{26}$ There are more women than men in Sierra Leone (a ratio of 94 men to 100 women), and the population is young (41.7\% of people are under the age of 14$){ }^{27}$

Due to limited time and resources, I focused my interviews on only one community in Sierra Leone. This focus allowed a more in-depth analysis of the specific context and issues in that community. My field work was carried out in and around the

\footnotetext{
${ }^{24}$ Maternal mortality rates are estimated at 857 deaths per 100,000 live births in 2008 , and remain among the highest in the world. Statistics Sierra Leone and ICF Macro, Sierra Leone Demographic and Health Survey 2008 (Calverton, Maryland, USA: Statistics Sierra Leone and ICF Macro, 2009), 27. And Hogan et al., "Maternal Mortality for 181 Countries," 1619.

${ }^{25}$ The World Bank Group, "Sierra Leone Country Data Profile," http://ddpext.worldbank.org/ext/ddpreports/ViewSharedReport?\&CF=\&REPORT_ID=9147\&REQUEST TYPE=VI EWADVANCED (accessed January 15, 2010).

${ }^{26}$ As of 2006 , only $41 \%$ of the national population was located in urban areas. World Health Organization, "WHO Statistical Information System (WHOSIS)," http://www.who.int/whosis/ (accessed August 13, 2009).

${ }^{27}$ Armand Thomas, Veronica M. MacCormack, and Peter S. Bangura, 2004 Population and Housing Census: Analytical Report on Population Size and Distribution Age and Sex Structure (Freetown, Sierra Leone: Statistics Sierra Leone, 2006), http://www.statistics.sl/2004\%20Pop.\%20\&\%20Hou.\%20Census\%20Analytical\%20Reports/2004\%20Cen sus\%20Report\%20on\%20Population\%20Size\%20Age\%20and\%20Sex\%20Structure.pdf (accessed August 13, 2009), 17 and 44.
} 
rural village of Mapaki (see Appendix 1 for a map). Mapaki is the principal town in the chiefdom of Paki Masabong, located in the district of Bombali in the Northern Province of Sierra Leone. As my internship was based in Mapaki, I had almost 8 weeks prior to beginning my field work to establish relationships, begin to build trust with community members, and identify potential interview subjects.

\subsection{Sampling: key informants and individual interviews}

The core component of my field work in Sierra Leone was in-depth, semistructured interviews both with women in the community of Mapaki and other key informants in the area. The field work was carried out between October 16 and December 20, 2009. This research was given ethics approval from Carleton University's Research Ethics Board and is considered to be of minimal risk to participants. While there was no formal ethics approval process in Sierra Leone, I received permission from both the Paramount Chief of Paki Masabong Chiefdom and the Bombali District Council to carry out my research in Mapaki.

I interviewed 25 people, 18 women and 7 key informants (three of which were women). Interviews were conducted in English, Temne or Krio. Where necessary, consent materials were orally translated into Temne or Krio in order to obtain oral consent. For any interview subject where written consent was appropriate, the English consent materials were used. A copy of the consent materials is available in Appendix 2.

A relatively homogenous sample was used for the individual interviews.

Homogenous samples are useful for studying the behaviour or beliefs of a group in 
depth, ${ }^{28}$ and in this case I was interested in poor, rural women. All individual interview subjects were women aged 18 or older from the rural community of Mapaki who either experienced illness or had been pregnant in the last year, and who did not earn a regular salary. Within this homogenous sample, I tried to include some variation along other variables such as age, marital status, religion, and number of children.

I used a mix of purposive sampling and snowball sampling to identify interview subjects. My translator, Mabinty Kamara, also assisted me with identifying individual interview subjects who met my sampling criteria. Table 1 below gives the basic characteristics of individual interview respondents.

Table 1: Characteristics of individual interview respondents

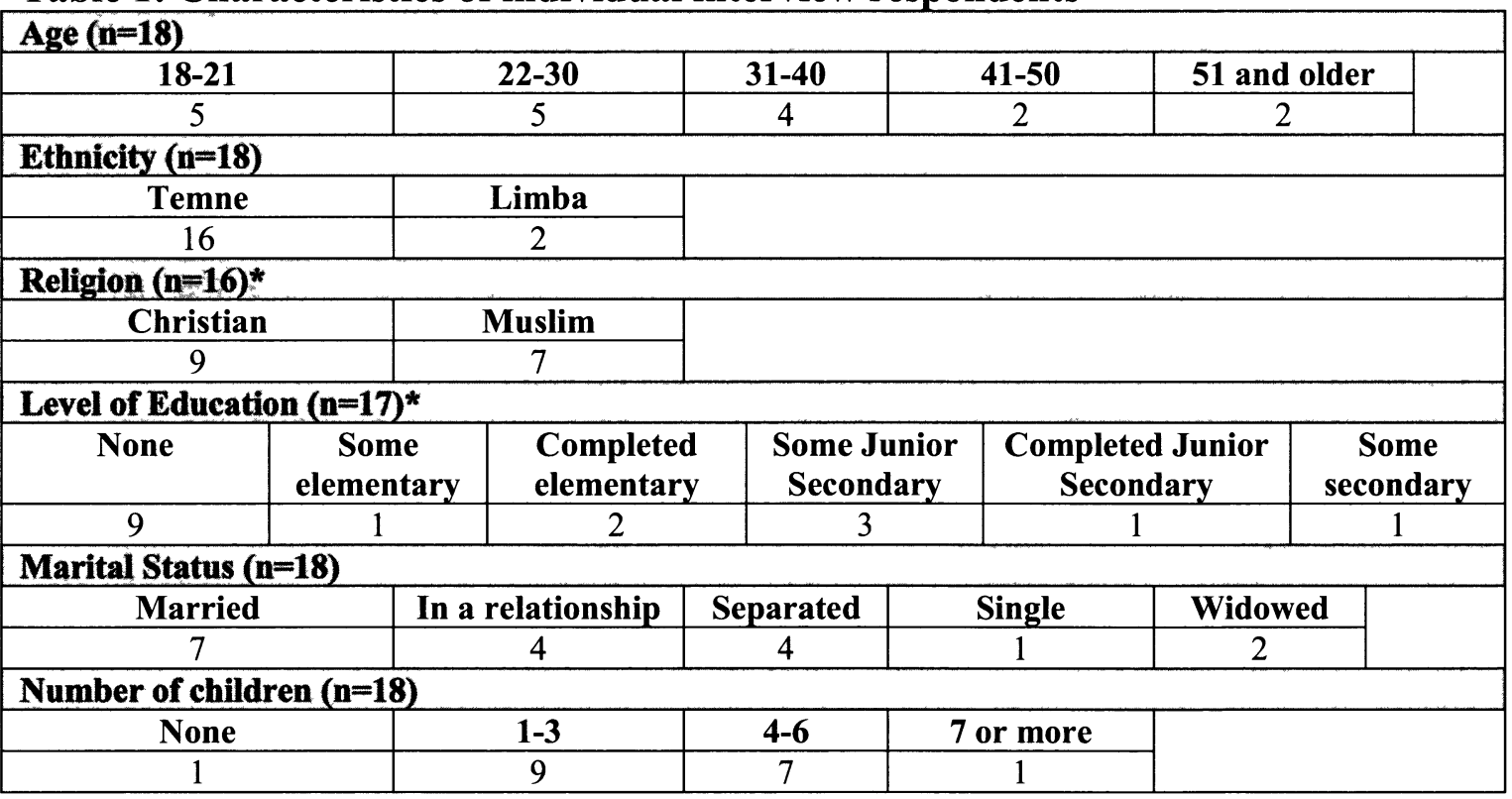

* Some respondents did not answer these questions.

Although women from both the Limba and Temne ethnic groups live in Mapaki, I was limited to interviewing women who spoke Temne because the translators that were available to me only spoke Temne. As a result, only two individual respondents were not from the Temne ethnic group. Unfortunately, there is virtually no data comparing the

${ }^{28}$ Ulin, Robinson, and Tolley, Qualitative Methods in Public Health, 57. 
characteristics of different ethnic groups (e.g. religion, incidence of polygamy, economic status, etc.) that would allow for a better understanding of the similarities and differences between groups. However, based on my own observations of life in Mapaki and anecdotal conversations about the similarities between the two groups, I do not expect this to create bias in my results as the Limba, Temne and other ethnic groups would all face similar barriers to accessing health services. There are no significant ethnic tensions in Sierra Leone that would result in different ethnic groups having different levels of access. Further research applying my analytical framework will help clarify the generalizability of these findings.

I did not consider or assess severity of illness in my selection of interview subjects. In many cases, the women themselves did not know the reason for their illness or what they received as treatment, so it was difficult for me as a layperson to know how to categorize these cases. In cases where interview subjects were able to identify the cause, the most common causes of illness were malaria and hypertension. The majority of the illnesses seemed to be less severe.

Key informant interviews were carried out with people either in positions of leadership, or with experience in health care in the community. The key informants cannot be named due to the ethical requirements of this research, but included 2 health practitioners, 2 political leaders, 2 leaders in the women's community and one other person involved in many aspects of community life in Mapaki. All the key informants lived either in Mapaki or in Makeni, the capital city of Bombali District, located about 25 km from Mapaki. 


\subsection{Research instruments and data collection}

A total of $26^{29}$ in-depth, semi-structured interviews were carried out throughout my field work. The interview questions for individual interviews and key informants were different, but focused on similar issues. The individual interview questions focused primarily on the participant's own experiences with and knowledge about health care.

Key informant interviews included questions about barriers to access for women and also assisted with data triangulation and provided further information about Sierra Leone's health system. A copy of the questions for both groups, and a brief overview of how the questions were developed and used is included in Appendix 3.

A translator was used for most of the interviews - only 5 of the interviews were conducted in English and the rest in Krio or Temne. The translator for the majority of the interviews was Mabinty Kamara, a woman living in Mapaki. Two interviews with key informants were translated by a second translator, Michael Kalokoh. Neither Kamara nor Kalokoh are professional translators. Both are teachers at nearby schools with good English and a good knowledge of the Mapaki community.

Using translators known in the community may have biased my results. It is possible that women were more willing to talk to me because of their trust in and familiarity with the translators. It is also possible that interview respondents would withhold information that they did not want their fellow community member to know. ${ }^{30}$ Unfortunately, it is difficult to know if the results were biased in either direction as a result of my selection of translators.

\footnotetext{
${ }^{29} \mathrm{I}$ interviewed one key informant a second time in order to clarify some of their earlier statements. ${ }^{30}$ Note that translators were subject to a confidentiality agreement and this was communicated to study participants.
} 
In addition to the interviews, I obtained copies of several important primary documents that were extremely helpful with data triangulation. I received draft copies of both the National Health Sector Strategic Plan (NHSSP), 2010 - 2015 and the Basic Package of Essential Health Services (BPEHS), and obtained a hard copy of the recentlyreleased complete results of the 2008 Sierra Leone Demographic and Health Survey.

\subsection{Data coding and analysis}

Once all of the interviews were transcribed, they were entered into NVivo, a data analysis program. ${ }^{31}$ I was the only person doing the coding and analysis, so the problem of multiple coders was not an issue. A copy of the coding structure I developed and used is included in Appendix 4. After all the interviews were coded, the codes were used to extract relevant information on each issue. In my analysis of the results, I have focused on the content of what was said rather than analysing the specific words used by interview subjects. Because the majority of interviews were conducted in Temne and I was working with a non-professional translator, I did not feel that use of specific words or language could be adequately examined.

\footnotetext{
${ }^{31}$ Using the NVivo software allowed me to be more flexible in my analysis of the interviews. Content could be coded according to issue or theme regardless of where in the interview they were discussed.
} 


\section{CHAPTER 3: A framework for assessing access to care: a review of the literature}

The issue of access to health care has been extensively studied over the last twenty to thirty years, and there is a significant existing body of literature on the subject. Many studies focus specifically on financial accessibility. Other studies look at access more holistically, or examine the quality of health care, a concept central to the notion of access. This chapter analyses the key literature on access in developing countries.

\subsection{Access to health care: the evolution of a definition}

What does it mean to have access to health services? The term has been used in different ways to mean different things, for example, that services are available, or are physically accessible. A 1981 study by Roy Penchansky and J. William Thomas states that "[a]ccess is viewed as the general concept which summarizes a set of more specific areas of fit between the patient and the health care system." 32 These areas are defined by Penchansky and Thomas as availability, accessibility, accommodation, affordability, and acceptability.

More recent literature ${ }^{33}$ focuses on a definition similar to, but somewhat simplified from that put forward by Penchansky and Thomas. The simplified concept includes only four components of access - geographic accessibility, financial accessibility, availability and acceptability - and places quality at the centre of all dimensions of access. This definition, depicted graphically in Figure 1 above, subsumes Penchansky and Thomas's concept of accommodation (the relationship between the way

\footnotetext{
${ }^{32}$ Roy Penchansky and J. William Thomas, "The Concept of Access: Definition and Relationship to Consumer Satisfaction " Medical Care 19, no. 2 (February 1981): 128.

${ }^{33}$ See for example Peters et al., "Poverty and Access to Health Care in Developing Countries," 162. And Center for Pharmaceutical Management, "Defining and Measuring Access to Essential Drugs, Vaccines, and Health Commodities" (paper presented at the WHO-MSH Consultative Meeting, Strategies for Enhancing Access to Medicines Program, Ferney-Voltaire, France, December 11-13, 2000), vii.
} 
supply resources are organized and the client's perception of their appropriateness - for example, waiting times in a doctor's office) into the concepts of both acceptability and availability. I have used this newer concept of access to guide my literature review.

Geographic accessibility means that clinics are close enough for patients to get to easily, and that patients have the means (e.g. access to public transportation and a road network of sufficient quality) to reach health facilities that are further away. Financial accessibility means that the formal, informal and indirect costs of services do not exceed users' ability and/or willingness to pay. The availability of health services refers to services relevant to the population being present and available when needed. For example, necessary medications, equipment, and sufficiently trained staff to meet the health concerns of the surrounding population must all be present. The concept of acceptability means that patients are not deterred from seeking health care because of their attitudes, expectations or opinions about the health system and/or health care providers. For example, if the only doctor available is a man, women may choose not to seek care because they are not comfortable with a male physician. ${ }^{34}$

Because access is related to both consumer demand for and willingness to use services, as well as the health system's ability to supply services, there are both demand and supply side factors in each of these components of access. A user's ability and willingness to pay for services is a demand side factor, and the cost of those services is the supply side factor.

The Peters et al. framework places quality at the centre of all the components of access, so studies examining the quality of health care are also relevant to gaining a better

\footnotetext{
${ }^{34}$ These four definitions are from Peters et al., "Poverty and Access to Health Care in Developing Countries," 162.
} 
understanding of issues affecting access. It can sometimes be difficult to separate one dimension of access from the other - for example, the geographical location of a clinic may affect user perceptions about its acceptability - but for the purposes of this literature review, I will examine the findings related to each dimension in turn.

A key element missing from the Peters et al. framework is the effect of gender on access. All four of the barriers to accessing care can and do affect women differently than they do men. For women, care appropriate to their specific health needs (such as obstetrical and gynaecological care), as well as family planning information, may not be available. In addition to the barriers of cost and distance to a health facility, cultural norms, provider attitudes and behaviours, and gendered structures of power may affect access to care. ${ }^{35}$ Women may lack control of household finances and may not have a say in household decision-making. ${ }^{36}$ They may not be able to access to the funds needed for care without revealing that they are going to the doctor, something that they may not want to share. Gender may also affect how barriers are perceived by the user. While the literature on gender and access is limited, I have included a gendered analysis for each component of access.

\subsection{Geographic accessibility}

Not surprisingly, research has shown that there is an inverse relationship between the distance to a health care provider and the use of health services. ${ }^{37}$ Studies in the

\footnotetext{
${ }^{35}$ Carol Vlassoff, "Gender Inequalities in Health in the Third World: Uncharted Ground," Social Science \& Medicine 39, no. 9 (November 1994): 1254.

${ }^{36}$ Vlassoff, "Gender Inequalities in Health in the Third World," 1249.

${ }^{37}$ Peters et al., "Poverty and Access to Health Care in Developing Countries," 195.
} 
Philippines, ${ }^{38}$ in Kenya,${ }^{39}$ and in Ghana ${ }^{40}$ have all found that increased distance from a health centre has a negative effect on health care utilization. The study in Ghana found that geographic accessibility was more important to health care users in relation to other barriers to access. When asked what they were willing to pay for different improvements to the quality of health services, respondents were willing to pay the largest amount in order to reduce the distance to the nearest health clinic. ${ }^{41}$ A number of other studies have also suggested that physical distance from a facility is one of the more important factors in decisions about whether or not to seek care. ${ }^{42}$ Improving geographic accessibility could therefore have a significant impact on increasing the use of health services.

Expanding the number and distribution of clinics would certainly improve geographic accessibility. Improving access to transportation would have a similar effect. A study of health care utilization in Zambia finds that access to a motor vehicle increases the use of health care services. ${ }^{43}$ Even when a vehicle is available, fuel shortages or the poor condition of the vehicle (a common problem in developing countries) can prevent its use. ${ }^{44}$ The ease of obtaining public transportation and the cost of this transportation can

\footnotetext{
${ }^{38}$ Emelita L. Wong et al., "Accessibility, Quality of Care and Prenatal Care Use in the Philippines," Social Science \& Medicine 24, no. 11 (1987): 935.

${ }^{39}$ Germano Mwabu, Martha Ainsworth, and Andrew Nyamete, "Quality of Medical Care and Choice of Medical Treatment in Kenya: An Empirical Analysis," Journal of Human Resources 28 (Fall 1993): 851.

${ }^{40}$ Victor Lavy et al., "Quality of Health Care, Survival and Health Outcomes in Ghana," Journal of Health Economics 15, no. 3 (June 1996): 351.

${ }^{41}$ Harold Alderman and Victor Lavy, "Household Responses to Public Health Services: Cost and Quality Tradeoffs," The World Bank Research Observer 11, no. 1 (February 1996): 10.

${ }^{42}$ See Stephen J. Fabricant, Clifford W. Kamara, and Anne Mills, "Why the Poor Pay More: Household Curative Expenditures in Rural Sierra Leone," The International Journal of Health Planning and Management 14, no. 3 (July 1999): 191. Margaret G. W. Hardiman and J. O. Midgley, "Planning and the Health of Mothers and Children in the Rural Areas of Sierra Leone," Journal of Tropical Pediatrics 27, no. 2 (April 1981): 85. Mwabu, Ainsworth, and Nyamete, "Quality of Medical Care and Choice of Medical Treatment in Kenya: An Empirical Analysis," 851.

${ }^{43}$ Catharina Hjortsberg, "Why Do the Sick Not Utilise Health Care? The Case of Zambia," Health Economics 12, no. 9 (July 2003): 767.

${ }^{44}$ Mamady Cham, Johanne Sundby, and Siri Vangen, "Maternal Mortality in the Rural Gambia, a Qualitative Study on Access to Emergency Obstetric Care," Reproductive Health 2, no. 3 (May 4, 2005), $\mathrm{http} / / / \mathrm{www}$.reproductive-health-journal.com/content/2/1/3 (accessed June 15, 2010).
} 
also have an impact. One study carried out in rural China also found that some drivers refused to transport pregnant women to the hospital in an emergency because they thought it would bring them bad luck. ${ }^{45}$

Increasing access to transportation can only be effective if the road network is in reasonable condition. In many developing countries, a lack of quality roads is a major problem. Even if the nearest clinic is located only a short distance away, if roads do not exist or are in such poor condition as to be unusable, this still poses a significant barrier. ${ }^{46}$ In addition, the quality of roads can vary through the year due to changing weather. In the rainy season in Sierra Leone, many roads are completely impassable by vehicle.

The availability of communication technologies (e.g. cell phones) can also affect the ease of travelling to access health care. ${ }^{47}$ If technology allows users to contact friends or family members to ask for assistance with accessing a health facility, this can be an important form of support. If phones or two-way radios are available, staff in peripheral health units (PHUs) can use them to contact referral centres to request transportation for a patient.

Almost none of the studies looked at geographic accessibility through a gender lens. One study by Germano Mwabu, Martha Ainsworth and Andrew Nyamete found women to be more constrained in seeking care by travel distance and costs. ${ }^{48}$ Women may need to ask their husband or another male family member for money or permission in order to get transportation to a health facility. Women may also find it harder to obtain public transportation because of their social status (e.g. not permitted to travel alone) or

\footnotetext{
${ }^{45}$ Lichun Tian et al., "Women's Status, Institutional Barriers and Reproductive Health Care: A Case Study in Yunnan, China," Health Policy 84, no. 2-3 (December 2007): 288.

${ }^{46}$ Peters et al., "Poverty and Access to Health Care in Developing Countries," 165.

47 _

${ }^{48}$ Mwabu, Ainsworth, and Nyamete, "Quality of Medical Care and Choice of Medical Treatment in Kenya: An Empirical Analysis," 853.
} 
specific health condition (for example, as was found in the study in China cited above with respect to pregnancy).

Geographic accessibility is also closely linked to financial accessibility. The costs of transportation and the opportunity costs of working time lost in order to get health care impose indirect costs that can be a significant financial barrier to accessing care in addition to the direct costs of care.

\subsection{Financial accessibility}

Much attention in both academic literature and in the policy debate on health financing has focused on the costs of health care for users. There are three types of health care costs: formal payments, informal payments (both direct costs) and indirect costs. For the purposes of this study, formal payments are defined as official charges to patients for health care goods and services as published in a health facility or in an official policy document. Informal payments are defined as other payments made by users not formally sanctioned in policy, but required in order to receive care (e.g. gifts or bribes). Indirect costs are defined as costs associated with seeking health care, but not direct charges at the point of service (e.g. the cost of transportation, lodging or meals; the opportunity cost of lost time, etc.).

Direct costs are thought by many to be one of the most important barriers to accessing health care in developing countries, and the impact of these costs on utilization has been studied extensively. ${ }^{49}$ Primary health care has been found to be relatively price inelastic - demand for care is not very sensitive to changes in price - but the poor are

${ }^{49}$ See the numerous studies cited in Owen O'Donnell, "Access to Health Care in Developing Countries: Breaking Down Demand Side Barriers," Cadernos Saúde Pública / Reports in Public Health 23, no. 12 (December 2007): 2825. 
more responsive to changes in price than those who are better off. ${ }^{50}$ Fees for health services can represent a significant proportion of the annual income of poor people. For example, in Vietnam, the average cost of a hospital visit is $22 \%$ of annual income. ${ }^{51}$ One study in Sierra Leone found that the average cost of an episode of illness represented 25 days of income. ${ }^{52}$ In another study in Sierra Leone, Stephen Fabricant et al. found that the absolute level of expenditures on health was similar across income groups (the lowest quintile spent approximately \$3.84 US in the survey recall period, and the highest income quintile about $\$ 5.44$ US). ${ }^{53}$ Those in the lower income groups made a much greater sacrifice to get health care, spending proportionately more of their income than those who are better off.

Because private, out-of-pocket health care costs in most developing countries are financed through direct individual payments rather than through any form of health insurance, prices charged to users are indeed an important determinant of access. User fees, any formal payment required from a patient for either public or private health services, were implemented across much of sub-Saharan Africa in the early and mid1990s, primarily with the aim of using the revenue generated by these fees to improve the quality of care.

Since their implementation, user fees for public services have been extensively studied and critiqued both in the academic literature and by development organizations for their impact on equity and efficiency.${ }^{54}$ Some researchers argue that user fees reduce

${ }^{50}$ O'Donnell, "Access to Health Care in Developing Countries," 2825.

51 , "Access to Health Care in Developing Countries," 2825.

${ }^{52}$ Médecins Sans Frontières, Access to Healthcare in Post-War Sierra Leone: Summary of a 2005 Survey in Four Districts: Kambia, Tonkolili, Bombali, Bo, 2006), http://www.msf.org/source/countries/africa/sleone/2006/Sierra_Leone_survey_2005_summary.pdf (accessed June 15, 2009), 6.

${ }_{53}$ Fabricant, Kamara, and Mills, "Why the Poor Pay More," 184.

${ }^{54}$ Gottret and Schieber, Health Financing Revisited, 230. 
efficiency in the health system because they provide an incentive for health providers to overprescribe medications in order charge a higher fee, or that the costs of revenue collection and management are too high. However, equity considerations are the main criticism of user fees; imposing a cost for health care deters the poor from accessing needed health services and can result in catastrophic expenditures on health for the poor when they do require medical care. ${ }^{55}$

The literature on the impact of user fees on health service utilization is mixed. There is certainly evidence that supports the claim that out-of-pocket payments are a significant barrier and result in decreased utilization of health services. Studies of the effect of the removal of user fees in several different countries in sub-Saharan Africa found that the use of health services increased, in some cases dramatically. For example, in Uganda, utilization rose between $55 \%$ and $77 \%$ when user fees were removed. ${ }^{56} \mathrm{~A}$ study by Médecins Sans Frontières (MSF) in Sierra Leone found the number of visits to their clinic increased five-fold when they eliminated user fees for services. ${ }^{57}$

There is also evidence that people are willing to pay more for higher quality services. ${ }^{58}$ When user fees were associated with improvements in the quality of service (including better availability of staff and medicines and greater proximity of health

\footnotetext{
${ }^{55}$ Fabricant, Kamara, and Mills, "Why the Poor Pay More," 180.

${ }^{56} \mathrm{~J}$. Nabyonga et al., "Abolition of Cost-Sharing Is Pro-Poor: Evidence from Uganda," Health Policy and Planning 20, no. 2 (March 2005): 106. South Africa saw a 77\% increase (David Wilkinson et al., "Effect of Removing User Fees on Attendance for Curative and Preventive Primary Health Care Services in Rural South Africa," Bulletin of the World Health Organization 79, no. 7 (July 2001).), and significant increases were also seen in Madagascar and in Kenya (70\%) (Rob Yates, International Experiences in Removing User Fees for Health Services - Implications for Mozambique (London: DFID Health Resource Centre, 2006), http://www.dfidhealthrc.org/publications/health_sector_financing/06Yates01.pdf (accessed July 1, 2009), 4-5.).

${ }^{57}$ Médecins Sans Frontières, Access to Healthcare in Post-War Sierra Leone, 8.

${ }^{58}$ For example: Gottret and Schieber, Health Financing Revisited, 234-35.; Jennie I. Litvack and Claude Bodart, "User Fees Plus Quality Equals Improved Access to Health Care: Results of a Field Experiment in Cameroon," Social Science \& Medicine 37, no. 3 (August 1993): 378. P. Gertler and J. vander Gagg, The willingness to pay for medical care: evidence from two developing countries (Baltimore: Johns Hopkins University Press, 1990) as cited in O'Donnell, "Access to Health Care in Developing Countries," 2825.
} 
services), the use of services increased, even though people had to pay more. In their survey of literature from Africa in this area, Harold Alderman and Victor Lavy find that "new or increased user fees in public health facilities, when accompanied by an improvement in services, can increase use. ${ }^{59}$ Research has also shown that the poor will bypass free facilities that are closer in order to go to a facility that they perceive as having better quality care available, incurring both greater direct and indirect costs. ${ }^{60}$ These studies suggest that although financial barriers are important, the quality of care may be equally as or more important in decisions about using various types of health care services.

Even if formal fees were completely eliminated, informal fees and the indirect costs of seeking health care can still act as a financial barrier to access. In some cases, these kinds of costs can be even more substantial than the official fees charged. Additional informal payments - gifts or bribes - may be expected by providers or anticipated by patients, even if no fee should officially be charged. ${ }^{61}$ The indirect costs of care, such as transportation, food and lodging, and lost working time have also been found to be substantial in some cases. Financial barriers to accessing health care are therefore broader than just the formal fees charged at a health facility.

A study by Catharina Hjortsberg found that women spend less on health care than men. ${ }^{62}$ This may be because women have less income available to them. Women are likely to earn less than men, and they may also have less say over decisions related to

\footnotetext{
${ }^{59}$ Alderman and Lavy, "Household Responses to Public Health Services: Cost and Quality Tradeoffs," 18.

${ }^{60}$ J. S. Akin and P. Hutchinson, "Health-Care Facility Choice and the Phenomenon of Bypassing," Health Policy and Planning 14, no. 2 (June 1999): 141.

${ }^{61}$ O'Donnell, "Access to Health Care in Developing Countries," 2825.

${ }^{62}$ Hjortsberg, "Why Do the Sick Not Utilise Health Care? The Case of Zambia," 765.
} 
household resources. ${ }^{63}$ Because women are less likely to have paid employment, they are also less likely to have access to health insurance provided by an employer. Other studies have found that women prioritise the health of other family members before their own, ${ }^{64}$ and are less likely to use modern methods of care, ${ }^{65}$ both of which could also be associated with a lower level of health expenditures.

\subsection{Availability}

A lack of availability, or perceptions of a lack of availability, can result in reduced use of services. Although a health facility may be located relatively close to a patient and services may be free, availability of those services is constrained if the facility is often closed because it is short-staffed, or if services are limited due to a lack of necessary supplies and equipment. Perceptions are especially significant in this component of access. Perceptions of poor quality or a lack of confidence in the health system may result in patients choosing not to seek care, even if the perceptions are not fully reflective of objective circumstances. $^{66}$

There are numerous studies that look at the connection between quality of care and utilization and examine availability as a component of quality. If health centres are not properly staffed, or if they lack appropriate pharmaceuticals and equipment, users are less likely to use those facilities. For example, a study in India found that in one rural area (Rajasthan), staff absentee rates are $36-35 \%$ and health centres were closed during

\footnotetext{
${ }^{63}$ Editorial, "Gender Equity Is the Key to Maternal and Child Health," 1939.

${ }^{64}$ Wim Hardeman et al., "Access to Health Care for All? User Fees Plus a Health Equity Fund in Sotnikum, Cambodia," Health Policy and Planning 19, no. 1 (January 2004): 27. And Tian et al., "Women's Status, Institutional Barriers and Reproductive Health Care," 288.

${ }^{65}$ Hjortsberg, "Why Do the Sick Not Utilise Health Care? The Case of Zambia," 758.

${ }^{66}$ Syed Saad Andaleeb, "Service Quality Perceptions and Patient Satisfaction: A Study of Hospitals in a Developing Country," Social Science \& Medicine 52, no. 9 (May 2001): 1360.
} 
regular hours $56 \%$ of the time. Utilization of services was lower at the centres that were open less often. ${ }^{67}$ In a study in Sri Lanka, John Akin and Paul Hutchinson find that people bypass health clinics that are closer in distance in favour of clinics that are generally in better condition, have more highly trained staff, and/or better availability of drugs. ${ }^{68}$ In particular, the availability of medications has been found to influence use of health care services. ${ }^{69}$

When availability and quality improve, health service utilization increases. A study by B. Leigh et al. of an effort to improve emergency obstetric care in a hospital in Makeni, Sierra Leone demonstrated that use of the hospital increased when the availability of care was improved by adding additional operating facilities and better trained staff. $^{70}$

None of the studies that addressed availability specifically identified gender as a significant factor. However, if services specific to women's reproductive health needs are not available, this would present a major barrier to women getting the care they need. For example, unsafe abortions are responsible for an estimated $13 \%$ of maternal deaths globally, ${ }^{71}$ indicating that there is a lack of available safe abortion services for women.

\subsection{Acceptability}

A lack of acceptability is another barrier to accessing health services. Even if appropriate care is available, users may not find it acceptable, and this will lead to a lower utilization rate. In a study of reproductive health care in China, Lichun Tian et al.

${ }^{67}$ O'Donnell, "Access to Health Care in Developing Countries," 2827.

${ }^{68}$ Akin and Hutchinson, "Health-Care Facility Choice and the Phenomenon of Bypassing," 144.

${ }^{69}$ Nabyonga et al., "Abolition of Cost-Sharing Is Pro-Poor: Evidence from Uganda," 106.

${ }^{70}$ B. Leigh et al., "Improving Emergency Obstetric Care at a District Hospital, Makeni, Sierra Leone," International Journal of Gynecology \& Obstetrics 59, no. Suppl. 2 (November 1997): S65.

${ }^{71}$ Campbell and Graham, "Strategies for Reducing Maternal Mortality," 1295. 
found that most respondents in their study cited the lack of a female physician as their primary reason for not seeking care, ${ }^{72}$ suggesting that although services were available and geographically and financially accessible, they were not accessed because they were not acceptable.

One aspect of acceptability that emerges from the literature is related to culture and traditional practices. People may have a continued preference for traditional therapies or for local village healers due to cultural and social norms around seeking health care. ${ }^{73}$ Traditional beliefs and practices may also affect the choices about when and how to seek health care. For example, in societies where elder women are considered to be experts on pregnancy and child birth, women may delay seeking health care if advised to wait by a respected elder. ${ }^{74}$ In traditional societies, it is unlikely that a patient would question the advice given by an elder. A lack of respect by health providers for traditional practices in relation to health may also deter women from seeking care. ${ }^{75}$

A lack of information or inaccurate information about the causes of illness may also play a role. If a patient believes their illness is the result of an evil spirit or witchcraft, they are more likely to seek care from a traditional healer, who they believe has greater capacity to heal that type of illness, rather than use conventional health services. ${ }^{76}$ An unpublished report on health care in Sierra Leone written by visiting

\footnotetext{
${ }^{72}$ Tian et al., "Women's Status, Institutional Barriers and Reproductive Health Care," 289.

${ }_{73}^{73}$ O'Donnell, "Access to Health Care in Developing Countries," 2826.

${ }^{74}$ Cham, Sundby, and Vangen, "Maternal Mortality in the Rural Gambia, a Qualitative Study on Access to Emergency Obstetric Care."

${ }^{75}$ Richard Konteh, "Socio-Economic and Other Variables Affecting Maternal Mortality in Sierra Leone," Community Development Journal 32, no. 1 (January 1997): 62.

${ }^{76}$ This has been observed in Sierra Leone. Gerald van Gurp, "Asset-Based Needs Assessment: Paki Masabong and Gbonkolenken Chiefdoms: Northern Province, Sierra Leone," (2009), 6.
} 
physician Dr. Gerald van Gurp suggests that a lack of knowledge about health concerns and health care is a key barrier in the country. ${ }^{77}$

Past negative experiences with the health system and how current patients are treated by health care providers can also influence decisions about the acceptability of health services. It is critical that users trust their health providers and find them friendly and helpful. ${ }^{78}$ A study in the Gambia found that some women were deterred from seeking care because of a fear of punishment by health care providers. ${ }^{79}$ This fear was sometimes based on gossip, other times on the patient's own negative past experience.

In their study of satisfaction with health services, Roy Penchansky and J. William Thomas found that acceptability is especially important for women. Carol Vlassof cites an example from Ecuador, where women were less likely to use modern health services because they felt "disempowered by the consultation process and became dependent for information upon the health provider." ${ }^{80}$ Many conventional health services "are not sufficiently comprehensive or responsive to the needs of women. Flexible services where trust, respect, privacy, and confidentiality can be ensured are essential if women are to actively seek prevention, treatment, or support services." ${ }^{\text {, } 11}$

\subsection{Conclusion}

Utilization of health care is determined by many different factors, including geographic, financial, acceptability and availability barriers to care, a woman's personal

\footnotetext{
${ }^{77}$ van Gurp, "Asset-Based Needs Assessment," 5.

${ }^{78}$ See for example Vlassoff, "Gender Inequalities in Health in the Third World," 1255. and Konteh, "SocioEconomic and Other Variables Affecting Maternal Mortality in Sierra Leone," 62.

${ }^{79}$ Cham, Sundby, and Vangen, "Maternal Mortality in the Rural Gambia, a Qualitative Study on Access to Emergency Obstetric Care."

${ }^{80}$ Vlassoff, "Gender Inequalities in Health in the Third World," 1254.

${ }^{81}$ Samb, "Reforming Country Health Systems for Women's Health," 355.
} 
circumstances, the current context in the country, and the functioning of the health system. Both real and perceived barriers matter to health decision-making. Perceptions are particularly important in the areas of acceptability and availability, where the user's trust in the provider, opinion of the quality of care, and past experiences with the health system play a larger role. In many cases, women face greater barriers to accessing care than men. 


\section{CHAPTER 4: Sierra Leone - the economic, social, political, and health context}

This chapter examines the economic, social, political and health conditions in Sierra Leone in order to better understand the context in which health care services are provided and in which people make decisions that affect their health. Sierra Leone is still in the process of recovering from a long and vicious civil war (1991-2002), so this chapter provides an analysis of the war, the current political context, and the effects of the war on the health system. The factors from my analytical framework that are examined in this chapter are highlighted in the figure below.

Figure 3: Economic social and political context in the analytical framework

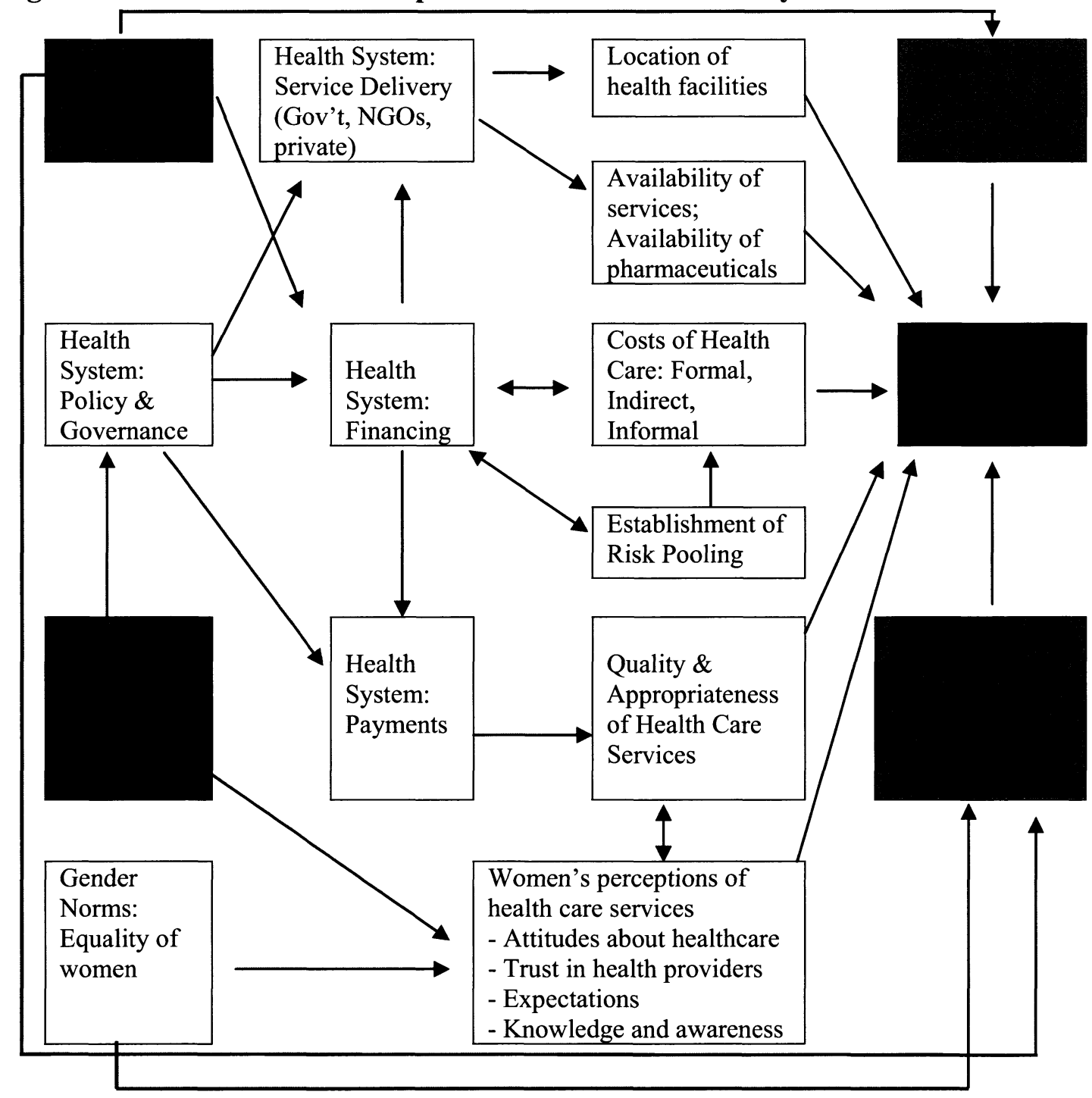


As is visible in the framework, the political, social and economic conditions influence the functioning of the health system, particularly in relation to policy and governance and to financing. A weak economy limits the government's capacity to finance health care, and women's ability to pay for care. The political context affects which health issues and interventions are prioritised, as well as factors like corruption in the health system. In particular, the relatively recent experience of conflict in Sierra Leone affects opinions about and attitudes towards health care.

\subsection{Economic and social conditions}

\section{Demographic and household characteristics}

Sierra Leone is a small country of approximately 5.5 million people, ${ }^{82}$ with a predominantly rural population. ${ }^{83}$ The population is young, and women outnumber men. ${ }^{84}$ Households in Sierra Leone tend to be large, and fertility rates are high. The mean size of a household is about 6 people. The total fertility rate is 5.1 births per woman, higher in rural areas (5.8 births), among poor women (6.3 births), and women with no education (5.8 births). Most households are headed by men. This is reflective of the typical gender roles found in the country. ${ }^{85}$

Polygyny (the practice of having more than one wife) is relatively common in Sierra Leone, with $37 \%$ of married women in polygynous relationships. Polygyny is most prevalent in the Northern Province of Sierra Leone, where almost 25\% of men reported

\footnotetext{
${ }^{82}$ The World Bank Group, "Sierra Leone Country Data Profile."

${ }^{83}$ As of 2006 , only $41 \%$ of the national population was located in urban areas. World Health Organization, "WHO Statistical Information System (WHOSIS)."

${ }^{84}$ Thomas, MacCormack, and Bangura, Report on Population Size and Distribution Age and Sex Structure, 17 and 44.

${ }^{85}$ Statistics Sierra Leone and ICF Macro, Sierra Leone Demographic and Health Survey 2008, 14-15, 54.
} 
having more than one wife. Men in rural areas were almost 3 times as likely as men in urban areas to report having more than one wife $(21.1 \%$ and $8.5 \%){ }^{86}$

The two largest ethnic groups in the country are the Mende and the Temne, each composing about $30 \%$ of the population. ${ }^{87}$ The other $40 \%$ of the population is composed of 14 other ethnic groups. In the Northern Province, Temne are predominant. Other ethnic groups found in the Northern Province include Limba, Loko and Mandingo. ${ }^{88}$ Religious beliefs are strong throughout the country - over $99 \%$ of the population declares adherence to some form of religious belief - and were found to be strongest in the Northern Province. ${ }^{89}$ The majority of the population (71\%) is Muslim. ${ }^{90}$

The level of education in Sierra Leone is generally fairly low. Two-thirds of women and almost half of men have never been to school. These proportions are even higher in the north and in rural areas. Less than $25 \%$ of women in the Northern Province report ever having attended school. While formal schooling takes place in English, which is the official language of the country, given the low rate of formal education, few adults are literate in English. ${ }^{91}$ Virtually all Sierra Leoneans speak Krio, an English-based language, which is the de facto national language in the country. In rural areas, Krio is

86 _ Sierra Leone Demographic and Health Survey 2008, 84-85.

${ }^{87}$ A.B. Zack-Williams, "International Intervention and Struggle for Democracy," in The Quest for Sustainable Development \& Peace: The 2007 Sierra Leone Elections, ed. A.B. Zack-Williams (Stockholm: Nordiska Afrikainstitutet, 2008), 32.

${ }^{88}$ Government of Sierra Leone, Sierra Leone Integrated Household Survey (SLIHS) 2003/04: Final Statistical Report (Freetown: Government of Sierra Leone, 2007), http://www.statistics.sl/SLIHS_REPORT.pdf (accessed January 13, 2010), 8.

${ }_{89}$ - SLIHS 2003/04: Final Statistical Report, 9-10.

${ }^{90}$ While there are no good data on the breakdown of religious beliefs by ethnicity, the proportion of population that is Muslim approximately the same in three provinces (75\% in Southern Province, $77 \%$ in Eastern Province and $81 \%$ in Northern Province), although the proportion in the Western Area is significantly less $(44 \%)$. This suggests that there is no specific tie between ethnicity and religious belief, as ethnic groups are not divided equally among the provinces. ——, SLIHS 2003/04: Final Statistical Report, 10.

${ }^{91}$ Only $26.2 \%$ of women and $43.5 \%$ of men are literate in English. Statistics Sierra Leone and ICF Macro, Sierra Leone Demographic and Health Survey 2008, 35-37. 
less common and people usually speak their ethnic language (e.g. Temne, Mende or Limba).

\section{Economic characteristics}

Although development outcomes in Sierra Leone have improved since the end of the war in 2002, the country continues to rank at the bottom of the United Nations Development Program's Human Development Index. ${ }^{92}$ Poverty remains a major issue. Gross National Income (GNI) per capita was only \$270 USD in $2008,{ }^{93}$ and in 2003/04, a full $70 \%$ of Sierra Leone's population was estimated to be living below the poverty line (2,111 LE per day).$^{94}$ The Northern Province is the second poorest province, and the severity of poverty (the gap between the poverty line and the actual level of income) in Bombali District, where Mapaki is located, was among the highest in the country. Although more recent data (2007) show some improvement in the levels of poverty in Sierra Leone, poverty rates remain above $50 \%$ for the country as a whole and at $70 \%$ and above for rural areas. ${ }^{95}$

The high levels of poverty are reflected in people's inability to access essential services and information, including those related to health. For example, only $35 \%$ of the population in rural areas has access to an improved source of drinking water, and $30 \%$ have no sanitation facilities. Inadequate water and sanitation facilities can have a

\footnotetext{
${ }^{92}$ Sierra Leone ranks \#180 of 182 countries. United Nations, "Human Development Report 2009 - HDI Rankings," Statistics - Human Development Reports (UNDP), http://hdr.undp.org/en/statistics/ (accessed January 18, 2010).

${ }_{93}$ GNI using purchasing power parity, in current international dollars was $\$ 750$ per capita. The World Bank Group, "Sierra Leone Country Data Profile."

${ }^{94}$ The average exchange rate during the time I was in the country (September 8 - December 20, 2009) was 3,603 LE to $\$ 1 \mathrm{CDN}$. http://www.oanda.com/

${ }^{95}$ Asset-based poverty estimates declined from $67.5 \%$ of the population to $61.6 \%$ and consumption-based poverty estimates declined from $66.4 \%$ to $56.6 \%$. Government of Sierra Leone, An Agenda for Change: Second Poverty Reduction Strategy (PRSP II), 2008-2012 (Freetown, Sierra Leone, 2008), 28-30.
} 
significant impact on health by increasing the spread of disease. Access to electricity in rural areas is extremely limited (1.3\%) and only $45 \%$ of the rural population owns a radio, the most common household possession. The limited electricity affects which health services are available in rural areas, and how they are delivered (e.g. lack of cold storage for pharmaceuticals). In addition, lack of access to even a radio may limit the ease with which health information can be shared. ${ }^{96}$

The majority of Sierra Leoneans are employed in agriculture, and much of the population relies on subsistence agriculture for their survival. Agricultural work is more common amongst poor, uneducated, rural women. In the Northern Province, $67 \%$ of women work in agriculture. ${ }^{97}$ Women who do agricultural work are not likely to be paid in cash for this work; the vast majority (83.4\%) report not being paid at all, and a further $5.9 \%$ are paid in-kind only. ${ }^{98}$ As we will see in subsequent chapters, limited access to cash is a major barrier to women's ability to access health services.

\section{The context in Mapaki}

All of my fieldwork in Sierra Leone was carried out in and around the rural village of Mapaki (see Appendix 1 for a map). Although statistics specific to the village or chiefdom level are not available, the data described above is roughly representative of the context in Mapaki. ${ }^{99}$ The estimated population for the village is about 2,000 people. ${ }^{100}$ The majority ethnic group is Temne, although there are Limba there as well.

\footnotetext{
${ }^{96}$ Statistics Sierra Leone and ICF Macro, Sierra Leone Demographic and Health Survey 2008, 15, 52, $25-$ 28.

${ }^{97}$ The terms "employed" and "work" used here refer to work in both the formal and informal sectors.

${ }^{98}$ Statistics Sierra Leone and ICF Macro, Sierra Leone Demographic and Health Survey 2008, 43 and 45.

${ }^{99}$ Based on my own observations and conversations with local people.

${ }^{100}$ Personal communication, Paramount Chief Masa Paki Kebombor II, November 18, 2009.
} 
The majority religion is Muslim. There are both a church and a mosque in the village, and villagers of both religions seem to live together harmoniously.

The majority of the population is poor and relies on subsistence agriculture. For those who do earn a cash income, the amount is generally very limited, and people usually also have a farm or garden to provide additional food or income. ${ }^{101}$ The most common crop is rice, Sierra Leone's staple food. Other common crops are groundnuts, maize, sorghum, cassava, and beans, as well as palm trees for palm oil and palm wine.

Education levels are low. Nine of my eighteen interview subjects had never attended school, and three others had only completed some or all of primary school. Younger women are much more likely to have received at least a primary school education, and many of them seem to have completed at least some secondary education. ${ }^{102}$ Of the interview respondents who had completed at least some junior secondary school, all except one were between 18 and 21 . There has been a primary school in Mapaki for many years, and in 2006, a junior secondary school was built in the village, likely a strong contributing factor to the higher education level of younger women in Mapaki.

One key informant indicated that approximately $80 \%$ of marriages in Mapaki were polygynous, but this estimate seems to be quite high considering that national and regional statistics estimate rates of $50 \%$ or less. ${ }^{103}$ Only two of the individual interview subjects were in polygynous relationships.

\footnotetext{
${ }^{101}$ The women I interviewed earned in the range of 5,000 LE to 30,000 LE a month, with one respondent earning 58,000 LE. Even employed professionals earn very little - a teacher's salary might be around $150,000-300,000$ /month, and the maternal and child health aides in the clinic earn 164,000/month. ${ }^{102}$ Primary school is free in Sierra Leone (although non-fee costs such as uniforms and books still pose a financial barrier for many), but the cost of junior secondary and senior secondary school is prohibitive for the majority of Sierra Leoneans (annual fees are around 300,000 LE and higher).

${ }^{103}$ Statistics Sierra Leone and ICF Macro, Sierra Leone Demographic and Health Survey 2008, 84-85.
} 
In terms of household characteristics, people tend to have larger families with 3 or more children, and extended families often live together in one house or compound. There are 3 wells in Mapaki, all covered and treated with chlorine. These wells provide sufficient water during the rainy season, but water can be limited towards the end of the dry season (in March and April). In terms of sanitation, there are numerous shared pit latrines in the village. The only electricity in the village is from private sources (generators and a solar panel that provides power for the community library). Many people have radios and cell phones, although the cell phone coverage in Mapaki is not reliable.

\subsection{Political context}

Formerly a British colony, Sierra Leone gained its independence in 1961. The country began as a democracy, electing to power the Sierra Leone People's Party (SLPP), led by Sir Milton Margai. The SLPP remained in power until 1967, when they were defeated by the All People's Congress (APC), led by Siaka Stevens. Stevens ruled Sierra Leone with an iron fist for the next 18 years.

During Stevens' tenure as President, he replaced the multi-party parliamentary system with a one-party dictatorship, and essentially destroyed and corrupted critical state institutions such as the military, the civil service, the judiciary, the universities and civil society. ${ }^{104}$ In 1985, General Joseph Momoh, Stevens' handpicked successor, became President. Under Momoh, the situation in the country became even more untenable. The government was unable to pay salaries for teachers and health care workers, and Momoh

\footnotetext{
${ }^{104}$ John L. Hirsch, Sierra Leone: Diamonds and the Struggle for Democracy (Boulder: Lynne Rienner Publishers Inc., 2001), 29.
} 
implemented devastating structural adjustment policies. ${ }^{105}$ Even before the outbreak of war in 1991, Sierra Leone was one of the poorest countries in the world, and was effectively a failed state, unable to provide essential services to its citizens. The country's health system was already crumbling due to lack of investment. While space does not allow a detailed analysis of the causes of the war here, the collapse of state institutions and government services were an important factor contributing to the outbreak of war. ${ }^{106}$ The civil war claimed the lives of tens of thousands, left thousands physically or mentally disabled, and displaced an estimated two and a half million people, half the country's population. ${ }^{107}$ The war also destroyed the country's infrastructure and severely limited the capacity of the national government to function.

The civil war in Sierra Leone began on March 23, 1991, when small groups of rebels from the Revolutionary United Front (RUF), led by Foday Sankoh and supported by Liberia, attacked eastern Sierra Leone. While the stated intention of the RUF was to overthrow Sierra Leone's APC government and 'liberate' the people, there is little evidence that the RUF actually had a developed social or political agenda. ${ }^{108}$ In fact, rather than fighting to liberate the people, the war was characterised by atrocities committed against civilians by the RUF, as well as by other forces fighting in the conflict.

In 1992, in the midst of war, the Momoh government was overthrown in a military coup and replaced by the National Provisional Ruling Council (NPRC), led by

\footnotetext{
${ }_{105}$ Zack-Williams, "International Intervention and Struggle for Democracy," 10.

${ }^{106}$ Joseph Hanlon, "Is the International Community Helping to Recreate the Preconditions for War in Sierra Leone?," The Round Table 94, no. 381 (September 2005): 460.

${ }^{107}$ Hanlon, "Is the International Community Helping to Recreate the Preconditions for War in Sierra Leone?," 460.

${ }^{108}$ Arthur Abraham, "Dancing with the Chameleon: Sierra Leone and the Elusive Quest for Peace," Journal of Contemporary African Studies 19, no. 2 (July 2001): 207.
} 
Captain Valentine Strasser. Eventually, in response to international and domestic pressure, the NPRC agreed to hold multi-party elections. ${ }^{109}$ Despite an RUF campaign of terror, amputating the hands and arms of many Sierra Leoneans in an attempt to deter people from voting, ${ }^{110}$ the 1996 elections took place as planned. Ahmad Tejan Kabbah, leader of the SLPP, was elected as President.

Following the elections, Kabbah signed the first of several peace agreements with the RUF, but peace did not last. In 1997, Kabbah was ousted in a coup led by Major Johnny Paul Koroma and the Armed Forces Revolutionary Council (AFRC), and Kabbah fled to Guinea. Kabbah was restored to power with the support of the Economic Community of West African States (ECOWAS) in 1998.

Fighting intensified through the late 1990s. By 1999, the RUF had control of a significant portion of the country, especially in the north and east, ${ }^{111}$ killing tens of thousands of civilians and maiming many more. Despite the presence of ECOWAS forces, the RUF invaded Freetown, the capital city in 1999. A second peace agreement was negotiated later that year. This agreement (the Lomé agreement) was to be supervised by a United Nations peacekeeping mission, the United Nations Mission in Sierra Leone (UNAMSIL).

May 2000 marked a turning point in the war. First, in response to the kidnapping of $500 \mathrm{UN}$ soldiers earlier that month, a contingent of British troops arrived. The British, who were not part of the UN mission, helped to secure Freetown and began training the disorganized and ill-equipped Sierra Leone army. Second, Foday Sankoh was arrested

\footnotetext{
${ }^{109}$ Adekeye Adebajo, Building Peace in West Africa: Liberia, Sierra Leone and Guinea-Bissau (Boulder: Lynne Rienner Publishers Inc., 2001), 85.

${ }_{110}$ Hirsch, Sierra Leone: Diamonds and the Struggle for Democracy, 45.

111 Zack-Williams, "International Intervention and Struggle for Democracy," 24.
} 
and imprisoned in May 2000, and later died in prison. The elimination of Sankoh as a spoiler in the conflict and the international military presence of both British and UNAMSIL peace-keeping forces led to the cessation of hostilities and the beginning of the demobilization, disarmament and reintegration process. The war was officially declared over by Kabbah on January 18, 2002.

In the eight years since the war ended, the political conditions in Sierra Leone have begun to improve, albeit slowly. Two national elections were held (May 2002 and August 2007), both of which took place without widespread violence and were judged to be free and fair by external observers. ${ }^{12}$ The 2007 elections, which were run predominantly by Sierra Leone institutions rather than by outsiders such as the UN, and which saw a peaceful transfer of power from the SLPP to the APC, were a particularly important turning point. The current national government is led by President Ernest Bai Koroma of the APC.

The civil war in Sierra Leone was not an ethnic war; neither combatants nor victims were divided along ethnic lines. However, ethnic and regional divides have played a role in Sierra Leonean politics since independence. The main ethnic and regional divide in the country is between the Mende in the south and the Temne and Limba in the north. The Mende have been traditional supporters of the SLPP and the Limba and Temne of the APC. In the past, politicians on both sides manipulated these divides in order to hold on to power. ${ }^{113}$

\footnotetext{
${ }^{112}$ On the 2002 elections, see Hirsch, Sierra Leone: Diamonds and the Struggle for Democracy, 46. On the 2007 elections see National Democratic Institute, Final Report on Sierra Leone's 2007 Elections (2008), http://www.ndi.org/files/NDI_Final_Report_on_2007_Sierra_Leone_Elections.pdf (accessed March 26, 2009), 35.

${ }^{113}$ Hirsch, Sierra Leone: Diamonds and the Struggle for Democracy, 24-25.
} 
Although political tension between ethnic groups remains an issue in Sierra Leone, and political parties continue to use ethnic and/or regional appeals to try to win votes, ${ }^{114}$ there are signs that the role of ethnicity in politics is diminishing. A new code of conduct for political parties developed and signed by all parties in 2006 prevents parties based solely on advancing "the interests of a particular tribal or ethnic group, geographical area, or religious faith." ${ }^{115}$ Voting results in the 2007 election reflected a shift away from the usual party loyalty lines as the APC gained support in the south, which is traditional SLPP territory. ${ }^{116}$ There is also evidence that regional and ethnic issues have begun to be subordinated to policy concerns such as the provision of government services and the elimination of corruption, and young voters in particular seem more interested in voting based on the performance of the political parties than on regional or ethnic ties. ${ }^{117}$ These are all positive signs that the effects of ethnic divisions in politics seem to be lessening over time.

Progress in other areas is also being made. For example, in the fall of 2009 , the Bumbuna hydro dam began operating, providing a fairly reliable source of electricity to Freetown for the first time in many years. Roads throughout the country are slowly being improved, and it is now possible to drive from Freetown to both Makeni and Bo (the second and third largest cities) on improved highways. In January 2010, the national government implemented a goods and services tax in an attempt to increase the government's ability to generate its own revenues and reduce reliance on donor funds.

\footnotetext{
${ }^{114}$ A.B. Zack-Williams and Osman Gbla, "The Conduct of the Elections: Challenges of Peacebuilding and Democratisation," in The Quest for Sustainable Development \& Peace: The 2007 Sierra Leone Elections, ed. A.B. Zack-Williams (Stockholm: Nordiska Afrikainstitutet, 2008), 75.

${ }^{115}$ National Democratic Institute, Final Report on Sierra Leone's 2007 Elections, 14.

${ }^{116}$ Zack-Williams and Gbla, "The Conduct of the Elections: Challenges of Peacebuilding and Democratisation," 76.

117 _ "The Conduct of the Elections: Challenges of Peacebuilding and Democratisation," 76.
} 
Despite these signs of improvement, Sierra Leone's current government still faces many ongoing challenges. Youth unemployment and government corruption, problems which are thought to have contributed to the outbreak of the civil war, are still fairly widespread. ${ }^{118}$ The resources available to the government for use in providing public services such as health and education remain quite limited, despite significant donor support. Koroma and the APC were elected in 2007 partly as a result of dissatisfaction with the previous government's ability to deliver services and deal with corruption. ${ }^{119}$ If the APC is not able to show improvements in these two areas, they may face defeat in the next presidential elections, scheduled for 2012.

\subsection{The health context}

Sierra Leone performs very poorly on health indicators compared to other developing countries, and if current trends continue, is not expected to meet any of the health-related Millennium Development Goals on time. ${ }^{120}$ According to the 2004 census, life expectancy at birth was only 48.4 years overall ( 49.4 years for women). ${ }^{121}$ The more recent Sierra Leone Demographic and Health Survey (SLDHS) did not calculate life

\footnotetext{
${ }^{118}$ International Crisis Group, Sierra Leone: A New Era of Reform? (2008), http://www.crisisgroup.org/library/documents/africa/west_africa/143_sierra_leone__a_new_era_of_refor m.pdf (accessed January 29, 2009), 1.

119 - Sierra Leone: A New Era of Reform?, 1.

${ }^{120}$ Government of Sierra Leone, European Commission, and UK Department for International Development, Sierra Leone - European Community Country Strategy Paper and National Indicative Programme for the Period 2008-2013: European Commission, 2007), http://ec.europa.eu/development/icenter/repository/scanned_sl_csp10_en.pdf (accessed August 13, 2009), 36.

${ }^{121}$ Joseph A.L. Kamara et al., 2004 Population and Housing Census: Analytical Report on the Mortality and Disability Status of the Population (Freetown, Sierra Leone: Statistics Sierra Leone, 2006), http://www.statistics.sl/2004\%20Pop.\%20\&\%20Hou.\%20Census\%20Analytical\%20Reports/2004\%20Pop ulation $\% 20$ and $\% 20$ Housing\%20Census\%20Report $\% 20$ on\%20Morbidity\%20and\%20Mortality.pdf (accessed August 13, 2009), 10.
} 
expectancy, but did calculate an adult morality rate of 5.8 per 1,000 for women $(6.1$ per 1,000 for men). This is a relatively high rate. ${ }^{122}$

Utilization of health services (public and private) in Sierra Leone is estimated at only 0.5 contacts per person per year, a low utilization rate compared to rates internationally. About half the visits are for vaccinations and growth monitoring, and the other half are for illness. ${ }^{123}$ This suggests that there is a significant unmet need for health care. This is also reflected in mortality statistics.

The majority of illnesses and deaths in Sierra Leone are preventable. The figure below illustrates the top ten causes of death as of 2002, the most recent data available. Major causes of death include lower respiratory infections, diarrhoeal diseases, perinatal conditions, malaria, and injuries (both intentional and unintentional).

Figure 4: Top ten causes of death in Sierra Leone, 2002

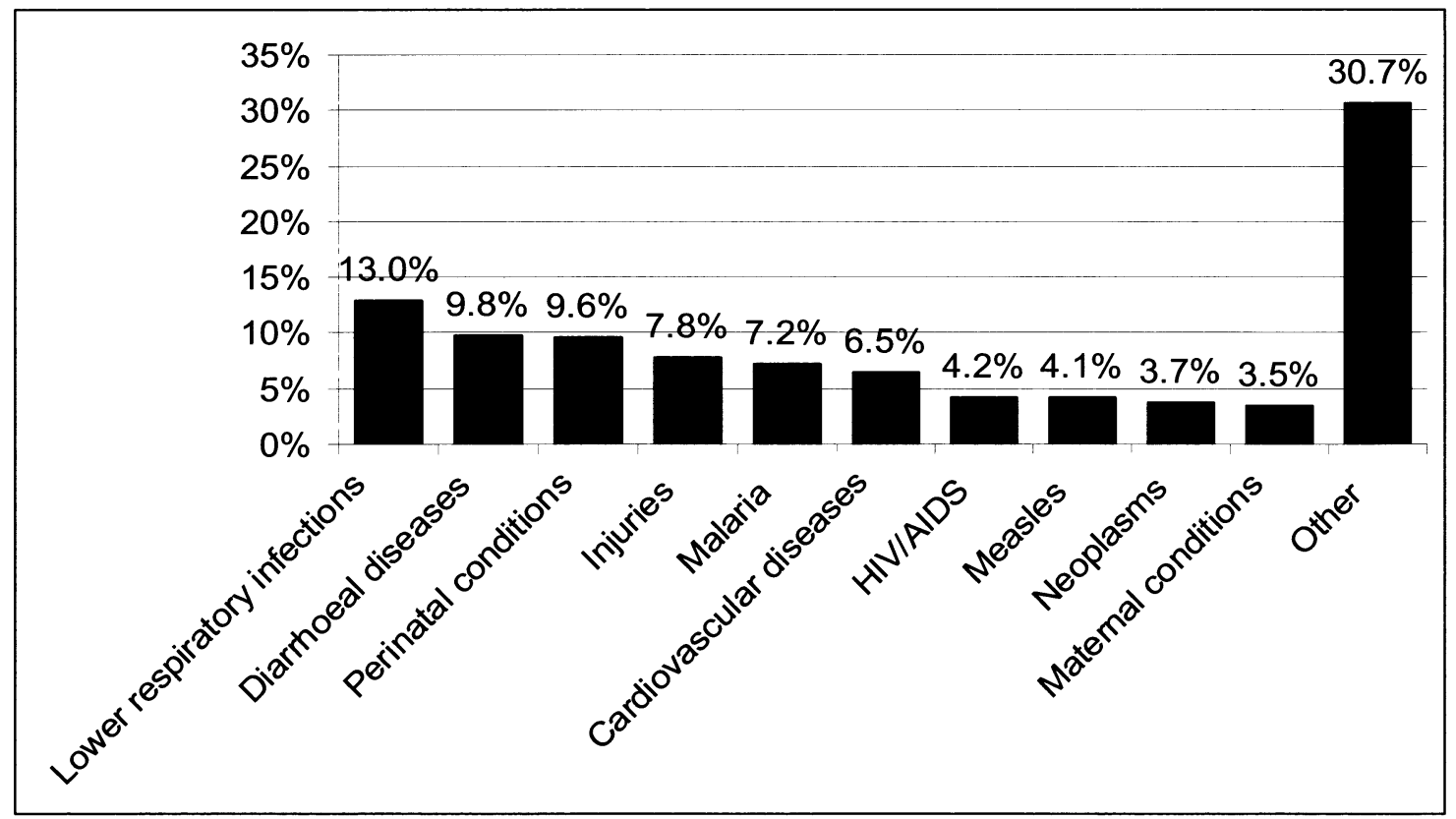

Source: World Health Organization, Country Health System Fact Sheet 2006 - Sierra Leone (2006), http://www.afro.who.int/home/countries/fact_sheets/sierraleone.pdf (accessed July 1, 2009).

\footnotetext{
${ }^{122}$ Statistics Sierra Leone and ICF Macro, Sierra Leone Demographic and Health Survey 2008, 270.

${ }^{123}$ Ministry of Health and Sanitation for the Republic of Sierra Leone, National Health Sector Strategic Plan (NHSSP), 2010 - 2015, Draft (Freetown, Sierra Leone, 2009), 16.
} 


\section{The civil war's impact on health}

The civil war had a significant negative impact both on Sierra Leone's health system and on population health, and the health system is still recovering. The Government of Sierra Leone (GoSL) estimates that approximately half of the health facilities in rural areas were destroyed, and most of the doctors and other health personnel left remote areas or left the country altogether. ${ }^{124}$ The number of medical officers, specialist physicians (e.g. OB/GYN, paediatrician), midwives and pharmacists present in the country in 2009 was less in all categories than the number present in 1991, prior to the outbreak of war. ${ }^{125}$ The decrease in both available facilities and staff affects the ability of the Sierra Leonean government to provide adequate health services, creating availability barriers to accessing care.

In addition, the conflict changed people's health behaviours. Due to the collapse of the formal health care system during the conflict, people turned to informal methods of care such as traditional medicine, local private providers, and self-medication. There is anecdotal evidence that these habits may still influence people's health care seeking behaviour, as they are slow to return to the formal health care system. ${ }^{126}$ A lack of trust in or reliance on formal health care during the conflict may have created an acceptability barrier to seeking conventional care that still exists today.

The health status of the population was also negatively affected by the war. Most directly, people were left physically or mentally ill or disabled as a result of their

\footnotetext{
${ }^{124}$ World Health Organization, WHO Country Cooperation Strategy: Sierra Leone, 2004-2007 (2004), http://www.who.int/countryfocus/cooperation_strategy/ccs_sle_en.pdf (accessed August 14, 2009 ), 14.

${ }^{125}$ Government of Sierra Leone, Free Healthcare Services, 10.

${ }^{126}$ For example, "Sierra Leone: Maternity Hospital Is "Last Resort"," http://www.irinnews.org/report.aspx?ReportId=77252 (accessed July 15, 2009).
} 
experiences during the conflict. ${ }^{127}$ In addition, people lost their livelihoods and had no access to cash income during and immediately after the war. Even now, people have not necessarily returned to the same economic status they had before the conflict. This has created greater financial barriers for people in accessing care, as it has reduced their ability to pay for health services and to protect their health in other ways (for example, through adequate nutrition).

These findings are supported by comments from interview subjects on the effect of the conflict on health:

"the war had a lot of problems in health. Many people were killed. A lot of areas ... different things were placed there that affected people, areas were contaminated." 128

"People suffered a lot in this war in Sierra Leone. During the war people didn't have money, you do not have no access to get money or to find money. Just after the war, struggle begins. We begin struggling fresh." 129

During the war, "[t]he $[\text { clinic }]^{130}$ was with the rebels. They occupied the [clinic] and the quarters. It was the headquarters of the rebels. People were in the bush, the rebels lived in the town. If you were sick, you have to take herbs ... that's all we had. Go to the bush, get the leaves, put it in a mortar and beat it, and put it all over your body. You do not even see a nurse. Who can you ask when your head is aching?" 131

". . . inside the war and after the war you will meet this clinic without anybody in it. It has the name of the clinic, but nothing in it ... During the war the rebels occupied all these places. They occupied the [clinic], the quarters, they were the managers of those places ... People died because

\footnotetext{
${ }^{127}$ Amputations of hands and feet were an extremely common war tactic and there are many amputees in the country.

128 "Interview No. 7," November 21, 2009.

129 "Interview No. 12," December 3, 2009.

${ }^{130}$ Note that the term "hospital" was used by all respondents interchangeably to refer to any medical facility (hospital, private clinic, peripheral health unit). In the quotes from interviews, it most often refers generically to any health facility (e.g. the costs at the hospital are high). When necessary for clarity, I have changed the word to clinic when it refers specifically to a PHU, and left it as hospital otherwise.

131 "Interview No. 18," December 10, 2009.
} 
of sickness. Even to get one paracetamol [pain relief drug], where were you to get it? Nowhere." ${ }^{132}$

Since the war ended in 2002, improvements in the health system have been made, and barriers to access have been reduced. Health centres are being re-established, new staff are being trained, and medications are more readily available. For example, between 2002 and 2006, the number of functional Peripheral Health Units (PHUs) increased almost three-fold, from 350 to $875 .{ }^{133}$ Almost every interview respondent remarked that there are more health centres and health staff available now than during or just after the war, and that medication is now more readily available. Several respondents also mentioned that people now had greater awareness of health issues and what to do to take care of their health (for example, malaria prevention, proper sanitation, and the importance of hand washing), suggesting that health education levels are improving. ${ }^{134}$

The general improvement in basic infrastructure in the country since the end of the war also supports better access to health services. The construction of roads is a major factor. In the Paki Masabong Chiefdom where Mapaki is located, all but approximately 5 villages (of a total of 73) are now accessible by motor vehicle. ${ }^{135}$ This has reduced geographic barriers to accessing care by making it easier to travel to a health facility. The improvements in communications, namely cell phones, makes it easier to get help in an emergency or to share health information. In 2008, there were 18 cell phone subscriptions per 100 people in Sierra Leone, up from only 1 subscription per 100 people in $2001 .^{136}$

\footnotetext{
132 "Interview No. 12."

${ }^{133}$ Ministry of Health and Sanitation for the Republic of Sierra Leone, Health Interventions to Reduce under-Fives and Maternal Mortality Rates (Freetown, Sierra Leone, 2009), 2.

134 "Interview No. 2," October 24, 2009. "Interview No. 7." And "Interview No. 9," November 26, 2009.

135 "Interview No. 7."

${ }^{136}$ The World Bank Group, "Mobile Cellular Subscriptions (Per 100 People)," World Development Indicators, http://ddp-
} 
The general development in Sierra Leone and the improvements in the country's health system do seem to be having a positive impact on health outcomes. Life expectancy in Sierra Leone in 2000 was only 37 years. ${ }^{137}$ This had increased to 48.4 years by 2004 .

\section{Women's health in Sierra Leone}

Unfortunately, specific break-downs of illnesses and deaths were not available by age or gender. The GoSL's National Health Sector Strategic Plan (NHSSP) states that, "[t]he greatest burden of disease is on rural populations, and on females within the rural population. ${ }^{138}$ However, without hard data, it is difficult to have an accurate picture of the health status of women, making the formulation of appropriate and effective health interventions and policies much more challenging.

Although they have declined in recent years, rates of maternal mortality and infant mortality in Sierra Leone are still among the highest in the world. ${ }^{139}$ High fertility rates, as seen above, are a major contributing factor to maternal mortality. More than $90 \%$ of married women have given birth at least once, and over a third of all women have given birth to 4 or more children. Contraceptive use among married women is extremely low, at $8.2 \%$, although this number is slightly higher if unmarried women are included (10.2\%). This low rate of use does not appear to be the result of an inability to access

ext.worldbank.org.proxy.library.carleton.ca/ext/DDPQQ/report.do?method=showReport (accessed January $15,2010)$.

${ }^{137}$ World Health Organization, "WHO Statistical Information System (WHOSIS)."

${ }^{138}$ Ministry of Health and Sanitation for the Republic of Sierra Leone, NHSSP, 3.

${ }^{139}$ Infant mortality has declined from 195 deaths per 1,000 in 2000 to 140 deaths per 1,000 in 2008.

Statistics Sierra Leone and ICF Macro, Sierra Leone Demographic and Health Survey 2008, 107. Maternal mortality rates have declined from 2,000 deaths per 100,000 live births in the year 2000 to 857 deaths per 100,000 live births in 2008. World Health Organization, Country Health System Fact Sheet 2006 - Sierra Leone (2006), http://www.afro.who.int/home/countries/fact_sheets/sierraleone.pdf (accessed July 1, 2009). and Statistics Sierra Leone and ICF Macro, Sierra Leone Demographic and Health Survey 2008, 27. 
contraception - of the women who did not intend to use contraception in the future, less than $1 \%$ indicated that it was because they did not know where to get contraceptives. ${ }^{140}$

Poor antenatal and postnatal health care, or lack of access to such care, contributes to high maternal mortality rates. While the vast majority of women in Sierra Leone have at least some antenatal care from a skilled health care provider (doctor, nurse, midwife, or maternal and child health aide), about half of all women receive fewer than the recommended 4 or more antenatal visits. Women also tend to begin antenatal care later in the pregnancy (fourth month or later), and a small proportion of women $(6.7 \%)$ receive no antenatal care at all. ${ }^{141}$

Nationally, approximately one quarter of women deliver at a health facility, and at least $42 \%$ of births are delivered with the help of a skilled health provider. However, these proportions are much lower for women who are poor, uneducated, or who live in rural areas. Although over half of women in Sierra Leone receive a postnatal check-up within the recommended 48 hours, a third of women receive no postnatal care at all. ${ }^{142}$ Almost half of women, especially those who live in more remote areas, deliver only with the assistance of other women in the community, or of a Traditional Birth Attendant (TBA). ${ }^{143}$

In addition to health issues related to pregnancy and child birth, the hard work that women do can cause health problems for women. Women are responsible for all of the household and childcare work, and also work in the fields. Here is one interview respondent discussing the labour burden on men and women:

\footnotetext{
${ }^{140}$ Statistics Sierra Leone and ICF Macro, Sierra Leone Demographic and Health Survey 2008, 54-56, 68 and 75 .

141 - Sierra Leone Demographic and Health Survey 2008, 116-17.

142 _ Sierra Leone Demographic and Health Survey 2008, 116-17, 21-24.

${ }^{143}$ Government of Sierra Leone, SLIHS 2003/04: Final Statistical Report, 122.
} 
"Men only have one work to be done, farm work. When morning came, he just takes his cutlass and goes to the farm, leaving everything with the woman. Preparing food, children, cooking . . . and . . . especially the women that work so hard in agriculture, they work so hard, they are always with pain. Complaining of back pain, chest, all over." 144

The physical labour that women in rural areas in particular are expected to carry out is another factor that can negatively affect their health.

\subsection{Conclusion}

The health section of this chapter demonstrates that women in Sierra Leone do not have sufficient access to health services. It is clear from the evidence presented that as indicated in my analytical framework, the political, social and economic conditions in the country limit women's ability to access health care. Social norms encourage high fertility rates and affect the family responsibilities and burden of work borne by women. Both of these factors contribute to the health problems women encounter.

The country's recent emergence from conflict means that the political and institutional systems needed to govern the health system and ensure accountability are weak. The poor economic situation in Sierra Leone means that women, especially those in poorer and rural demographic groups, face a number of challenges in accessing health care, including limited access to cash income and a lack of transportation options. The weak economy also reduces the government's ability to fund and provide public services. The next chapter will examine this latter factor in greater detail, looking at the functioning of the country's health system.

\footnotetext{
144 "Interview No. 4," October 29, 2009.
} 


\section{CHAPTER 5: Sierra Leone's health system}

In addition to the social, economic and political conditions that shape women's lives in Sierra Leone, the functioning and performance of the health system is also a key factor in determining potential barriers to accessing health care services. Sierra Leone's health system is quite weak. Major constraints include inadequate finance and infrastructure, a limited number and uneven distribution of health facilities, limited availability of drugs, and a lack of qualified staff. ${ }^{145}$ This chapter examines the health system in more detail, looking at governance and policy, financing, service delivery, human resources, and the role of traditional health care in order to better understand how these factors influence access to health services.

The World Health Organization (WHO) defines a health system as, "the sum total of all the organizations, institutions and resources whose primary purpose is to improve health."146 The WHO identifies six building blocks in the health system, outlined below:

\section{Figure 5: The WHO Health System Framework}

SYSTEM BUILDING BLOCKS

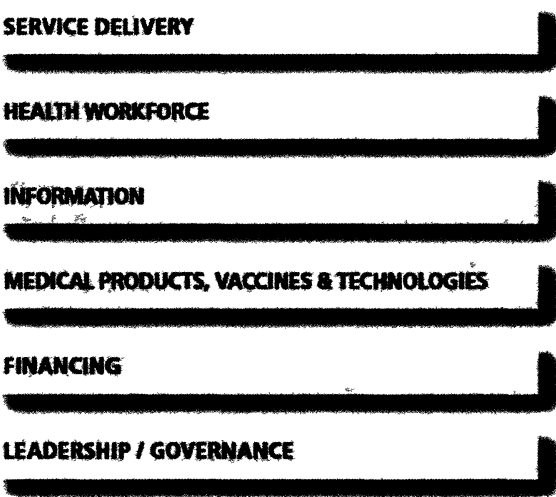

OVERALL GOALS / OUTCOMES

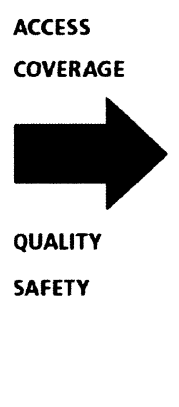

IMPROVED HEATH (CVRA AND EQUTY RESPOASIVENESS

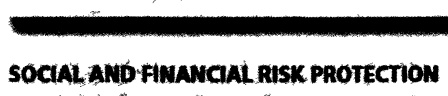

SOCIAL AND FINANCAL RISK PROTECTION

IMPAOVED EFFICIENCY

Source: World Health Organization, Everybody's Business: Strengthening Health Systems to Improve Health Outcomes: Who's Framework for Action (Geneva: World Health Organization, 2007), http://www.who.int/healthsystems/strategy/everybodys_business.pdf (accessed June 26, 2010), 3.

\footnotetext{
${ }^{145}$ Government of Sierra Leone, European Commission, and UK Department for International Development, Sierra Leone - European Community Country Strategy Paper, 12.

${ }^{146}$ World Health Organization, "What Is a Health System?," http://www.who.int/features/qa/28/en/ (accessed January 16, 2010).
} 
I have identified similar components of the health system in Sierra Leone and have included them in my analytical framework. As mentioned in the introduction, although the WHO does not include payments as a separate component of the health system, ${ }^{147}$ I have separated out financing and payments in my framework.

Figure 6: The health system in the analytical framework

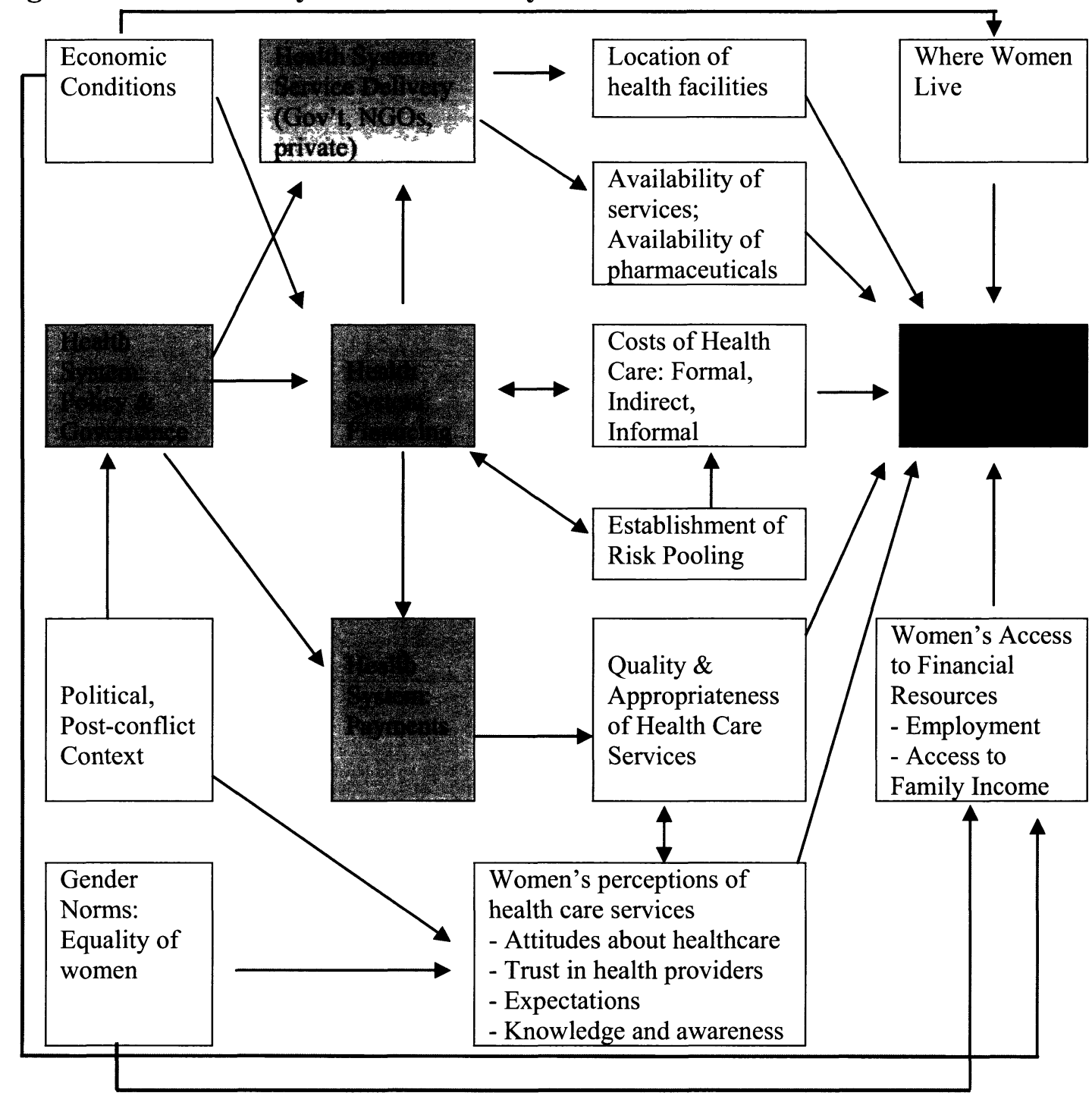

The way in which the health system interacts with and influences barriers to care is outlined in the figure above, and the factors discussed in this chapter are highlighted.

147 ,Everybody's Business: Strengthening Health Systems to Improve Health Outcomes: WHO's Framework for Action, 3. 
As seen in the previous chapter, the functioning of the health system, particularly with respect to financing and governance, is affected by the economic and political context in Sierra Leone. The health policies set at the national and local level in Sierra Leone determine how the rest of the system (service delivery, financing and payments) functions, and this influences which accessibility barriers are present in Sierra Leone from the supply side.

The health system in Sierra Leone is pluralistic, meaning that health services are delivered by a range of actors, including government, local and international nongovernmental organizations (NGOs), the private sector, and religious missions. Only approximately half of health services are provided by the Government of Sierra Leone (GoSL). ${ }^{148}$ In addition to the public, private for-profit and private non-profit services, traditional health care (delivered primarily through traditional healers and traditional birth attendants or TBAs) is also an important component of the health system.

\subsection{Policy \& governance}

The oversight and management of health care was decentralized with the passing of the Local Government Act and the election of local councils in 2004. All primary and secondary health services are now managed by 19 local councils (one for each of the 12 districts outside of the Western Area, plus 5 town councils, the Freetown City Council and the Western Area Rural Council). In each district, a District Health Management Team (DHMT) is responsible for the overall planning, implementation, coordination, monitoring and evaluation of the district health services. The central Ministry of Health and Sanitation (MoHS) focuses on policy formulation, standards, resource mobilization, 
coordination of national services, capacity-building and monitoring and evaluation activities. $^{149}$

Figure 7: Diagram of health sector responsibilities, by level

\begin{tabular}{|c|c|}
\hline \multicolumn{2}{|c|}{ Ministry of Health } \\
\hline $\begin{array}{l}\text { Policy formulation } \\
\text { Resource mobilization } \\
\text { Capacity-building }\end{array}$ & $\begin{array}{l}\text { Standards } \\
\text { Coordination of national services } \\
\text { Monitoring and evaluation activities }\end{array}$ \\
\hline \multicolumn{2}{|c|}{$\begin{array}{l}\text { At the district level, responsible for: } \\
\text { Implementation of National health policies } \\
\text { Provision of curative and rehabilitative services } \\
\text { Health education } \\
\text { Health data collection and management }\end{array}$} \\
\hline \multicolumn{2}{|c|}{ District Health Management Teams } \\
\hline $\begin{array}{l}\text { At the district level, responsible for: } \\
\text { Planning } \\
\text { Coordination }\end{array}$ & $\begin{array}{l}\text { Implementation } \\
\text { Monitoring and evaluation }\end{array}$ \\
\hline
\end{tabular}

Below the district councils, the chiefdoms are led by the Paramount Chiefs, and each chiefdom is divided into wards, which are represented by an elected councillor at the district level. Planning for the delivery of government health services is done by the district council, usually under the supervision of the District Medical Officer (DMO) and a council committee that coordinates the work. At the national level there is a Health Sector Coordinating Committee (HSCC) to coordinate the work of partners in the health field.

\footnotetext{
${ }^{149}$ Ministry of Health and Sanitation for the Republic of Sierra Leone, NHSSP 8.
} 
Government partners, including local and international NGOs, the international financial institutions (IFIs), the various United Nations (UN) agencies, and major donor countries all play a significant role in the health sector in Sierra Leone. However, the MoHS warns that "the health sector in post-conflict Sierra Leone is fragmented by vertical programs and global initiatives." ${ }^{150}$ As of 2007, there were 97 different international NGOs operating health-related programs in the country, over and above the IFIs, the UN agencies, other major bilateral donors, and of course, the national government and private providers. ${ }^{151}$

Coordination and monitoring of all of these activities is a major challenge. One of the interview respondents complained of the lack of coordination between the NGOs and the local councils in the area of health: "the NGOs, they are also contributing to the problem because they have failed spectacularly to co-exist with the [local district] councils." ${ }^{152}$ It is evident that the lack of coordination between the health activities of the private and non-profit sectors and those of government remains an area of weakness in the governance of the health sector.

There are several regulatory bodies and laws that also form part of the governance system for health in Sierra Leone. Regulatory bodies include the Nurses and Midwives Board, the Pharmacy Board, and the Medical and Dental Council. Laws relevant to health governance include the Local Council Act (2004), the Hospital Boards Act (2003), the Environmental Protection Act, and the Public Health Act (1960).

\footnotetext{
150 _ Basic Package of Essential Health Services (BPEHS) (Freetown, Sierra Leone, 2010$), 15$.

151 __ "List of Health Registered NGOs in Sierra Leone 2007,"

http://www.health.sl/drwebsite/uploads/health_2007.xls (accessed January 19, 2010).

152 "Interview No. 15," December 8, 2009.
} 
In addition to legal and regulatory instruments, policy has a direct impact on how health services are financed, distributed, and delivered. There are a number of policies at the national level that guide the planning and delivery of health care in Sierra Leone. The National Health Policy (2002) identifies 10 priority health areas and emphasizes the importance of strengthening and expanding the provision of primary health care in the country. The ten priority areas are malaria, sexually transmitted infections (STIs) including HIV/AIDS, tuberculosis, unsatisfactory reproductive health including maternal and neo-natal mortality, acute respiratory infections, childhood immunisable diseases, nutrition-related disease, water, food and sanitation-borne diseases, disability, and mental illness. ${ }^{153}$

Other key policies related to health include the National Policy on Traditional Medicine, the Reproductive Health Policy, and the Child Health Policy. Only the Policy on Traditional Medicine and the National Health Policy are publicly available on the MoHS website. In general, it is quite difficult to get information and data from the government in Sierra Leone. Two key policy documents, still in draft form at the time of my field work, will guide the future development of health services in Sierra Leone. These are the National Health Sector Strategic Plan (NHSSP), 2010 - 2015 and the Basic Package of Essential Health Services (BPEHS).

The main purposes of the NHSSP are "the fulfilment of the health sector's contribution to the PRSP [Poverty Reduction Strategy Paper] II, Ouagadougou Declaration ${ }^{154}$ and MDG goals of reducing maternal and child mortality; and to reducing

153 - National Health Policy (Freetown, Sierra Leone: Republic of Sierra Leone, 2002), http://www.health.sl/drwebsite/uploads/national_health_policy.doc (accessed August 13, 2009), 5 and 10. ${ }^{154}$ The Ouagadougou Declaration on Primary Health Care and Health Systems in Africa focuses on nine major priority areas, namely Leadership and Governance for Health; Health Services Delivery; Human 
fertility; malnutrition; and the burden of HIV/AIDS, Tuberculosis and Malaria, and reduce disparities in health outcomes among the low and high income groups in Sierra Leone." ${ }^{155}$ The document provides a comprehensive overview of the strengths and challenges in the health system in Sierra Leone, and identifies strategic objectives in each of the six components of the health system (leadership and governance, service delivery, human resources, health financing, medical products and technologies, and health information) that government aims to achieve over the next five years. ${ }^{156}$

The objectives laid out in the NHSSP address many of the key health system barriers to access. A few of the specific actions planned are:

- "Construct/re-const/rehabilitate health facilities in accordance with the national guidelines (hospital/clinic structures, staff quarters, water supply, toilets, medical waste disposal facilities).

- Provide adequate and appropriate drugs, equipment and medical supplies (ensure that by $2011,60 \%$ of all facilities have at least $80 \%$ of identified tracer essential drugs in stock all year round).

- Deploy adequate numbers of health professionals to ensure that $70 \%$ of facilities have the full complement of skilled staff by 2013.

- Fast track recruitment process and improve retention for human resources for health including special packages for hard to reach areas.

- Advocate for dedicated taxes for health (e.g. on alcohol, tobacco, cell phones) to ensure that at least $15 \%$ of national budget is allocated to health.

- Develop and implement innovative prepaid health schemes, e.g. social health insurance, community based health insurance schemes.

- Continuous training programmes [for health staff] introduced in various priority areas of work by 2011."157

The implementation of a basic package of essential health services (BPEHS) is also a key component of the NHSSP. The BPEHS is modeled after similar approaches in

Resources for Health; Health Financing; Health Information Systems; Health Technologies; Community Ownership and Participation; Partnership for Health Development; and Research for Health. It is the result of an international conference on primary health care and health systems in Africa, held in April 2008, on the $30^{\text {th }}$ anniversary of the Alma Ata Declaration.

${ }^{155}$ Ministry of Health and Sanitation for the Republic of Sierra Leone, NHSSP, 12.

156 - NHSSP, 35-51.

$157 \longrightarrow$ NHSSP, 39, 41, 43. 
other post-conflict countries. It focuses on cost-effective, evidence-based services that will have the greatest impact on the major health problems in the country, in particular maternal and child health. A full range of basic services are included in the package, including antenatal, delivery, and postnatal care, expanded programme on immunization (EPI) services, community nutrition, information, education and communication (IEC) campaigns, control of communicable diseases, emergency care, mental health services, and environmental health services. ${ }^{158}$ The BPEHS also includes lists of the medications, supplies and staff that should be present in each health facility in order to effectively deliver the services that are part of the BPEHS.

In terms of a policy on fees, the NHSSP clearly states that there is currently no publicly available, standardised fee scale, and no clear policy on health service fees and charges. ${ }^{159}$ I did hear several references to a government policy on cost-recovery ${ }^{160}$ in my interviews, but there does not seem to be any clarity on exactly what the policy contains. Subjects mentioned that a certain proportion of the costs of drugs should be paid by patients (both $60 \%$ and $70 \%$ co-pay from patients were mentioned ${ }^{161}$ ) and that some populations identified as "vulnerable groups" (pregnant women, lactating mothers, children under 5 and the elderly) should not have to pay any fees for medical care. Actual practices in terms of fees and fee exemptions, as well as a new government policy on fees for health care for women and children are discussed in the next section.

\footnotetext{
$158 \_, B P E H S, 11-13$.

$159 \longrightarrow$ NHSSP, 23-24.

${ }^{160}$ Cost recovery means that patients pay a certain percentage of the cost of the medications, while the rest of the cost is paid by government.

161 "Interview No. 15." and "Interview No. 1," October 19, 2009.
} 


\subsection{Financing}

Funding for the health sector in Sierra Leone comes from three main sources: government own-source revenues, direct out-of-pocket payments by households, and international donors (e.g. bilateral donors, multilateral agencies, the Global Fund, GAVI, and many other NGOs). In $2006,69.25 \%$ of total health expenditures were financed from out-of-pocket payments, $11 \%$ from donors, and $19 \%$ from GoSL. ${ }^{162}$ This financing pattern is fairly similar to that found in other low-income countries, although the public share of expenditures in Sierra Leone is lower than the average of $29 \%$ for all lowincome countries, and the proportion financed by both private spending and donors is slightly higher. ${ }^{163}$ Financial accessibility therefore presents a major barrier to care, as the majority of expenditures are financed from out-of-pocket payments.

Current public spending on health in Sierra Leone comprises $7.8 \%$ of the total budget. The current level of spending is equivalent to approximately \$4 US per capita and represents 3.5\% of Sierra Leone's GDP. ${ }^{164}$ The BPEHS states that the government is committed to meeting the target agreed to in the Abuja Declaration of ECOWAS Heads of State of spending $15 \%$ of the national budget on health care. In addition, the NHSSP estimates a cost of $\$ 248$ million in 2010 (approximately 13\% of 2009 GDP), rising to $\$ 361$ million in 2014 in order to implement the plan. ${ }^{165}$ Meeting these commitments, which represent an approximate tripling of spending, will present a major challenge.

Inadequate funding is one of the major barriers to the development of Sierra Leone's health system and to the elimination of financial barriers to accessing care.

\footnotetext{
${ }^{162}$ Ministry of Health and Sanitation for the Republic of Sierra Leone, NHSSP, 21-22.

${ }^{163}$ Gottret and Schieber, Health Financing Revisited, 3-4.

${ }^{164}$ World Health Organization, "WHO Statistical Information System (WHOSIS)."

${ }^{165}$ Ministry of Health and Sanitation for the Republic of Sierra Leone, NHSSP, 71.
} 
Currently, only about $30 \%$ of the approved health budget is actually funded by government own source revenues. ${ }^{166}$ In Bombali District, where Mapaki is located, the local council receives approximately 600 million Leones per year (roughly $\$ 180,000$ CDN) to fund health services for its entire population of 408,000 people. ${ }^{167}$ This is less than $\$ 0.50 \mathrm{CDN}$ per person per year, significantly less than the $\$ 34$ per person suggested by the WHO Commission on Macroeconomics and Health. ${ }^{168}$

Although non-governmental sources provide a significant proportion of funding for health, this can sometimes be problematic. As described above, the work of NGOs and donors is often poorly coordinated, resulting in a fragmented system. There is no Sector Wide Approach (SWAp) to the health sector, and as a result, funding tends to be unpredictable, is not necessarily aligned to national health priorities, and is not harmonised with government systems. The MoHS actually runs two parallel financial management systems in order to report on and manage expenditures - one following GoSL policies and procedures, and the other following donor-specific guidelines. ${ }^{169}$

Private or community based health insurance is virtually non-existent in Sierra Leone. ${ }^{170}$ The vast majority of private expenditures are out-of-pocket payments. User fees are charged for public health services as a cost recovery strategy, and private clinics, NGOs, and traditional healers also collect fees. Fees charged to patients can vary widely depending on the care required and the provider.

Although fees can vary significantly, it is important to get a sense of the range of costs patients may face to access health services. In a survey carried out by Médecins

\footnotetext{
$166 \_$NHSSP, 23.

167 "Interview No. 15."

$168 \longrightarrow$, NHSSP, 21.

$169+$ NHSSP, 15.

${ }^{170}$ Statistics Sierra Leone and ICF Macro, Sierra Leone Demographic and Health Survey $2008,45$.
} 
Sans Frontières (MSF) in Sierra Leone in 2005, half of survey respondents paid more than 8,250 LE (about $\$ 2.50 \mathrm{CDN}$ ) for care at the nearest health centre. ${ }^{171}$ A caesareansection can cost between 100,000 and 200,000 LE in a government hospital. ${ }^{172}$ To put the fees charged in context, the monthly income of interview subjects was in the range of 5,000 to 30,000 LE per month, and $70 \%$ of the population in Sierra Leone earns 65,000 LE a month or less. It is clear that for many people, the costs of health care would present a major barrier to accessing needed services.

During the period of this study, exemptions to user fees for vulnerable groups (pregnant women, lactating mothers, children under 5 and the elderly) did theoretically exist in the public system, but no clear criteria identified the vulnerable populations, and in practice exemptions were not implemented for a variety of reasons. Lack of knowledge about the policy among both providers and recipients of health services is one reason, as individuals did not seem to be aware of these exemptions. ${ }^{173}$ Corruption is another.

The insufficient resources, equipment and medication available in the public system is also a major factor undermining fee exemptions. For example, the health centre in Mapaki had not received their supply of drugs from the government supplier in six months. Instead, the clinic staff purchased the required medications, paying for this from their own personal funds. In order to be able to live, and to purchase more medication in future, they had to charge for what they provided to patients in order to recover the

\footnotetext{
${ }^{171}$ Respondents were asked about prices at the nearest health facility - there is no indication of whether these were public or private facilities. Médecins Sans Frontières, Access to Healthcare in Post-War Sierra Leone, 5.

172 van Gurp, "Asset-Based Needs Assessment," 5.

${ }^{173}$ Several key informants mentioned the exemption policy but no individual respondent seemed to know about it. See also Médecins Sans Frontières, Access to Healthcare in Post-War Sierra Leone, 7.
} 
costs. ${ }^{174}$ This is an example of how even components of the health system that may seem unrelated (e.g. supply chains) can affect financial or other barriers to care.

Recently (April 2010), Sierra Leone implemented a national health care program providing free health care for pregnant women, lactating mothers and children under 5 years of age. The cost of implementing this program is estimated at approximately $\$ 91$ million USD for the first year. Of this amount, the GoSL will contribute $1.4 \%$ of the total. The rest will be contributed by multilateral and bilateral donors. ${ }^{175}$ Although my fieldwork was conducted prior to the implementation of this program, the findings remain relevant. Even though this plan may help to reduce financial barriers for some women, many other women will not benefit. In addition, other non-financial barriers to care will not be affected by this change to the fee structure.

The GoSL lists a number of priority health system interventions as central to the implementation of this limited health insurance scheme. These include health system strengthening interventions such as improving supply chains for drugs and equipment, strengthening government operating procedures, increasing the number of trained staff available, and strengthening oversight and management. ${ }^{176}$ Based on past experience with fee exemptions, it will likely be difficult to successfully implement any kind of exemption until the health system as a whole is strengthened. This will take time, meaning that financial barriers to care will continue to deter access to health.

\footnotetext{
174 "Interview No. 1."

175 This was announced following a donor conference that took place in London, United Kingdom in November 2009. Government of Sierra Leone, Free Healthcare Services, 5.

$176 \_$Free Healthcare Services, 8-10.
} 


\subsection{Payments}

Payments in the health system reflect decisions about which organizations will be paid to deliver services, how they will be paid, and which services they will be paid to deliver. The way in which the payment system operates provides a strong incentive to how, where, and which health services are delivered. For example, if doctors are paid per patient versus being paid a set salary, this influences how many patients they see and how long they spend with each patient. Payment systems can therefore affect both the quality and quantity of care provided. ${ }^{177}$

In the public health system in Sierra Leone, the primary method of payment is to pay health care workers a monthly salary. This type of payment method may result in a lower number of patient visits, reduced number of services provided per visit and/or a lack of responsiveness to patient needs and demands. ${ }^{178}$ In fact, the Ministry of Health and Sanitation acknowledges that, "current remunerations in the health sector do not create performance incentives, and payment mechanisms in the public health institutions may not encourage maximum output and cost containment." 179

\subsection{Service delivery}

The way in which services are organized and delivered can affect barriers to access related to availability. Sierra Leone's health system organizes service delivery based on the principles of primary health care. There are three key levels of care: peripheral health units (PHUs), which provide primary care, district hospitals for secondary care, and regional/national hospitals for tertiary care. In each district, there are

${ }^{177}$ Roberts et al., Getting Health Reform Right, 191-92.

178 _ Getting Health Reform Right, 199.

${ }^{179}$ Ministry of Health and Sanitation for the Republic of Sierra Leone, NHSSP, 24. 
a number of PHUs. PHUs are also classified into three levels: maternal and child health posts (MCHPs) for villages with less than 5,000 people, community health posts (CHPs) for towns with populations between 5,000 and 10,000, and Community Health Centres (CHCs) which generally serve a population of 10,000 to 20,000 and are found at Chiefdom level. Each type of PHU provides different services. The table below shows the staff and services that are supposed to be available at each level.

Table 2: Staffing and services available by type of PHU

\begin{tabular}{|l|l|l|}
\hline Type of PHU & \multicolumn{1}{|c|}{ Staff } & \multicolumn{1}{c|}{ Services } \\
\hline MCHP & $\begin{array}{l}\text { Two Maternal and Child Health } \\
\text { Aides (MCH Aides) }\end{array}$ & $\begin{array}{l}\text { Focused on maternal and child } \\
\text { health (antenatal and postnatal } \\
\text { care, immunizations, health } \\
\text { education, etc.) }\end{array}$ \\
\hline CHP & $\begin{array}{l}\text { State Enrolled Community Health } \\
\text { Nurse (SECHN) and an MCH Aide }\end{array}$ & $\begin{array}{l}\text { As above plus prevention and } \\
\text { control of communicable } \\
\text { diseases and rehabilitation }\end{array}$ \\
\hline CHC & $\begin{array}{l}\text { As above plus Community Health } \\
\text { Officer (CHO), epidemiological } \\
\text { disease control assistant, } \\
\text { environmental health assistant }\end{array}$ & $\begin{array}{l}\text { As above plus environmental } \\
\text { sanitation services and } \\
\text { supervision of CHPs and } \\
\text { MCHPs in the Chiefdom }\end{array}$ \\
\hline
\end{tabular}

Source: Ministry of Health and Sanitation for the Republic of Sierra Leone, National Health Sector Strategic Plan, 2010 - 2015, Draft (Freetown, Sierra Leone, 2009), 5.

There is at least one District Hospital in each of Sierra Leone's 13 districts. Many districts also have other hospitals that are operated by missions or private providers, and these are not regulated by government. The District hospital is supposed to provide outpatient services for cases referred from PHUs and people living nearby, inpatient and diagnostic services, management of accidents and emergencies, and technical support to PHUs.

The distribution of health facilities affects geographic access to care. As is visible in Table 3 below, facilities are unevenly distributed across the country. The number of hospitals per 100,000 people ranges from 0.3 in Kono to 2.3 in Bonthe. Bombali District, where Mapaki is located, has a fairly high number of facilities available in relation to its 
population (23.5 health facilities per 100,000 people), and has 5 hospitals in the district, second only to the Western Area in number of hospitals.

Table 3: Distribution of health facilities in Sierra Leone

\begin{tabular}{|c|c|c|c|c|c|c|c|c|c|c|c|}
\hline & \multicolumn{5}{|c|}{ Government } & \multicolumn{2}{|c|}{ Mission } & \multicolumn{2}{|c|}{ Private } & \multirow{2}{*}{$\begin{array}{l}\text { NGO } \\
\text { Clin. } \\
\end{array}$} & \multirow[b]{2}{*}{ Total } \\
\hline $\begin{array}{l}\text { District } \\
\text { (Pop'n) }\end{array}$ & $\mathrm{CHC}$ & $\mathrm{CHP}$ & MCHP & Clin. & Hosp. & Hosp. & Clin. & Hosp. & Clin. & & \\
\hline $\begin{array}{l}\text { Kenema } \\
(497,948)\end{array}$ & 21 & 17 & 63 & 1 & 2 & 1 & 2 & 0 & 3 & 1 & 111 \\
\hline $\begin{array}{l}\text { Bo } \\
(463,668)\end{array}$ & 23 & 12 & 50 & 1 & 1 & 1 & 6 & 0 & 11 & 3 & 108 \\
\hline $\begin{array}{l}\text { Western } \\
\text { Area } \\
(947,122)\end{array}$ & 20 & 10 & 15 & 7 & 12 & 2 & 11 & 2 & 23 & 3 & 105 \\
\hline $\begin{array}{l}\text { Bombali } \\
(408,390)\end{array}$ & 16 & 20 & 49 & 0 & 2 & 2 & 3 & 1 & 3 & 0 & 96 \\
\hline $\begin{array}{l}\text { Port Loko } \\
(453,746)\end{array}$ & 11 & 21 & 55 & 0 & 2 & 1 & 4 & 0 & 1 & 0 & 95 \\
\hline $\begin{array}{l}\text { Tonkolili } \\
(347,197)\end{array}$ & 9 & 8 & 65 & 0 & 1 & 2 & 1 & 0 & 0 & 1 & 87 \\
\hline $\begin{array}{l}\text { Moyamba } \\
(260,910)\end{array}$ & 12 & 6 & 56 & 1 & 2 & 0 & 5 & 0 & 0 & 1 & 83 \\
\hline $\begin{array}{l}\text { Kono } \\
(335,401)\end{array}$ & 11 & 15 & 46 & 0 & 1 & 0 & 1 & 0 & 4 & 4 & 82 \\
\hline $\begin{array}{l}\text { Kailahun } \\
(358,190)\end{array}$ & 9 & 34 & 12 & 0 & 2 & 1 & 1 & 0 & 0 & 0 & 59 \\
\hline $\begin{array}{l}\text { Kambia } \\
(270,462)\end{array}$ & 11 & 8 & 31 & 0 & 1 & 0 & 2 & 0 & 0 & 1 & 54 \\
\hline $\begin{array}{l}\text { Koinadugu } \\
(65,758)\end{array}$ & 12 & 6 & 33 & 1 & 1 & 0 & 0 & 0 & 0 & 1 & 54 \\
\hline $\begin{array}{l}\text { Pujehun } \\
(228,392)\end{array}$ & 14 & 10 & 25 & 0 & 1 & 0 & 0 & 0 & 0 & 0 & 50 \\
\hline $\begin{array}{l}\text { Bonthe } \\
(139,687)\end{array}$ & 9 & 9 & 20 & 0 & 2 & 1 & 2 & 0 & 0 & 2 & 45 \\
\hline $\begin{array}{l}\text { Total } \\
(4,776,871)\end{array}$ & 178 & 176 & 520 & 11 & 30 & 11 & 38 & 2 & 45 & 17 & 1028 \\
\hline
\end{tabular}

Source: Ministry of Health and Sanitation for the Republic of Sierra Leone, National Health Sector Strategic Plan, 2010 - 2015, Draft (Freetown, Sierra Leone, 2009), 6.

Even when health facilities are physically proximate, they may lack the necessary medications and equipment to deliver health services. One clinic I visited in Tonkolili District did not even have umbilical scissors to use during births. As mentioned above, the Mapaki clinic had not received a supply of drugs in six months. They had received some drugs from various NGOs, but this was not a reliable source of supply. ${ }^{180}$

Even when medications are available, they may not be of sufficient quality.

180 "Interview No. 1." 
Although the Pharmacy Board regulates and tests medications in Sierra Leone, the quality of medications can still be poor as there are very limited resources available to support the Board's work. Inappropriate use of medicines and counterfeit or expired medications are common. ${ }^{181}$ In rural areas, there are peddlers (also referred to as pépé doctors) that sell medications that they have purchased from a private pharmacy. People often turn to medication from peddlers as an alternative to the clinic, either because the drugs cost less, or because the required medication is not available in the clinic. ${ }^{182}$ These peddlers are not trained or regulated. Although the drugs they sell are often cheaper, there is a risk that they are counterfeit or expired. Peddlers may also sell incorrect doses of drugs. ${ }^{183}$ Both under and over-dosing can be problematic, leading to the development of drug resistance, or even to death or further complications for the patient.

Laboratory facilities in Sierra Leone are extremely limited. There is no national public health laboratory. The inability to test for certain illnesses can lead to misdiagnosis and inappropriate treatment. "Without the testing, the $\mathrm{MCH}$ aide will be guessing, guessing, guessing until someone dies. Because they do not know. The symptoms of malaria, typhoid, and the other, they are all the same," says one key informant. ${ }^{184}$

\subsection{Human Resources}

A lack of trained and qualified staff is a major issue in Sierra Leone's health system, in both public and private facilities. This affects the availability of health services and possibly the acceptability of services as well. As described in the previous chapter,

\footnotetext{
$181 \_$, NHSSP, 26-27.

${ }^{182}$ Five interview respondents mentioned purchasing drugs from a peddler in the past.

183 "Interview No. 26," December 18, 2009.

184 "Interview No. 15."
} 
many health workers left Sierra Leone during the war. While staffing shortages did exist before the conflict, emigration during that period exacerbated the problem. Table 4 below shows current staff shortages, ${ }^{185}$ which are evident in every category, ranging from $20 \%$ of required staff not available, to $100 \%$ in 9 categories and over $80 \%$ in 14 other categories. Shortages of $100 \%$ are highlighted in pink, $80-99 \%$ in yellow, and $50-79 \%$ in green. Shortages are the smallest in the least specialized categories, such as MCH Aides, SECHNs, and Medical Officers. Specialists are in short supply; for example, there is a $92 \%$ shortfall for anaesthesiologists and a $100 \%$ shortfall for nephrologists, neurosurgeons, gastro-enterologists, and neurologists. Given the current post-war context in Sierra Leone, and the brutal and traumatic nature of the war, it is especially concerning that there are no psychiatrists at all in the country.

In addition to the overall shortages, the table also demonstrates that health workers are not well distributed throughout the country. Although the majority of the population live in rural areas, almost half of all staff are concentrated in and around the capital city of Freetown. In the three provinces combined (Southern, Eastern and Northern), where approximately $80 \%$ of the population lives, there are only two surgeons, one pharmacist, one OB-GYN and two dentists. The vast majority of the health staff found in the provinces are MCH Aides or SECHNs. This is partly due to the reluctance of health personnel to live and work in rural areas. ${ }^{186}$ Without sufficient human resources for health, it will be extremely difficult for government to reduce barriers to health care related to availability of services.

\footnotetext{
${ }^{185}$ Ministry of Health and Sanitation for the Republic of Sierra Leone, NHSSP, 19. The document does not clearly indicate whether this table includes only health staff in government facilities or private facilities as well.

$186 \_$, BPEHS, 15.
} 
Table 4: Health workforce distribution by category and region

\begin{tabular}{|c|c|c|c|c|c|c|c|}
\hline \multirow[b]{2}{*}{ Specialisation/study } & \multirow[b]{2}{*}{ Number } & \multicolumn{4}{|c|}{ Location } & \multirow[b]{2}{*}{ Needed } & \multirow{2}{*}{$\begin{array}{c}\% \\
\text { Shortfall }\end{array}$} \\
\hline & & $W A$ & South & North & East & & \\
\hline Anaesthesiologist & 1 & 1 & 0 & 0 & 0 & 12 & $92 \%$ \\
\hline Clinical Pharmacologist & 1 & 1 & 0 & 0 & 0 & 24 & $96 \%$ \\
\hline Dentists & 6 & 4 & 1 & 0 & 1 & 30 & $80 \%$ \\
\hline Dermatologist & 1 & 1 & 0 & 0 & 0 & 6 & $83 \%$ \\
\hline ENT & 1 & 1 & 0 & 0 & 0 & 8 & $88 \%$ \\
\hline Haematologist & 1 & 1 & 0 & 0 & 0 & 6 & $83 \%$ \\
\hline Medical Officers & 115 & 97 & 5 & 8 & 5 & 150 & $23 \%$ \\
\hline Obstetrician/Gynaecologist & 5 & 4 & 1 & 0 & 0 & 26 & $81 \%$ \\
\hline Ophthalmologist & 1 & 1 & 0 & 0 & 0 & 22 & $95 \%$ \\
\hline Paediatrician & 2 & 2 & 0 & 0 & 0 & 30 & $93 \%$ \\
\hline Pharmacist & 33 & 32 & 1 & 0 & 0 & 52 & $37 \%$ \\
\hline Physician & 3 & 3 & 0 & 0 & 0 & 26 & $88 \%$ \\
\hline Public health & 24 & 15 & 3 & 3 & 3 & 30 & $20 \%$ \\
\hline Radiologist & 1 & 1 & 0 & 0 & 0 & 30 & $97 \%$ \\
\hline Surgery/Surgeons & 5 & 3 & 0 & 1 & 1 & 26 & $81 \%$ \\
\hline \multicolumn{8}{|l|}{ NURSES } \\
\hline Midwives (Practicing) & 95 & 95 & 0 & 0 & 0 & 300 & $68 \%$ \\
\hline Nurse anaesthetist & 20 & 15 & 2 & 1 & 2 & 34 & $41 \%$ \\
\hline Ophthalmic Nurses & 20 & 10 & 6 & 1 & 3 & 30 & $33 \%$ \\
\hline SECHN & 635 & 425 & 60 & 80 & 70 & 1,500 & $58 \%$ \\
\hline SRN & 245 & - & - & - & - & 600 & $59 \%$ \\
\hline \multicolumn{8}{|l|}{ OTHERS } \\
\hline Cataract Surgeons & 2 & 1 & 0 & 0 & 1 & 12 & $83 \%$ \\
\hline $\mathrm{CHO}$ & 132 & 50 & 30 & 25 & 17 & 300 & $56 \%$ \\
\hline $\mathrm{EHO}$ & 135 & 45 & 30 & 30 & 30 & 300 & $55 \%$ \\
\hline ICU nurses & 2 & 2 & 0 & 0 & 0 & 20 & $90 \%$ \\
\hline MCH Aides & 825 & 225 & 200 & 220 & 180 & 1,500 & $45 \%$ \\
\hline Pharmacy Technicians & 80 & 62 & 5 & 8 & 5 & 300 & $73 \%$ \\
\hline Vector controllers & 30 & 16 & 6 & 4 & 4 & 75 & $60 \%$ \\
\hline Totals & 2,435 & 1,121 & 352 & 383 & 324 & 6,089 & $60 \%$ \\
\hline
\end{tabular}

*14 CHAs graduated in 2008 but have not yet been recruited.

Source: Ministry of Health and Sanitation for the Republic of Sierra Leone, National Health Sector Strategic Plan, 2010 - 2015, Draft (Freetown, Sierra Leone, 2009), 19. 
Loss of staff due to poor conditions and low pay is a major problem. As one key informant stated about the clinic in Mapaki, "so many CHOs have come here, but the working conditions are not favourable, so they return back." ${ }^{187}$ An $\mathrm{MCH}$ Aide, even one with many years of experience, will earn only about 160,000 LE (about $\$ 50 \mathrm{CDN}$ ) per month. ${ }^{188}$ In March 2010, public health workers in Sierra Leone went on strike to protest the poor pay and conditions, resulting in the closure of several hospitals in Freetown. One of the main areas of concern for the striking workers was the planned implementation of free health care for pregnant women and children in government facilities. The strikers were concerned that this initiative would significantly increase their workload. Although the government at first threatened to fire the striking workers, eventually they gave in to demands to increase pay. News reports suggest that pay rates for doctors and nurses will increase six fold. ${ }^{189}$ However, given the financial circumstances of the country's health system, and the loss of the income that was coming in from users as co-payments, it is difficult to see how this increase will be funded.

In addition to the problems of low pay and poor working conditions, there are several other key challenges in training and recruiting new health care staff. Training itself is problematic due to limited resources and teaching staff in colleges and universities. It generally takes at least 2-3 years to become trained as a health worker, and the capacity of training programs to take in new students is limited. The "delayed and

\footnotetext{
187 "Interview No. 26."

188 "Interview No. 26."

189 "Sierra Leone Doctors and Nurses Get Massive Pay Rise," http://news.bbc.co.uk/2/hi/africa/8591682.stm (accessed March 29, 2010).
} 
heavily bureaucratic recruitment processes" mean that some health professionals leave the country "even before they are considered for an interview." 190

\subsection{Traditional health care}

In addition to conventional health care, informal or traditional methods of care are also popular. Most larger villages have a resident traditional healer, and traditional birth attendants are still widely used. According to the NHSSP, Traditional healers and Traditional Birth Attendants (TBAs) provide a significant proportion of health care, especially for rural populations. ${ }^{191}$ The greater availability of traditional health care services may be the reason for their greater usage. Another contributing factor to the use of traditional forms of care is a strong belief among many people in magic or witchcraft as causes of ill health.

Traditional birth attendants are used frequently, especially in communities where there are no other health facilities or staff. Almost $45 \%$ of deliveries nationally are still assisted by only a TBA. ${ }^{192}$ In the catchment area in and around the Mapaki CHC, there are 18 TBAs. Eight of them have been trained by the $\mathrm{MCH}$ Aides at the $\mathrm{CHC}$, and the rest are untrained. A good relationship between TBAs and health facility staff is important, and may improve rates of antenatal care and increase referrals. However the contribution that TBAs are able to make to reducing maternal mortality is limited by their inability to provide any kind of immediate emergency obstetric care. ${ }^{193}$ This is a factor

\footnotetext{
${ }^{190}$ Ministry of Health and Sanitation for the Republic of Sierra Leone, NHSSP, 20-21.

$191 \longrightarrow$, NHSSP, 4.

${ }^{192}$ Government of Sierra Leone, SLIHS 2003/04: Final Statistical Report, 122.

${ }^{193}$ Ministry of Health and Sanitation for the Republic of Sierra Leone, BPEHS, 18.
} 
especially in remote communities where it may take hours to get to a hospital for emergency care.

Traditional healers provide a range of services and claim to treat all kinds of ailments of both conventional and magical origin, including tuberculosis, stomach ache, asthma, and malaria. ${ }^{194}$ There is no clear evidence on the effectiveness of these traditional treatments. Some patients claim to be cured, and others find that they do not work. Traditional healers generally charge for their services, but the prices are not fixed. Traditional healers may be more willing to take in-kind payments for their services instead of cash, or to be paid over time, reducing financial barriers to access.

\subsection{Conclusion}

Sierra Leone's health system faces major challenges in supplying appropriate and timely health care to an impoverished population. Issues such as inadequate funding, limited facilities and staff, and a lack of essential medications and equipment affect barriers to access (highlighted in yellow in the analytical framework, Figure 2, p. 10) and reduce utilization of health services. As indicated by my analytical framework, poor financing and payment systems and weak service delivery suggest that there are major barriers to accessing care from the supply side related to geographic and financial accessibility and to availability. The next five chapters examine the evidence from my research on each component of access.

\footnotetext{
194 "Interview No. 3," October 24, 2009.
} 


\section{CHAPTER 6: Gender and access to care}

"[S]ocial roles, expectations, norms and values of behaviour mean that women are more vulnerable to ill health, yet have fewer resources and opportunities to protect their health or to utilise health care. Access [to] and utilization [of] health care is not only limited by economic barriers but also socio-cultural." 195

Women's health and their ability to access health services and information is significantly affected by their status and socially acceptable roles in the community and in the home. Despite this, the analysis of access issues through a gender lens is a neglected area of research. It is, however, an important component in my analytical framework (see Figure 8 below). This chapter examines some of the gender-related barriers to care present in Mapaki.

As illustrated in the analytical framework, gender roles and norms can affect women's access to financial resources and their opinions and perceptions of health care services. My literature review found that women have more difficulty than men seeking care due to distance and costs, spend fewer resources on health, and are less likely to use conventional methods of health care. A lack of decision-making power or a lack of access to or control over financial resources due to gender could create additional barriers to seeking care, especially in the areas of financial accessibility and acceptability. Gaining a better understanding of the way in which gender roles and norms affect women is therefore essential for addressing the barriers to access that women may face.

195 , NHSSP, 16. 
Figure 8: Gender in the analytical framework

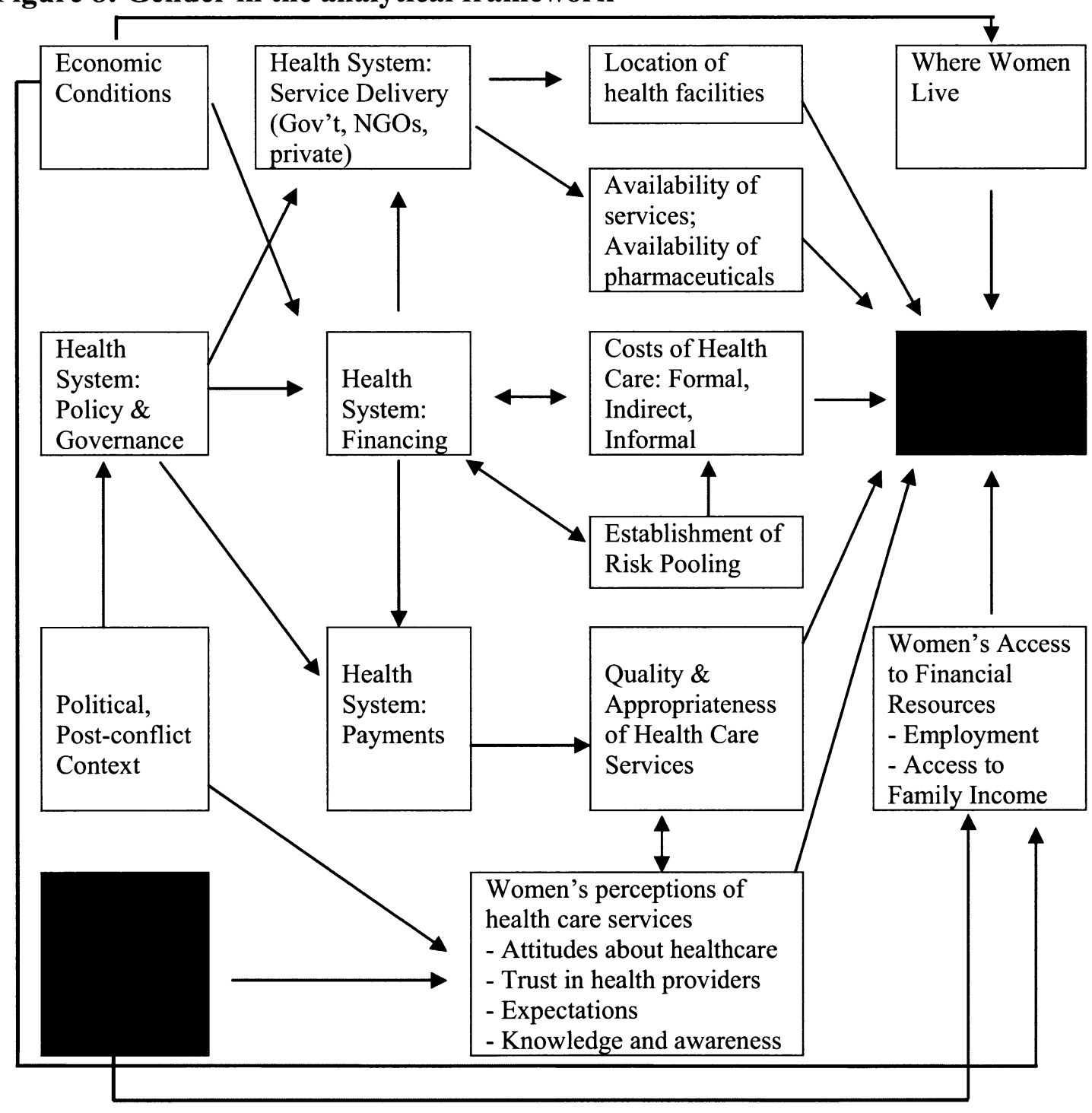

The 2008 Sierra Leone Demographic and Health Survey (SLDHS) looks at

women's participation in decision-making as an indicator of women's empowerment.

This indicator is particularly relevant for access to health, as one of the questions was specifically about decisions regarding the woman's health care. While almost $12 \%$ of women reported making health decisions themselves, almost half of women (46.7\%) indicated that decisions about her health care are made primarily by her husband. Women who are poorer, have less education, live in rural areas, and those who do not earn a cash 
income themselves are less likely to participate in household decision-making in general, and in decisions about their own health care specifically. ${ }^{196}$

This issue was reflected in the responses of my interview subjects. All of the married women interviewed said that they would discuss health-seeking decisions with their husbands. The reason for this seems to be related primarily to access to cash. Even if women earn their own income, they still may not have control over how that income is used. If women do not have the ability to decide how income is spent, they do not have the ability to seek needed health services without permission from a husband or other family member.

The majority of women responding to the SLDHS indicated that decisions about the woman's cash earnings were made either by the woman herself or jointly. However, at least a quarter of respondents indicated that these decisions were made primarily by the husband. In the Northern Province, where Mapaki is located, this proportion was significantly higher $-46 \%$ of women said that the decisions about how their earnings are used were made by their husbands. ${ }^{197}$

In my interviews, no woman said that her husband discouraged her from seeking health care or refused to give her the money for care if he had it available. In fact, several of the women interviewed indicated that their husband or boyfriend encouraged them to get care. Only one woman, who was no longer with her husband, talked about him not providing her with money when she needed it: "when my husband was here, when he had

\footnotetext{
${ }^{196}$ Statistics Sierra Leone and ICF Macro, Sierra Leone Demographic and Health Survey 2008, 239-41.

197 _- Sierra Leone Demographic and Health Survey 2008, 239-41.
} 
money, he went to girlfriends. Instead of giving me the money, he would use it on girlfriends." 198

Key informants tended to discuss the issue of health care decision-making for women and control over financial resources more readily than individual respondents. Several of the key informants talked about the responsibility of men as the head of the family to provide care for their wives:

"It is an obligation for that man to take care of the woman. Because the woman is in the house for his own sake. So if that woman has any sickness, it is an obligation for that man to take care of that woman." 199

"For us here, the men, they owe obligation for the women. When your wife is pregnant, you are going to be responsible for the health care of that particular woman. Because if you do not take care, if it comes to a case wherein a referral takes place, you will suffer the most. The woman is there feeling the pain, but the responsibility or the expenditure is going to rely on you, the man. So in most cases the men take great care for the health of their wives." 200

These responses, and the responses of the women themselves suggest that while women do consult with their husbands when seeking health care, men also generally feel an obligation and a desire to have their wives get care when it is needed, and to provide the financial resources necessary for them to do so.

It is difficult to say whether this can be generalized to the country as a whole. It is clear from both the national data and the participant responses that men act as an intermediary between women and their health care utilization. It is certainly possible that the husbands of women I interviewed were more benevolent, or that they had more

\footnotetext{
198 "Interview No. 6," November 21, 2009.

199 "Interview No. 3."

200 "Interview No. 17," December 9, 2009.
} 
resources at their disposal or fewer frivolous items on which to spend their money. Given the existing power structures and gender inequality in Sierra Leone, it would not be surprising if men did sometimes prevent women from getting needed health care.

Even though individual interview respondents generally did not indicate that this happened, it is possible that the respondents were not comfortable talking to me about this kind of situation. Several key informants did speak about this happening, perhaps because they were able to talk about this issue in a more general way rather than referring to their own specific situation. Three of the key informants indicated that they were aware of situations where the husband refused to give the woman money for health care, demonstrating that this does indeed happen, and perhaps more frequently than others would admit. ${ }^{201}$ Two of these key informants associated men not supporting their wives in seeking health care at least partially with the prevalence of polygynous relationships.

"You see that's the bad side of [polygyny]. Some men are careless. If he has two women, maybe he is more interested in one than the other. If one wants to go to the clinic, maybe he will give money to her, but the other one, he will not give money. Or if there is a small misunderstanding between the women, he will refuse to give money to the one he has a problem with. So that usually happens." 202

\section{Conclusion}

The evidence presented in this chapter indicates that women's status did not act as a barrier to care for most of the women in my study. However, the national data on the role of women and their ability to act autonomously suggests that it may be a barrier for women in some cases. Because of their responsibilities at home, women have less of an opportunity to earn a cash income than men, reducing their ability to pay for the direct

\footnotetext{
201 "Interview No. 4." "Interview No. 7." And "Interview No. 15."

202 "Interview No. 7."
} 
and indirect costs of obtaining health care. Women also have less control over both family income and income they earn themselves, and reduced ability to make their own decisions regarding health care.

When men control the income and the decision-making, they have the ability to prevent women from getting the health care they need. As Badara Samb states, "[e]liminating the persistent gender disparities in relation to health will not be possible without a wider process of transformation that goes beyond the health sector." ${ }^{203}$ In addition to addressing more broadly the issue of gender inequality, interventions that emphasize the role that men play in facilitating or preventing women's access to health services could also enhance access.

${ }^{203}$ Samb, "Reforming Country Health Systems for Women's Health," 354. 


\section{CHAPTER 7: Geographic accessibility barriers}

This chapter analyses the main findings from my interviews in relation to geographic accessibility. The factors relevant to geographic accessibility are highlighted in my analytical framework, below. The distance between the user and the health facility is the primary factor. This is determined by where both women and health facilities are located. These locations are affected by how services are delivered in the health system and by the general economic and social conditions in Sierra Leone.

\section{Figure 9: Geographic accessibility barriers in the analytical framework}

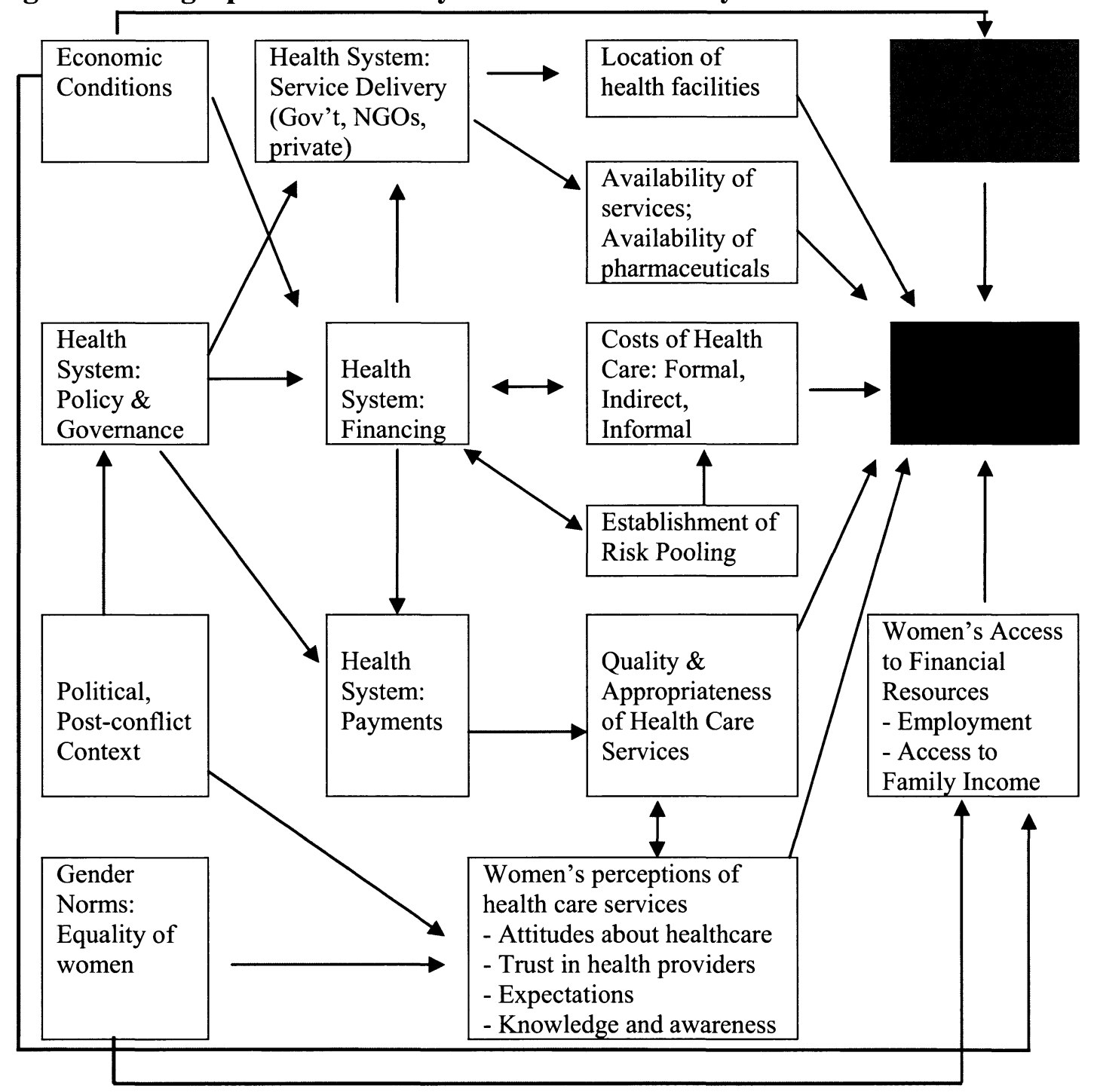


Other issues that affect geographic accessibility include access to different forms of transportation (for example, public transportation, a motor vehicle, or a bicycle) and the condition of the road network. Geographic accessibility is also linked to financial accessibility. Sometimes the costs of travelling to a health facility are greater than, and a larger deterrent than, the direct costs of care. In Sierra Leone, I found that all of these types of geographic barriers are present, to varying degrees.

\subsection{Distance to a health facility}

The women of Mapaki are fortunate to be located relatively close to health facilities. In Bombali District, where Mapaki is located, there are five hospitals, two district hospitals and three private hospitals. Even though Makeni is the district headquarter town and is where official referrals from the PHU in Mapaki are directed, because the town of Magburaka is closer (about $13 \mathrm{~km}$ by road vs. about $25 \mathrm{~km}$ to Makeni), patients would often go there instead when they needed hospital services. ${ }^{204}$ There is a PHU located in the village of Mapaki that is able to meet many basic health needs. The PHU is a Community Health Centre (CHC) and provides services such as testing for and treating malaria, some pain relief medications and antibiotics, ante- and post-natal health care, and immunizations and nutritional support to children under five. Mapaki women would primarily face a geographic barrier to accessing health care when they had to seek health care services elsewhere. For example, they may be referred to secondary or tertiary services for a more serious condition, or they may need to go to a private pharmacy to purchase medication.

\footnotetext{
204 "Interview No. 2."
} 
Although one key informant indicated that women travelled to other towns frequently for health reasons, ${ }^{205}$ this was not a common occurrence among the individual women I interviewed. Of the 18 individual interview respondents, half had never been to a hospital, they had only used the health care services available in Mapaki. Of the nine women who had been to a hospital, five of those women went to the hospital only because they were already close to it (i.e. not in Mapaki) when they needed care. One woman explained that if the same services were provided at the PHU in Mapaki and at a hospital, she would always choose to attend the clinic in Mapaki because of the travel costs associated with going to the hospital. ${ }^{206}$

Women in other rural parts of Sierra Leone would likely face greater geographic barriers to seeking health care than women in Mapaki. For example, in Bombali District, there are 1,865 villages, but only 91 health centres, so for the majority of the population living in rural areas, physical distance to a health facility remains a major barrier to access even to primary care. ${ }^{207}$ It is not uncommon for a village to be $25 \mathrm{~km}$ or more from a health facility. ${ }^{208}$ Many rural villages in the country are still not connected to the road network, or the roads are impassable; almost two-thirds of the villages in Bombali District are not accessible by road. ${ }^{209}$

\subsection{Access to transportation}

The most common way that people in Sierra Leone travel is by walking. In rural areas, less than $3 \%$ of the population has access to a car, truck or motorcycle, and only

\footnotetext{
205 "Interview No. 3."

206 "Interview No. 5," November 4, 2009.

${ }^{207}$ Ministry of Health and Sanitation for the Republic of Sierra Leone, NHSSP, 16.

208 "Interview No. 15."

209 "Interview No. 15."
} 
$12.6 \%$ of rural people have access to a bicycle. ${ }^{210}$ It is therefore not uncommon for people to walk long distances to get to school, the market, the clinic, or to go visit a family member. In the case of villages not accessible by road, walking is the only option:

"Some areas, the areas are not motorable. You do not even have an access for a [motor] bike. That again is another problem. So if you have a village, like Mamaso, wherein the road is not motorable, a bike cannot even enter there, a woman, if she wants to deliver, or she is sick, they just have to put her on a hammock." 211

While walking does not impose a significant financial cost, it does represent a larger opportunity cost because of the time involved in walking to the nearest health centre, which could take many hours. Patients who are sick may not be able to walk at all. Even in the catchment area for the Mapaki clinic, women in the outlying villages (the furthest was approximately $8 \mathrm{~km}$ from Mapaki on a decent road) were far less likely to visit the PHU than women living right in Mapaki itself. ${ }^{212}$

In a health situation where a patient was required to go from Mapaki to the hospital for emergency care, public transportation is also a common option. ${ }^{213}$ Because Mapaki is a headquarter village, vehicles providing public transportation do pass through relatively regularly, and the dirt road between the village and the main highway is well maintained. Mapaki is also relatively close to two major cities, Makeni and Magburaka, both of which have government hospitals, private hospitals, and private pharmacies.

The cost of transportation is a major barrier; "There is no free transport!" one key informant told me, laughing at my question about how women would get to a hospital. ${ }^{214}$ The cost of a motorbike taxi from Mapaki to Magburaka is 10,000 LE (about \$3 CDN)

\footnotetext{
${ }^{210}$ Statistics Sierra Leone and ICF Macro, Sierra Leone Demographic and Health Survey 2008, 28.

211 "Interview No. 4."

212 "Interview No. 26."

213 "Interview No. 7." and "Interview No. 17."

214 "Interview No. 2."
} 
and to Makeni, 15,000 LE (about \$5 CDN). In addition to the cost, motorbike taxis are not readily available in the village. The patient would either have to contact someone they knew who had a motorbike or simply wait by the side of the road for a bike to come by and pick them up. Depending on the day and the time, the person may have to wait for several hours.

Other possible transportation options include going by bicycle (there were a number of bikes in Mapaki), or getting a ride for free. Respondents mentioned a few different options for getting free transportation: the $\mathrm{MCH}$ Aides working at the $\mathrm{PHU}$ in Mapaki have access to motorbikes and were able to transport women who needed hospital care. ${ }^{215}$ One woman said that she was given a free ride to the hospital by a motorbike taxi driver when she was sick, ${ }^{216}$ but this did not seem to be a common occurrence. The Paramount Chief's vehicle also doubles as a community ambulance and the Chief will often take people to the hospital. Almost every key informant and a number of individual respondents mentioned that the Chief uses his vehicle to provide free transport to the hospital for people who are ill, but it is also evident from the quote above that not all villagers are aware of this service.

\subsection{Geographic barriers and choice of health provider}

Geographic barriers may also be a factor affecting women's choice of health services. In addition to modern health care services, traditional forms of health care, such as traditional healers and traditional birth attendants, play a role in women's health in

\footnotetext{
215 "Interview No. 1."

216 "Interview No. 6."
} 
Sierra Leone. Several key informants referred to the fact that in more remote villages, traditional healers are all that people have access to:

"Traditional healers, they seem to take a bigger role in helping to cure people, much more than even government, because when you look at the number of people that traditional healers take care of, it's much greater than the one the government takes care of. In some areas that are not accessible, there are only traditional healers when they are sick. They take care of lactating mothers, they take care of pregnant women, they take care of everyone who is sick. Because many times people find it difficult to travel from their villages, villages that are not motorable, to come to the bigger towns for treatment. Most women, they do not have enough money to come and pay the medical fees or the hospital bills. So the traditional healers are very, very important in the villages." 217

"Interviewer: so why do you think people are still relying on traditional medicine?

Subject: because they do not have the conventional one."218

The view of some key informants that villagers mainly rely on traditional healers

when conventional medicine is not available is also supported by findings from the individual interviews. Only four women in Mapaki said that they had ever used a traditional healer, and almost all indicated a preference for the conventional medicine available at the clinic.

\subsection{Conclusion}

The evidence presented in this chapter supports the argument that geographic barriers deter poor rural women from using health services. As indicated by my analytical framework, the distance between the women and the nearest health care provider is a major factor. Women in Mapaki were fortunate to have fewer geographic barriers to

\footnotetext{
217 "Interview No. 7."

218 "Interview No. 15."
} 
accessing care due to the PHU located in the village, a decent road connection to other towns, and more transportation options. This resulted in increased utilization of health services, especially at the local PHU (as compared with women from other nearby villages). However, women in Mapaki still face geographic barriers in accessing secondary and tertiary care. 


\section{CHAPTER 8: Financial accessibility barriers}

This chapter analyses the findings from my interviews in relation to financial accessibility. The costs of care (formal, informal and indirect), and the financial resources available to individuals, including the existence of risk-pooling schemes (highlighted in the figure below), are the two major factors determining financial barriers to the use of health services. These are strongly influenced by both the general economic conditions in Sierra Leone and by how financing and payments are set up in the health system.

Figure 10: Financial accessibility barriers in the analytical framework

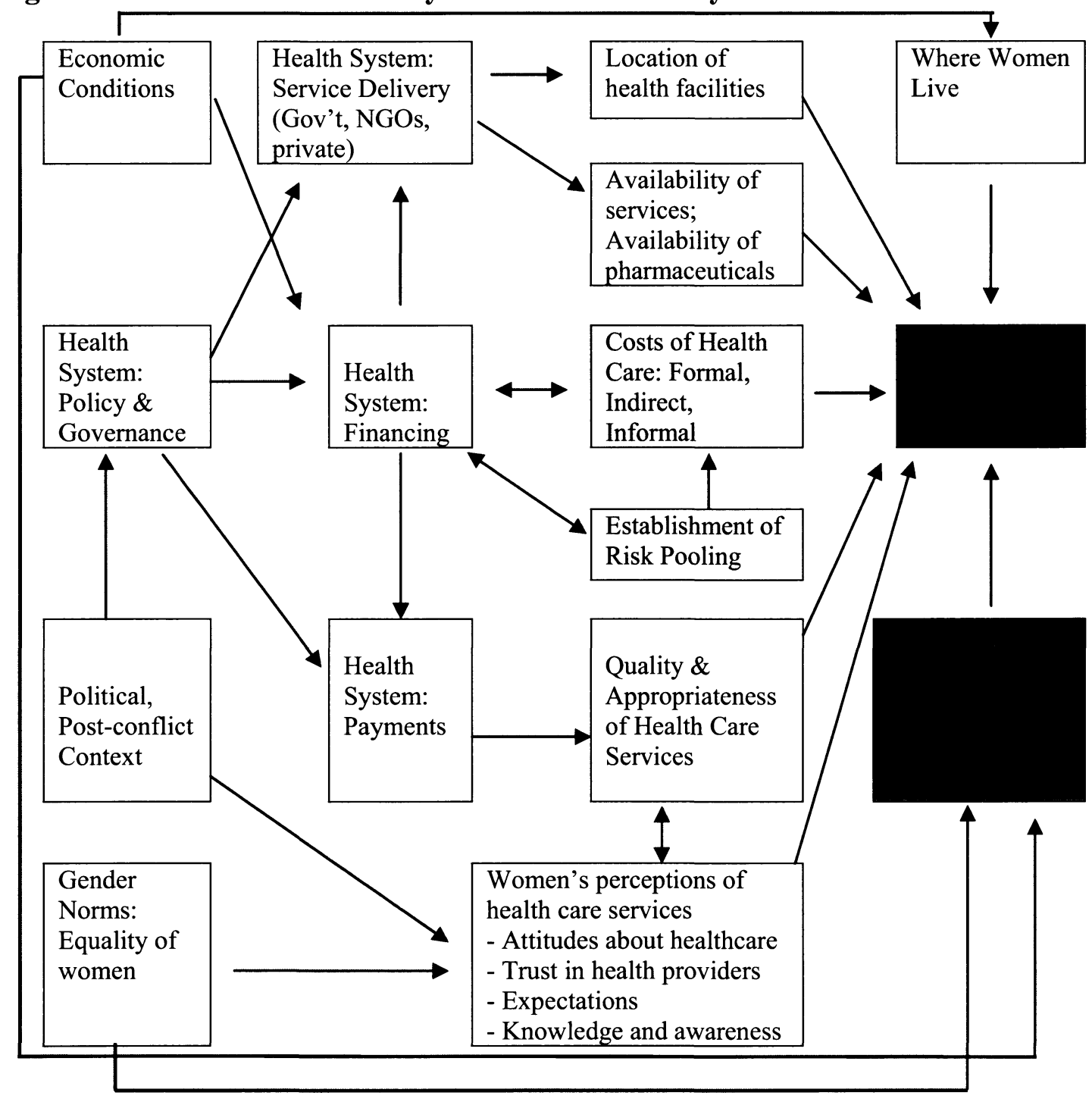


The literature review on access to health revealed that financial constraints present a major barrier to access for many women in developing countries. The research shows that in general, when the direct costs of care were reduced, usage of health services increased, in some cases significantly. This suggests that there is a significant unmet need for health care, especially among the poor.

Financial accessibility was most often identified by both key informants ( 5 out of 7) and individual respondents (9 out of 18) as the main barrier preventing women in Sierra Leone from accessing health care. "The main tumbling block is the money." 219 "Money stops me from going, because I do not have money. If you go there without money, you will not be treated." 220 "Because of the money, most women decided to stay home." $" 221$ “. . . if you do not have money you can not go to the hospital.",222

These quotes demonstrate the importance of financial barriers in preventing access to health services. As indicated in Chapter 5, most people in Sierra Leone pay directly for their health services, and health insurance is virtually non-existent. ${ }^{223}$ Fees are not publicly posted, and there is no standardised fee structure in the country. ${ }^{224}$ For example, one respondent who delivered at the government hospital in Magburaka (a nearby town) paid 50,000 LE to deliver, double what she would have paid at the clinic in Mapaki. ${ }^{225}$ The costs of accessing health care, especially at the secondary or tertiary level, can represent a significant portion of a family's income.

\footnotetext{
219 "Interview No. 2."

220 "Interview No. 11," November 30, 2009.

221 "Interview No. 4."

222 "Interview No. 23," December 13, 2009.

${ }^{223}$ Ministry of Health and Sanitation for the Republic of Sierra Leone, NHSSP, 21-22.

224

225 "Interview No. 21," December 12, 2009.
} 
However, it is not just the direct costs of health services that are important in determining financial accessibility; three other factors also matter. These are the patient's own financial resources, the patient's knowledge and information about fees and costs, and the patient's access to different methods of payment for health care costs. All of these factors can pose potential barriers to accessing care.

\subsection{Financial resources}

Access to material resources is a major factor in the ability to make use of health services, as services require payment of some kind and more than $50 \%$ of the population lives below the poverty line, earning less than 65,000 LE per month. ${ }^{226}$ The vast majority of women in Sierra Leone do not receive cash payment for their work. When they do earn money, women typically earn less than men. ${ }^{227}$ All of the women I interviewed earned very little cash income. Of the 18 women, three relied on farming, six on petty trading, and another three on a combination of petty trading and farming to support themselves and their families. One third of the women had no means of generating an income themselves and relied completely on the support of family or neighbours.

Most of the women did not know exactly how much they earned in a month because they spent the cash as they received it. For the women who did know, the amount ranged between 5,000 and 58,000 LE per month. Most responses were in the 5,00020,000 LE range. These amounts do not take into account income earned by the husband or other family members. Although some women's husbands earned a regular income (for example, as a carpenter, a teacher, or a trader), the women did not know the amount

\footnotetext{
${ }^{226}$ Government of Sierra Leone, An Agenda for Change: Second Poverty Reduction Strategy (PRSP II), 2008-2012, 28-30.

${ }^{227}$ Statistics Sierra Leone and ICF Macro, Sierra Leone Demographic and Health Survey 2008, 239-41.
} 
earned and would only have access to this money if they requested and were granted help from their husband.

\subsection{Knowledge and information about fees and costs}

When patients don't know what services are supposed to cost, or what fee exemptions may be available, they may be charged higher fees for health services, creating a larger barrier to accessing care. As one interview respondent states, “...because of the fact that the patients do not know about cost recovery [of medication costs], they will charge you any amount and you have to pay what is charged because you need the medicine. ${ }^{228}$ There was also little awareness among interview respondents of services that were available for free. Only one woman mentioned a free service that was currently offered, but this was immunizations for children, and not a health service for women. ${ }^{229}$ The evidence from my interviews suggests that women in Sierra Leone do not have a sense of what fees should be or whether they should be able to access free services. This means that women have little choice but to pay whatever is asked when they need health care.

Several of the key informants also spoke of women's lack of knowledge about fees as a deterrent to seeking care. "When [they] do not have the money, they would not like to be embarrassed when they go to the clinic, they ask them to pay some money and they do not have it, and they will be ashamed." ${ }^{230}$ Because women either did not know that some services might be available free of charge, ${ }^{231}$ or they expected to have to pay a

\footnotetext{
228 "Interview No. 7."

229 "Interview No. 5."

230 "Interview No. 7."

231 "Interview No. 1."
} 
certain level of costs for services, they did not even explore the options and try to get health care. This lack of information about the costs therefore results in decreased health care utilization.

\subsection{Methods of payment}

There was a broad belief among interview respondents that without money, there was no way to receive health services. One key informant stated that, “. . . in the [clinic] there, when you go you will be charged, and if you do not pay, they will not take care of you." 232 An individual interview respondent told me that, “. . . if I do not have money, the nurses will not look at me. They will just tell me to get out and come back with the money to get medication. ${ }^{233}$

This belief does not seem to be based on actual practice at the Mapaki clinic, although this may be the case at hospitals or clinics in other locations. Only one individual interview respondent actually had an experience of being turned away from the Mapaki clinic due to lack of payment. ${ }^{234}$ Other respondents indicated that they had never heard of a patient being turned away because of a lack of funds, ${ }^{235}$ or that they could go to the clinic and get treatment even if they could not pay in full. ${ }^{236}$

Respondents indicated that they could pay for services in the formal health system in different ways, reducing the financial barriers to accessing services. One person mentioned pledging clothing or jewellery to the nurses, and then getting these items back

\footnotetext{
232 "Interview No. 17."

233 "Interview No. 14," December 6, 2009.

234 "Interview No. 5."

235 "Interview No. 26."

236 "Interview No. 20," December 11, 2009.
} 
once they had the cash available to pay the fee. ${ }^{237}$ Others indicated that health workers could be paid in-kind with items such as rice, firewood, or palm oil instead of with cash. $^{238}$

This difference between user beliefs about costs and actual practice at the Mapaki clinic is a good illustration of how perceptions of users affect decisions about accessing health care, even if they do not reflect reality. When women are not aware that there are multiple payment options and they fear they will be turned away, they are less likely to even try to seek health care when they have limited resources available. ${ }^{239}$

When they do need to pay for health care costs, women in Sierra Leone do not have much choice of methods to make these payments. Some women could get the necessary cash from their husbands. Key informants indicated that many women would sell what they produced in their farms or gardens (e.g. rice, ground nuts, vegetables) in order to get the needed cash. While these kinds of strategies would provide enough cash to meet the smaller costs of more minor health care needs, most families would struggle to pay any large health costs without affecting their longer-term ability to survive.

In the literature, expenditures on health above $10 \%$ of income are generally considered to have a potentially catastrophic effect, resulting in reductions in food consumption, increases in debt levels, and further impoverishment of families. ${ }^{240}$ In Sierra Leone, $10 \%$ of the average income is only $\$ 27$ US per year. ${ }^{241}$ In order to cover the costs of a major health care expense, there were three main strategies that women

\footnotetext{
237 "Interview No. 2."

238 "Interview No. 4." "Interview No. 7."

${ }^{239}$ For example, "Interview No. 21.", "Interview No. 23."

${ }^{240}$ Diane McIntyre et al., "What Are the Economic Consequences for Households of Illness and of Paying for Health Care in Low- and Middle-Income Country Contexts?," Social Science \& Medicine 62, no. 4: 861.

${ }^{241}$ GNI per capita in 2008 was $\$ 270$ USD. The World Bank Group, "Sierra Leone Country Data Profile."
} 
spoke of. All three of these strategies could result in negative long-term consequences for women and their families.

The most commonly mentioned approach was to ask friends or family members

for a loan:

"Subject: if you do not have it in your house and you go to the hospital and they say you have to pay 100,000 or 50,000 , you have to go and take a loan to somebody else, and after you got better you pay the money back to the owner.

Interviewer: so who would you get a loan from? Family or friends?

Subject: in some families for instance, if they find out that you are at the point of death, they will pass contributions so that the person will not die. Then after she got better, she would pay back the money."242

This reliance on family for support in times of financial need demonstrates the importance of family and community networks in Sierra Leone. For women without a family network to rely on, it is even more difficult to access needed funds. Some studies have found that households take a long time to repay debt incurred as a result of a health care need, suggesting that this type of debt can have a long term effect on a family's economic status and wellbeing. ${ }^{243}$

A second payment strategy that was described was going to explain the situation to staff at the health facility to see if it was possible to receive treatment now and pay the fees over time:

"If I didn't have help from my family I would go to the clinic and talk to the nurses so that they would help me with medication. Then later I would give them the money." 244

242 "Interview No. 14."

${ }^{243}$ McIntyre et al., "What Are the Economic Consequences for Households of Illness and of Paying for Health Care in Low- and Middle-Income Country Contexts?," 862.

244 "Interview No. 22," December 12, 2009. 
This type of strategy would allow women to get the care they needed, but is highly

dependent on the individual health care providers involved and what sort of terms, if any, they would accept.

The third payment strategy women mentioned was to sell assets such as clothing or food in order to meet the immediate needs of paying for health care.

"Interviewer: What would you do if you ever needed a lot of money for treatment, like 50,000?

Subject: [laughs] I can not afford the money. Unless, if that is the case, when the family came, if we have rice in the house and the rice is for the feeding of the children, the only way is to sell the rice to solve the problem in the hospital.

Interviewer: But then you would not have food.

Subject: Yes, the children would go without food. The hunger might kill them."245

This quote illustrates the catastrophic effects that large health expenses can have for families in Sierra Leone.

\subsection{Financial barriers and choice of health provider}

Although interview respondents indicated that traditional healers were generally less expensive than conventional health care, this did not seem to result in greater usage of traditional methods of care. In general, greater financial accessibility did not seem to be the primary reason for using these types of health care. In addition to the geographic barriers to care mentioned above, other more frequently cited reasons for using traditional care were related to availability and acceptability. These will be discussed further in the next two chapters.

245 "Interview No. 11." 


\subsection{Conclusion}

Financial barriers to accessing care can be significant, and can result in decreased utilization of health care services. As indicated in my analytical framework, the costs of care, and the financial resources women have access to are the major factors affecting use of services. The majority of Sierra Leonean women do not have access to any substantial cash income. Health care in Sierra Leone is not universal, and costs are high compared to average incomes. When faced with health care expenditures that exceed their ability to pay, many women would choose to stay home and not get care. Even when they do not deter use, large payments for health care can have a catastrophic effect, limiting the future ability of women to earn income and provide for their families. In addition to the actual costs of care, the low level of information among women about potential free services, the costs of health care, and possible methods of payment also acts as a deterrent to seeking health care because women are not aware of ways in which they could pay for services or access free services. 


\section{CHAPTER 9: Availability barriers to access}

This chapter examines my findings on availability barriers. The availability of services is affected primarily by the organization of health service delivery (including location of clinics and the presence of staff, medications and equipment). More distal factors affecting availability indirectly via their effect on health service delivery are the financing of the health system, health policies, and the economic and political conditions in the country.

Figure 11: Availability barriers in the analytical framework

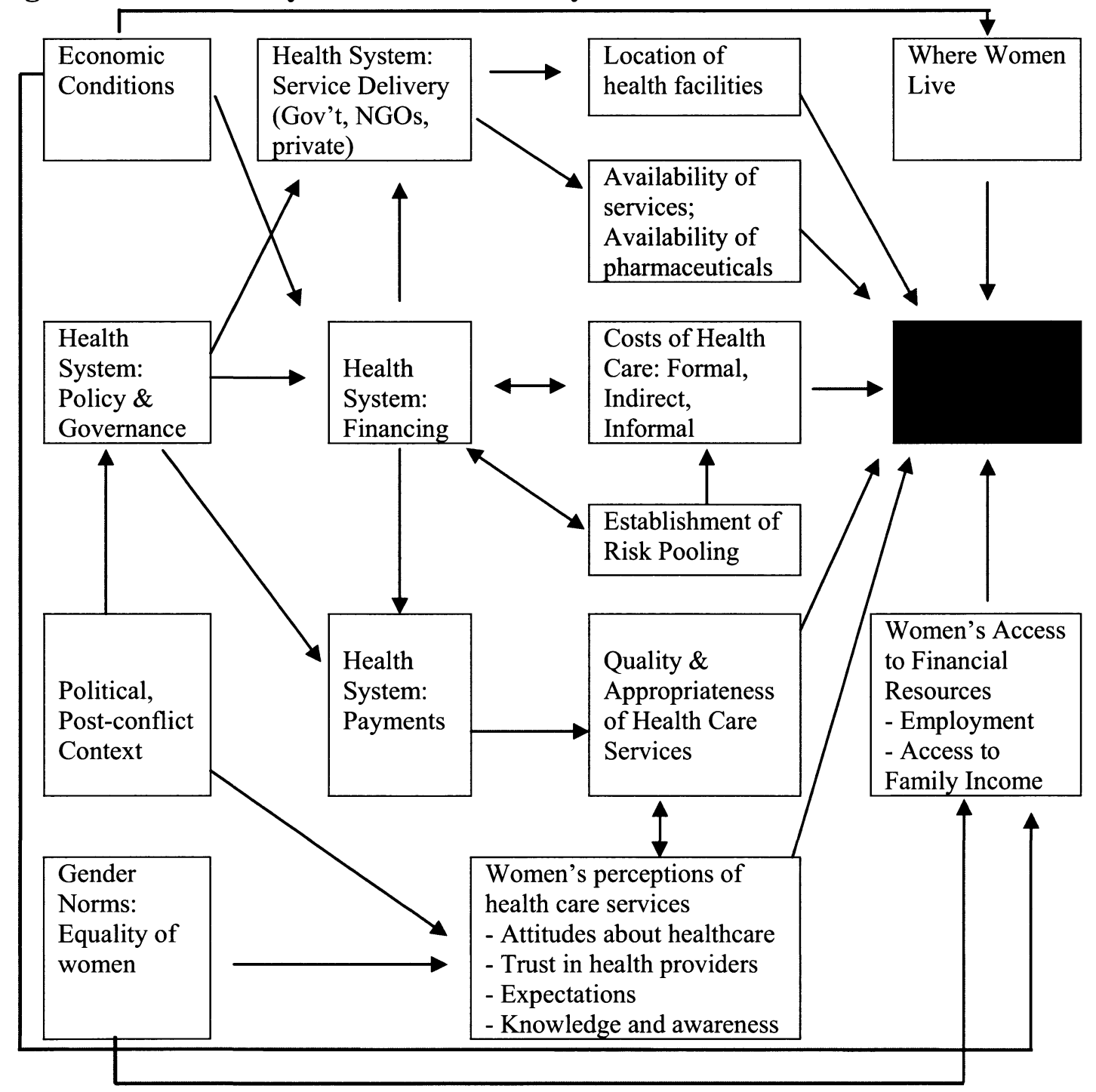


Both the actual availability of staff, equipment, and medications, and user perceptions about availability play a role in a woman's ability to access health care services. The literature review found that a lack of availability, or perceptions of a lack of availability may deter users from accessing health services. Availability can also affect the choice of health service, as patients may bypass a facility with poor availability in favour of one with better services available, even if that means paying more or travelling greater distances.

\subsection{Staff availability and skill level}

There are two components to staff availability: the first is that staff are actually in the clinic when they are needed, and the second is that the staff who are there have the necessary skills and training to provide appropriate medical care. The clinic in Mapaki is a Community Health Centre and is supposed to be staffed by a CHO, an epidemiological disease control assistant, an environmental health assistant, two MCH Aides, and an SECHN. Currently the clinic is staffed only by two MCH Aides. While two key informants mentioned that the clinic should be staffed by a CHO but is not ${ }^{246}$ no one else mentioned this insufficient staffing. This suggests that there is a lack of awareness amongst the general public about the qualifications of health care workers, and about which health care workers are supposed to provide which types of services. This means that women may not be able to accurately assess whether or not they are getting appropriate health care.

$\mathrm{MCH}$ Aides, such as those at the PHU in Mapaki, are not trained to provide the level of services that they are currently relied upon to provide in many PHUs in Sierra

\footnotetext{
246 "Interview No. 26." And "Interview No. 4."
} 
Leone. They are trained solely in maternal and child health, but often deal with all kinds of other health problems, such as high blood pressure, snake bites, STIs, malaria, tuberculosis, acute respiratory infections (ARIs) and more. However, the majority of respondents indicated that the $\mathrm{MCH}$ Aides at the Mapaki clinic were generally well qualified and doing a good job, whether they had had direct experience with the clinic in Mapaki or not. For those respondents who had visited other health facilities, most were favourable about the care and treatment they had received at those facilities as well.

The majority of interview respondents, both individuals and key informants, indicated that the staff working at the Mapaki clinic were physically available when people needed them. Although the official hours of the clinic are 8 am to 2 pm each day, several respondents commented that care was available any time of the day or night. ${ }^{247}$ One of the MCH Aides had arrived in Mapaki only recently (September 2009). Before her arrival, when there was only one $\mathrm{MCH}$ Aide staffing the clinic, there were sometimes problems with availability when the MCH Aide was away or sick herself. ${ }^{248}$ However, individual respondents were asked explicitly if they had ever visited the clinic and found no one there, and only one respondent said that this had happened. ${ }^{249}$ While the availability of staff seems to be good in Mapaki, with an overall staffing shortage of $58 \%$ for SECHNs and $45 \%$ for MCH Aides across the country (see Table 4 on page 72), a lack of even basic staff is certainly a bigger issue in other rural communities.

\footnotetext{
247 "Interview No. 1." "Interview No. 11."

248 "Interview No. 4."

249 "Interview No. 19," December 11, 2009.
} 


\subsection{Availability of medications and equipment}

Although opinions of staff availability were generally high, several interview respondents mentioned that access to medications was limited. This was referred to by four key informants and by three individual interview respondents as a problem. The three individual interview respondents all indicated that they had had the experience of going to the clinic in Mapaki and not being able to get required medication. Several respondents explained that they had either been referred to the district hospital or had purchased drugs from a pépé doctor when the drugs were not available at the clinic.

"When you go to the [clinic], they do not have much medication. There are no sufficient medicines. Sometimes when somebody goes there they have to refer you to the government hospital because they do not have sufficient medication." 250

In urban areas, if basic medications are not available at public hospitals or clinics, they can be purchased at private pharmacies. However, in rural areas, the supply of medications can be quite limited. While the Mapaki clinic had some of the basic pain relief and antibiotic drugs, they lacked many other medications. For example, they did not have medication to treat either hypertension or dysentery, both of which are relatively common ailments. ${ }^{251}$ In addition, the supply of drugs can be quite unpredictable as they come sometimes from government, sometimes from NGOs, and not on a regular schedule in either case. The MCH Aides in Mapaki supplement the drugs supplied by government and NGOs by purchasing additional supplies from a private pharmacy with their own funds. ${ }^{252}$

\footnotetext{
250 "Interview No. 4."

251 van Gurp, "Asset-Based Needs Assessment," 4.

252 "Interview No. 1."
} 
The availability of medical supplies and equipment is even more limited than the availability of medications. The Mapaki clinic lacked basic dressings and bandages, syringes, gloves, umbilical scissors, and had only one blood pressure cuff. The items that were available at the clinic were often provided by NGOs working in the area rather than by government. ${ }^{253}$ For example, the local NGO Centre for Development and Peace Education (cdpeace) provided the Mapaki clinic with a range of equipment and supplies donated in Canada and shipped to Sierra Leone.

While most respondents indicated that they would go the Mapaki clinic as a first step if they were ill, several also acknowledged that there were certain services that the clinic was not able to provide. Operations and blood transfusions were two procedures that respondents mentioned where the patient would have to be transferred to a hospital in Magburaka or Makeni to receive treatment. Blood transfusions - often required to treat post-partum haemorrhage - were mentioned specifically in reference to pregnant women and the respondent indicated that this happened frequently. ${ }^{254}$

Although interview respondents were generally positive about the availability of staff, services, and supplies at the Mapaki clinic, this is likely due at least in part to a lack of knowledge and/or low expectations about the health services that should be provided. The literature has found that expectations of the poor about the quality of health care tend to be low. ${ }^{255}$ In addition, the availability of care can seem better if a relatively low point is used as a comparison. Many respondents mentioned how much they thought health care had improved since the war ended, and that there was much greater availability of health facilities, staff and supplies now than there was during the war. As there were

\footnotetext{
253 "Interview No. 26."

254 "Interview No. 21."And "Interview No. 13," December 4, 2009.

${ }^{255}$ O'Donnell, "Access to Health Care in Developing Countries," 2827.
} 
virtually no health services available in Mapaki during the war, even a small improvement would be noticeable.

The improvements in the availability of care in Mapaki since the war, however small, have led to increased use of services, especially in the area of maternal health. Of the nine individual interview respondents who reported being pregnant in the last year, all but one ${ }^{256}$ reported attending the clinic for regular antenatal care (mostly on a weekly basis). Five of the women gave birth at the clinic in Mapaki, and one at the hospital in Magburaka. This compares favourably with only $50 \%$ of women nationally who receive the recommended 4 antenatal care visits, and only $25 \%$ who deliver at a health facility. ${ }^{257}$

\subsection{Conclusion}

Based on the evidence presented in Chapter 5 on the delivery of health services in Sierra Leone, we might expect to find availability barriers to access that reduce the use of services. However, the data in this chapter suggests that users generally believed that the availability of health care in Mapaki was good. Although availability remains a barrier in many parts of Sierra Leone, it was less of a barrier for interview respondents in Mapaki. While a small number of respondents indicated that a lack of medication or proper staff was an issue, most respondents spoke very favourably about the health care that is available, and the evidence shows that women made greater use of health services because they were available locally.

\footnotetext{
${ }^{256}$ The ninth woman's pregnancy ended in miscarriage.

${ }^{257}$ Statistics Sierra Leone and ICF Macro, Sierra Leone Demographic and Health Survey 2008, 116-17.
} 


\section{CHAPTER 10: Acceptability barriers to access}

This chapter examines my findings on acceptability barriers. Not only do health services have to be geographically close, financially accessible, and readily available, they must also be acceptable to the user given the social and cultural context. Some of the key factors identified in the literature that may affect the acceptability of care include traditional or cultural beliefs about the causes and treatment of illness, the patient's trust in the health provider, the quality of care provided, and the gender or gender bias of the health providers or patients. As illustrated in Figure 12 below, distal factors such as gender roles and norms and the political and social contexts influence women's expectations and attitudes about health services. The quality and appropriateness of the services that are provided are affected indirectly by health policies, especially those related to the training of health staff and the provision of services, and more directly by the incentives provided by the payment system in Sierra Leone.

Acceptability barriers to accessing health care are more difficult to assess or measure than other types of barriers. With barriers in other areas (geographic, financial and availability), objective evidence and information is more readily available. With acceptability, barriers are much more dependent on user preferences, beliefs and perceptions, and on the social context and community norms. 
Figure 12: Acceptability barriers in the analytical framework

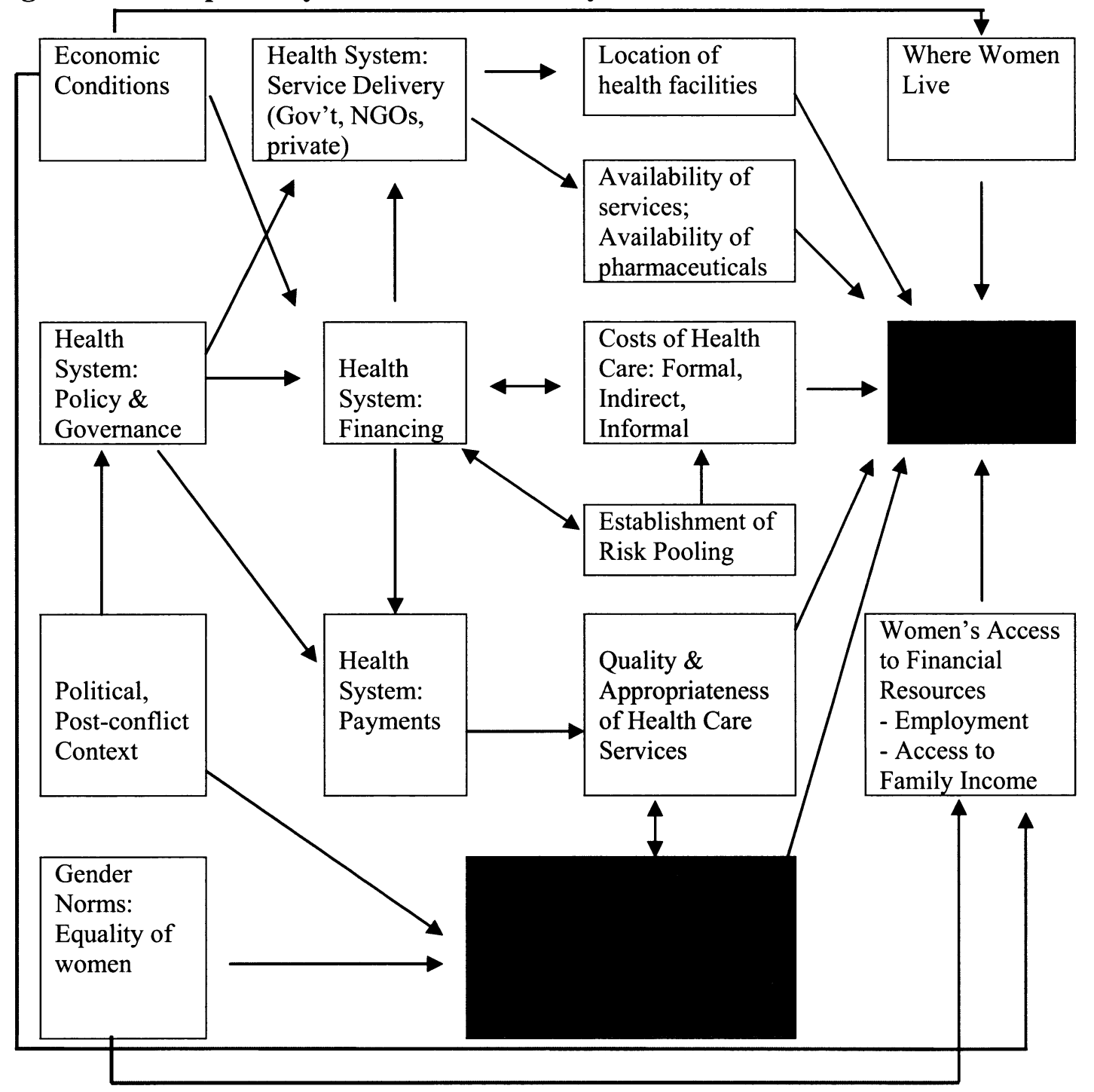

In the planning stages of my research, I hoped that the qualitative interviews I was conducting would draw out information on acceptability barriers and help to shed more light in this area. Although I understood from speaking to Sierra Leonean colleagues that it was unlikely that anyone would discuss the details of secret society activities with me, I was hopeful about getting further information about the role of witchcraft and beliefs in traditional medicine. Unfortunately, there was limited discussion of these issues in the 
interviews, even when I asked about them directly. Although only 4 of the 18 individual respondents said that they had ever been to a traditional healer, it was informally suggested to me that even if women went to the healer, they would do it in secret and would be reluctant to share that information with me. This reluctance to share information is understandable given the significant social, cultural and economic gap between myself as the interviewer and the interview subjects.

\subsection{Traditional and cultural beliefs}

Despite the challenges in getting opinions on this subject, several respondents did talk about the cultural factors affecting health care decision-making and the role of traditional medicine and beliefs in witchcraft. It was much easier to get detailed information and stories from the key informants on this topic. ${ }^{258}$

Several respondents identified traditional beliefs and practices as barriers to accessing needed health care. A few indicated that seeking traditional care rather than conventional treatments had led to death or serious complications for some patients. ${ }^{259}$ Because the patients went first to the traditional healer, they were not able to get conventional treatment in time, and the delay resulted in a more serious problem or even in death.

The evidence from the interviews on why patients choose traditional healers is mixed. A small number of respondents, primarily key informants, indicated that people use traditional healers mainly because their services are cheaper, or because conventional

\footnotetext{
${ }^{258}$ Because I lived in Mapaki for some time, I had already established a relationship of trust with most of the key informants so they were more willing to be open and honest with me. Although I knew some of the individual interview subjects, most of them I had not met before. Also, the key informants were speaking about these issues in general and not necessarily referring to their own specific experiences, likely making it easier for them to share information.

259 "Interview No. 1." And "Interview No. 4."
} 
medicine is not available, not because there was a real belief in these methods.

Respondents also questioned the effectiveness of traditional medicine.

"So when someone feels ill and goes to the hospital, to the health centre, and they say there is no drugs, well someone will say there is a woman there who knows these leaves. So they go to the traditional. Otherwise they do not go there. Their first port of call is the health centre, but there is nothing in the health centre so you have to find an alternative." 260

"If I do not have money, and my husband do not give me money, and I have nothing at hand, I know that if I go to the hospital I have to pay money. But because I do not have money then I use our local herbs. And using our local herbs, you have also problems on that. The herbs that you are using, maybe that herbs are not the good treatment for the sickness that the pregnant women get or the child. Maybe the herbs do not work. Because you do not have the money, you keep on delaying, delaying, delaying, that also causes the death of the patient.".261

"Subject: traditional healers ... the fee to pay is less. Interviewer: so if you didn't have enough money to go to the clinic, you'd go to a traditional healer? Subject: yes." ${ }^{262}$

"The sickness I had, traditional medicines will not help it. I just go to the hospital to get the medication. If I went to a traditional healer, he would not be able to solve my problem."263

Respondents who did not believe in traditional practices were in the minority.

Many other respondents, both individuals and key informants, indicated confidence in the healing powers of traditional medicine. In some cases, this was associated with a strong belief, prevalent throughout Sierra Leone, in witchcraft and evil spirits as a cause of ill

\footnotetext{
260 "Interview No. 15."

261 "Interview No. 4."

262 "Interview No. 5."

263 "Interview No. 9."
} 
health. In these cases, people believe that seeking modern health care will not help them, and that they need a traditional remedy instead.

"Subject: They might think that this sickness is from witch people, from bad people, from witchcraft, so they may decide to go to traditional healers to find out what is the issue, what is the point ... If life is still with that patient, we can take care of those sicknesses.

Interviewer: could people get help at the clinic for that, or is that something the clinic can not help with?

Subject: no, only the traditional healers." 264

"Subject: There are sometimes people who say they use some native gun, a witch gun. .. And that is very serious. You cannot rule out, you cannot deny. It does affect people." 265

"The elder people told me that it wasn't a hospital sickness and they advised me to see the traditional healer."266

"Witchcraft can make people sick. At times if you have a baby, a witch can set eyes on the baby, even if you take that baby to the clinic, they will not see any sickness, they will just say that the baby is well. But when you come with her or him in the house, he or she will give you a problem."267

One respondent also spoke of going to see a "future teller" when there is a belief that an illness has been caused by someone else through witchcraft. People believe that the future tellers have the ability to reveal who or what is causing the illness and to treat the patient accordingly:

"At one time I was attacked with a very serious sickness . . . My parents tried so much. We go to the hospital, but still . . . unless when we go to a future teller, you know, he told us everything. What is the cause, what is disturbing me. That particular person goes to the bush and prepare some charm, and bring some leaves, boil them, cook them. I was

\footnotetext{
264 "Interview No. 3."

265 "Interview No. 7."

266 "Interview No. 13."

267 "Interview No. 14."
} 
covered with big blankets, with the pots, I was smoked . . . then everything wipe off.

Interviewer: and that made you better?

Subject: yes, of course. So it works, it works.",268

The secret societies also play a significant role in establishing social and cultural norms in Sierra Leone. The Bondo society is the society for women. Members of the secret society are not supposed to speak of it to outsiders, so I did not expect to learn much about the secret societies from my interviews. One respondent did explain that the Bondo society had their own herbs and remedies that they used for maintaining health when they were in the bush, similar to those used by the traditional healer. ${ }^{269}$

\subsection{Social and community norms}

Community norms around health behaviour also help to determine what is acceptable in terms of health services. In Mapaki, these community norms have helped to encourage increased utilization of health services, especially in relation to care during pregnancy. For example, women belonging to the Bondo secret society (the majority of women) used to give birth in the bush, essentially in secret from men. ${ }^{270}$ However, this practice seems to now have declined or stopped. The evidence presented in Chapter 8 on the rates of antenatal care and delivery in a health facility among interview respondents also provides evidence of this shift in norms.

There is clear evidence that in Mapaki it is frowned upon if a pregnant woman does not go to the health clinic for antenatal care and for delivery. For example, a

\footnotetext{
268 "Interview No. 17."

269 "Interview No. 2."

270 "Interview No. 7."
} 
community law regarding delivery was created in the Paki Masabong chiefdom, where Mapaki is located:

"[T]hrough the sensitization that we get from health workers saying that to deliver in homes is very dangerous, so we have made a law in our community that whenever a pregnant woman wants to deliver, she must go to the hospital. Every pregnant woman should go to the hospital for treatment.,271

This law demonstrates the shift in attitudes around childbirth, from having women deliver in their homes with the assistance of a TBA or elder to having a delivery in the clinic supervised by a skilled health care worker. This is also a good demonstration of the way in which norms that affect the acceptability of certain health-seeking behaviours can be changed over time through information and education.

\subsection{Trust}

Another factor related to acceptability is that of trust and confidence in the health care provider. If patients do not trust the staff at the nearest health clinic, they may be tempted to bypass that facility, or may choose not to use the formal health care system at all. There was evidence of this problem in the interviews as some respondents mentioned nurses or $\mathrm{MCH}$ Aides that were harsh with women. Two key informants indicated that this was a major barrier preventing some women from accessing the care they needed.

"We need to retrain our nurses, or these MCH Aides, on ethics. You do not need to make yourself too fearful to the community. There are some pregnant women who are afraid to meet the nurses or these $\mathrm{MCH}$ Aides, because some of them, their mannerisms, their approach to the women." 272

\footnotetext{
271 "Interview No. 4."

272 "Interview No. 15."
} 
"[N]urses will tend to use some harsh words to the women. Maybe they will say they are dirty, that they do not take care of themselves or the children, they may disgrace the women, the parents. So I think those are some of the barriers that prevent the women to go to the hospital.,"273

In Mapaki, there seemed to be a high level of trust in the health providers, and participants generally spoke very highly of the $\mathrm{MCH}$ Aides. Only one respondent mentioned ever having a problem with one of the MCH Aides, ${ }^{274}$ and all respondents were asked directly whether they had ever experienced a problem or knew someone else who had experienced a problem. All the other respondents indicated that the MCH Aides in Mapaki did a good job, and that there were no problems or issues.

One of the MCH Aides, Hannah, was thought of particularly highly. She had a long history in the community and had recently returned to work there again. "So the people have hope on Hannah. She has interest, she comes to their houses, she talks to them nicely.. . . she takes everybody as her relation." ${ }^{275}$ These comments suggest that trust in the local health providers reduced acceptability barriers in Mapaki and led to increased utilization of health care services.

\subsection{Other acceptability barriers}

In terms of acceptability barriers related to the quality of care provided, in some of the literature, researchers have observed the phenomenon of bypassing, where patients choose to go to a more expensive or further away facility because they believe that care will be of better quality in those facilities. This would indicate an issue of acceptability, as the care that is more readily available is not acceptable to the user.

\footnotetext{
273 "Interview No. 17."

274 "Interview No. 5."

275 "Interview No. 7."
} 
I did not find evidence of bypassing among my interview respondents - the majority indicated a strong preference for the clinic in Mapaki as their first choice in case of illness. Bypassing is likely more common in higher income groups in Sierra Leone, ${ }^{276}$ but in low income groups, where cash is not readily available, the evidence collected in my interviews suggests that other barriers (geographic and financial) lead people to access the facility closest to them as their preferred option in seeking health care.

I did not find any evidence of acceptability barriers related to the gender of the health care provider. The individual interview respondents indicated no specific preference for seeing a health care worker of one gender over another, and no woman said that she had not sought care because of the health provider's gender. Although the current health workers in Mapaki are both women, several respondents that had visited a hospital had their care provided by a man, and this did not seem to be an issue of concern. It could be that there are specific issues that female patients would not be comfortable discussing with a man (for example, family planning or contraception), but I did not delve deeply into this in my interviews.

\subsection{Conclusion}

Acceptability barriers are present in Sierra Leone, and they clearly have an impact on health service utilization. As indicated in my framework, user beliefs and expectations about health services play an important role, in addition to the quality and appropriateness of the health services themselves. In Mapaki, the evidence I collected suggests that traditional or cultural beliefs about the causes and treatment of illness,

\footnotetext{
${ }^{276}$ I did hear anecdotal stories of others choosing to go to health facilities that were perceived as better, even if the cost was higher, but this was among Sierra Leoneans who were earning a regular salary and had more disposable cash income.
} 
especially the belief in witchcraft as a cause of ill health, deterred some women from seeking conventional health care. This delay in accessing conventional treatment may result in further complications or even in death.

Community norms around use of health services and a high level of trust in the current health staff in Mapaki likely contributed to increased use of services. However, there was some evidence that a lack of trust might be preventing women elsewhere in Sierra Leone from seeking health care. Utilization of health services was not deterred by acceptability barriers related to either gender of provider or quality of care. 


\section{CHAPTER 11: Conclusion and policy recommendations}

Understanding which barriers to accessing health care exist and how these

barriers influence utilization is essential to improving health and development outcomes.

Access to health services, and in particular, women's access, is a neglected area in the current research and policy debates. My thesis contributes to those debates through the development of an analytical framework (below) that can be used to better understand access issues and to design more effective policy interventions.

Figure 13: Analytical framework

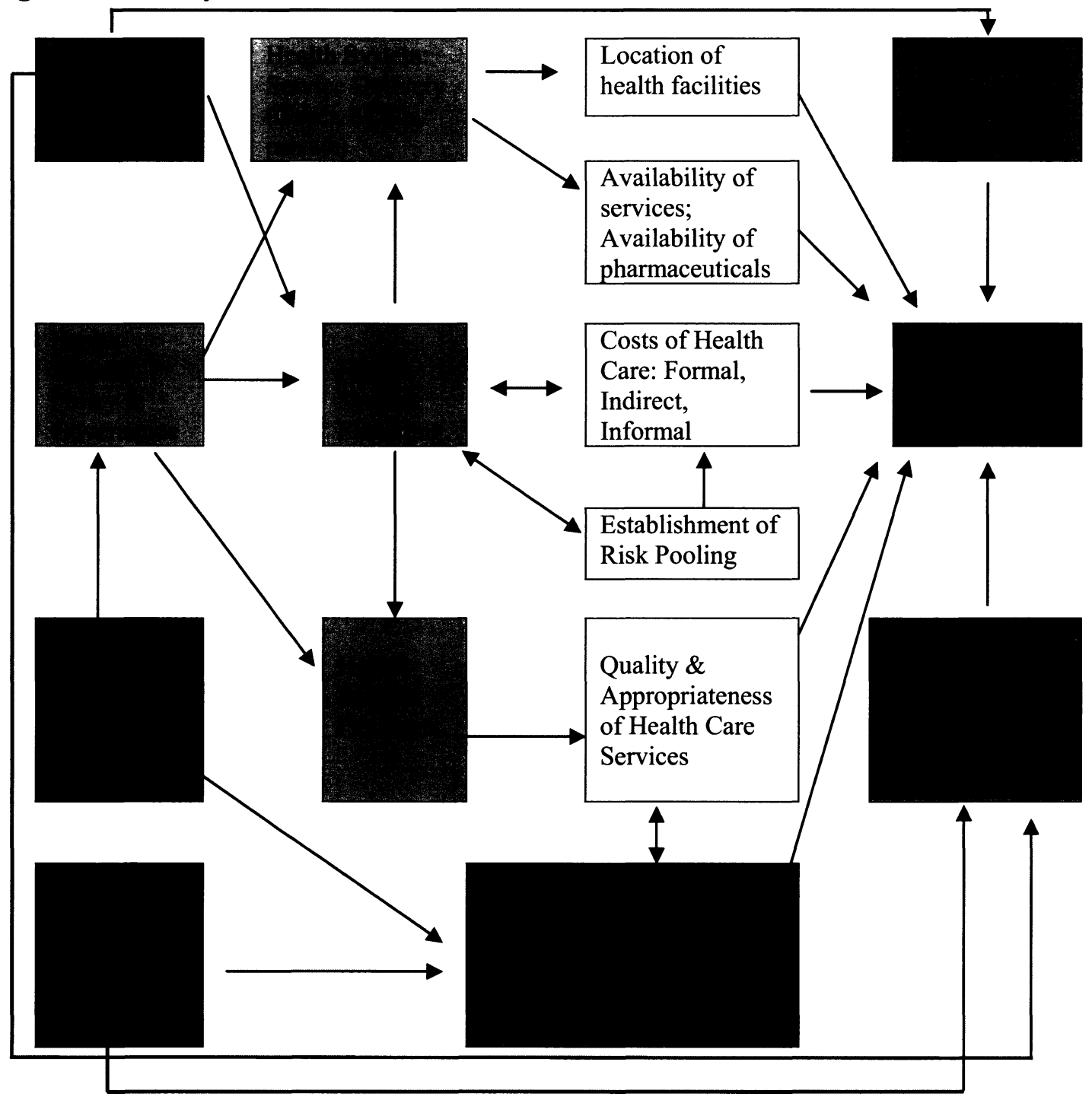


In this chapter, I return to my initial research questions and summarize the findings. The second section of the chapter looks at some of the policy recommendations that stem from this research, and the third section provides suggestions for future research.

\subsection{Barriers to accessing health care and their impact on health service utilization}

Utilization of health services nationally is estimated at only 0.5 visits per person per year. ${ }^{277}$ This suggests that accessibility barriers deter utilization, and the evidence from my interviews demonstrates that this is the case. Due to limited time and a lack of local comparative data, ${ }^{278}$ I was not able to quantify the effect of barriers on utilization, but I was able to determine the direction of a particular effect. In Mapaki, financial and geographic factors had the strongest negative impact on utilization. Geographic factors limited access to primary care for those outside the village, and to secondary and tertiary services for all women in and around Mapaki.

A patient's perceptions about health care (for example, a patient's feelings about the health care provider, or their beliefs about how much services cost) also affect health care utilization. There is sometimes a difference between what users believe to be barriers and the actual barriers that exist. Where relevant, I outline the differences between perceived and actual barriers.

The identification by study participants of financial accessibility as the most important barrier is not surprising, and this is one of the reasons why so much of the literature on access focuses on financial barriers. All of the women in my study lived on

\footnotetext{
${ }^{277}$ Ministry of Health and Sanitation for the Republic of Sierra Leone, NHSSP, 16.

${ }^{278}$ I was able to obtain some data on utilization rates at the Mapaki clinic, but only for the present year. However, it was not helpful for analysis because it was not possible to compare this data to utilization rates elsewhere (no comparable data was readily available for other clinics or previous years, and it is not possible to compare to national data because there was no available population estimate for the catchment area around Mapaki served by the clinic).
} 
incomes that were below the poverty line in Sierra Leone, equivalent to less than \$1 USD per day. Health care in Sierra Leone was not free, and costs were high when compared to average incomes. The combination of low income and high costs means that women were deterred from accessing health care because of financial barriers.

While barriers related to women's status did not appear to deter use of services in Mapaki, gender roles in Sierra Leone do limit a woman's ability to access financial resources or to make decisions about her own health. No woman I interviewed indicated that they were prevented from seeking health care by their husbands, or that they were not given the money necessary for treatment if it was required. However, almost every married woman indicated that they would discuss seeking care with their husband, demonstrating that men still generally act as intermediaries between women and health care. This is backed up by national data that shows that women in Sierra Leone lack a voice in household decision-making, and that they have fewer financial resources and less free time available to them than men. Gender-related barriers heighten the financial barriers that women face if they do not have the income to pay for the costs of care.

Although the women I interviewed in Mapaki had more options for transportation than women in more remote areas would have, the possibilities are still limited. Particularly for accessing secondary and tertiary care, geographic barriers are still a major deterrent of health service utilization. In many cases, reduced geographic accessibility also contributed to financial barriers to accessing care, as there is limited free transportation, and the cost of taking public transportation is high.

In the areas of both geographic and financial barriers, user perceptions were generally in agreement with the objective evidence. These two types of barriers are easier 
to objectively measure and quantify, and the available evidence certainly supported the statements of survey respondents about the difficulty of accessing health care due to financial or geographic constraints.

User perceptions of financial accessibility differed from objective evidence and affected utilization in the area of knowledge about payment options. Several interview respondents indicated that they would be deterred from getting care because they believed that if they did not have the money to pay for services, they would not be treated. While women may be refused health care due to a lack of money in other places, particularly in bigger facilities, in Mapaki there was no evidence that this was a the case. If more women knew that they would be given free care, or that alternate payment arrangements could be made, they would be more likely to visit the clinic.

Surprisingly, given the challenges the government faces in supplying health care, interview respondents did not identify availability as a major barrier. This was primarily because availability of services in Mapaki had increased in contrast to what was available during the war. The additional services and facilities available in Mapaki, when compared with other rural areas, also contributed to positive opinions on the availability of health services.

Acceptability barriers also did not seem to deter health care utilization in Mapaki. Barriers connected to community norms around pregnancy care and the level of trust in the health care providers have been reduced, and this resulted in increased use of health services. The responses of participants in my study suggested that as long as conventional care is available, women generally prefer to use that rather than traditional methods of care. However, there was some evidence that traditional and cultural beliefs, especially 
beliefs in witchcraft as a cause of ill health, continue to deter women from using conventional health care services. Although this was not identified as a major issue among individual interview respondents, it is possible that women might have been reluctant to share with me their real feelings and beliefs about this issue. This could have been a reflection of the way the interviews were structured, or due to insufficient trust with interview respondents.

The findings of my research support the validity of my analytical framework, as I found that a range of determinants affect women's ability to access health care. Health service utilization is shaped not just by immediate factors such as the location of clinics, or the user's ability to pay, but also by more distal factors such as the political, social, and economic history and current context and the functioning of the health system. For example, availability was seen to be less of a barrier than it might have been in another context because of Sierra Leone's history of conflict and the lack of health services available during that time. Examining these distal factors can predict which issues may present the biggest challenges for access to care, and can help to determine where policy solutions would best be targeted in order to improve health care utilization.

\subsection{Policy responses}

Addressing barriers to access in Sierra Leone must take place within the broader context in the country. The analytical framework presented in this thesis allows for the development of more effective solutions that will address not only the immediate challenges but also the more distal factors that influence access to health services. Each of the green, blue and purple shaded boxes in Figure 13 represent an area in which 
changes could be made to reduce barriers to access. Policies that address more than one of these factors at the same time could be more effective in improving utilization. This section outlines some of the policy responses that the GoSL could implement to reduce existing barriers even further.

In some cases, a simple solution may be available to address a barrier. For example, the lack of information about the costs of care could easily be addressed by posting the fee schedule publicly in each health facility. Addressing other barriers - for example, the existence of gender inequality, which affects women's access to money and ability to make decisions - will require much longer-term interventions.

Financial accessibility barriers emerged from my research as the major factor deterring women from accessing care. In the long-term, the Government of Sierra Leone plans to put a national social health insurance scheme into place. ${ }^{279}$ However, it will take a number of years to properly implement such a policy, so short and medium term interventions that address financial accessibility will also be beneficial.

Community risk pooling programs could provide an appropriate shorter-term alternative. Community based health insurance $(\mathrm{CBHI})$ can be effective in "realizing the benefits of risk-pooling in countries without the organizational capacity to operate formal schemes on a national level," 280 and there is strong evidence that CBHI can provide effective financial protection. ${ }^{281}$ In a community like Mapaki, where there is already strong leadership committed to improving development outcomes and community based decision-making in place, this type of risk pooling could be particularly effective.

\footnotetext{
${ }^{279}$ Ministry of Health and Sanitation for the Republic of Sierra Leone, NHSSP, 24.

${ }^{280}$ Philip Davies and Guy Carrin, "Risk-Pooling - Necessary but Not Sufficient?," Bulletin of the World Health Organization 79, no. 7: 587.

${ }^{281}$ Björn Ekman, "Community-Based Health Insurance in Low-Income Countries: A Systematic Review of the Evidence," Health Policy and Planning 19, no. 5 (2004): 252.
} 
Community risk pooling may also help to improve women's access to care if the program ensures that both women and men are recruited equally to participate in the scheme.

A community insurance scheme implemented in Guinea-Bissau could provide a potential model for Sierra Leone. The program involved villagers in setting initial prices and contributions based on willingness to pay rather than costs. Annual contributions were equivalent to a quarter of a chicken per person, and the consultation fee at the clinic for non-members was higher than the annual contribution, encouraging people to join. This scheme provided free treatment and medications at the local level, and was eventually expanded to also include referrals. The government supported the scheme by providing an initial six month supply of drugs until the program could generate its own revenue. $^{282}$

Even if it could be an effective short to medium term solution to minimize the financial burden of accessing health services in some communities, it is important to note that $\mathrm{CBHI}$ is not the ideal long-term policy solution to health financing. This is because its ability to sustainably generate revenues sufficient to fund the health system is limited. The very poorest may also still remain excluded from these types of schemes. ${ }^{283}$ Therefore, a national social health insurance scheme, which the GoSL plans to implement, should remain the top priority intervention in order to permanently reduce financial barriers to accessing care.

The GoSL is already working to implement risk pooling at the national level, recently launching a new initiative making health care for pregnant and lactating women

\footnotetext{
${ }^{282}$ Peter C. Smith and Sopie N. Witter, Risk Pooling in Health Care Financing: The Implications for Health System Performance (Washington, DC: The International Bank for Reconstruction and Development / The World Bank, 2004), http://www.heartintl.net/HEART/061508/RiskPoolinginHealth.pdf (accessed July 2, 2010), 24.

${ }^{283}$ Ekman, "Community-Based Health Insurance in Low-Income Countries," 256.
} 
and young children free of charge. ${ }^{284}$ This initiative has the potential to significantly improve the accessibility of health care for many women. However, even with the removal of official user fees for these populations, indirect (e.g. travel costs) and informal (bribes, gifts, etc.) costs could still prevent women from accessing care. Providing women with information about the costs of care (which services are free and which are not) via sensitization campaigns and information posted in health care facilities could help to reduce or eliminate informal costs, reducing financial barriers even further.

Early media coverage of the GoSL's new initiative highlighted the fact that shortages of staff, facilities, and medications remain major potential barriers to successfully implementing the strategy. ${ }^{285}$ This illustrates how potential barriers to access are inter-connected, and are situated within and influenced by the health system as a whole, as indicated in my analytical framework. Financial barriers can be reduced even further by strengthening other components of Sierra Leone's health system. For example, interview respondents explained that previous fee exemption policies were not honoured because a lack of regular funding from the government or donors meant that health workers had to charge in order to cover the costs of their own salaries or of purchasing drugs or supplies. Strengthening supply chains and improving support for health workers will help to further reduce informal payments for health care. These types of health system interventions will also help to reduce availability barriers even further, so they have a dual effect.

\footnotetext{
${ }^{284}$ Government of Sierra Leone, Free Healthcare Services.

${ }^{285}$ See for example Mohamed Fofanah, "Bold Plan for Maternal Health," http://www.ipsnews.net/africa/nota.asp?idnews=51279 (accessed May 1, 2010). And "Sierra Leone Starts Free Care for Mothers and Children," http://news.bbc.co.uk/2/hi/8645968.stm (accessed April 28, 2010).
} 
Fortunately, the GoSL does recognize the importance of strengthening the health system as a whole in order to respond to some of these challenges. In the document outlining its new free health care strategy, the government identifies five main improvements that will need to be made in order for the strategy to be successful. These are increasing financing to the health sector through the development of new financing mechanisms, strengthening the procurement supply chain, increasing the number of health care workers, strengthening oversight, coordination and management, and ensuring that the policy is communicated to people so that they can exercise their right to free health care. ${ }^{286}$

Although I have not explicitly addressed the issue of the collection of health data, this is an important component of the health system. There are many current challenges with the collection of health data in Sierra Leone, including a lack of policy on the development of the health information system, inadequate equipment, operational guidelines and tools, and incomplete and poor quality data collected by PHUs. Unfortunately, utilisation of data for local planning is minimal. ${ }^{287}$

Having accurate and complete health information will help to ensure that interventions are as effective and efficient as possible. The GoSL has made some improvements in recent years, such as the collection of electronic data and the development of a costed plan for improving the country's health information system. However, further development is certainly needed, especially in relation to the collection of data at the local level that can be compared nationally. The GoSL does recognize this

\footnotetext{
${ }^{286}$ Government of Sierra Leone, Free Healthcare Services, 6.

${ }^{287}$ Ministry of Health and Sanitation for the Republic of Sierra Leone, NHSSP, 29.
} 
need, and includes the strengthening of the health information system in its National Health Sector Strategic Plan. ${ }^{288}$

As one of the key informants stated, "it will take 50 years before we have a health post in each village. ${ }^{289}$ Because of the slow progress on increasing the number of health facilities, the improvement of Sierra Leone's transportation network is a policy intervention that, while not specifically health-related, will help to reduce geographic barriers to health. With better quality roads that are in good condition year-round, and with more roads providing access to rural areas and remote villages, it will be easier for people to get transportation to a health care facility when it is needed. Road improvements combined with an ambulance system would help more women get emergency obstetric care in a timely manner, reducing the number of maternal deaths.

Even with improvements to the road and transportation network, the costs of transportation (indirect costs of care) may still present a significant financial barrier. Although having a health post in each village may not be possible for some time, having locally-based community health workers (CHWs) is another possible policy option. CHWs could provide basic, mostly preventative services at the local village level. This type of intervention has been shown to contribute significantly to reducing rates of maternal mortality. ${ }^{290}$ The GoSL recognizes the importance of having health workers at the local community level and plans to use CHWs to assist with the delivery of the BPEHS. ${ }^{291}$ While CHW programs are not necessarily cheap or easy, if properly

\footnotetext{
$288 \_,$NHSSP, 27-29.

289 "Interview No. 15."

${ }^{290}$ Campbell and Graham, "Strategies for Reducing Maternal Mortality," 1292.

${ }^{291}$ Ministry of Health and Sanitation for the Republic of Sierra Leone, BPEHS, 17.
} 
implemented they can be effective at getting care to people who would otherwise not have access. ${ }^{292}$

Expanding and improving training for health workers could also make a difference to use of health services. If conventional health workers were trained on techniques for working more closely with traditional healers, this would help to ensure that health workers were able to access more patients, and that patients received the care they needed. Training for health workers around bedside manner, respect for cultural practices, and appropriate treatment of patients who do not follow recommendations could also help to reduce acceptability barriers to care related to trust in health providers.

Providing information and education to the public can also help to reduce acceptability barriers to using health care. Sensitising women about the importance of visiting the clinic when they are sick or when they are pregnant and ensuring that they are aware of policies that affect them is critical. Because of the low literacy rates in the country, it is important to emphasize the use of oral or graphic methods of sensitization over written methods. Sensitization in Sierra Leone is usually done through community meetings where the Chief, other community leaders, or health workers share important information, through door to door visits from health workers, through radio shows, and using tools such as drama and music. Improving health education and information will help to build trust and confidence in the conventional health system.

Finally, as indicated throughout this thesis and in the framework above, the political, social and economic context in the country has a significant influence on

\footnotetext{
${ }^{292}$ Uta Lehmann and David Sanders, Community Health Workers: What Do We Know About Them? The State of the Evidence on Programmes, Activities, Costs and Impact on Health Outcomes of Using Community Health Workers (Geneva: WHO, Evidence and Information for Policy, Department of Human Resources for Health, 2007), http://www.who.int/hrh/documents/community_health_workers.pdf (accessed July 1, 2010), 27.
} 
barriers to care, so changes to this context can help reduce barriers and improve health service utilization. For example, improving general economic conditions will help to reduce financial barriers to accessing health care both by boosting incomes and by increasing available government funding. Policies and programs that help to improve agricultural productivity will also raise incomes of individuals and families. Government efforts to increase own-source revenue generation will allow for more financial resources to be devoted to the health system. Addressing gender inequality and improving the status of women in the home and the community will help to ensure that women have the ability to access resources and make decisions about their own health.

\subsection{Recommendations for future research}

My research has made a contribution to a better understanding of ways to improve health care utilization for women in developing countries by undertaking an in-depth analysis of factors that influence access to and utilization of care, and by developing a comprehensive analytical framework to understand the factors which shape and influence the ability of women to use health care. Due to limited time and financial resources, the size of my survey group was small, and focused in only one location. This limits the extent to which the findings of my research can be applied across the country or to other developing country contexts without further testing of this analytical framework. This framework now needs to be tested in other locations and on a larger scale. Future research should be conducted to see if the framework is effective more generally in explaining and predicting access. 
One of the areas about which I hoped to learn more during my research were the barriers to care related to acceptability, especially in relation to traditional and cultural beliefs that would affect health care utilization. However, in order to get a better understanding of the issues in this area, I believe that research of this nature would be better carried out by a Sierra Leonean. Alternatively, if a researcher from another country carried out this work, it would be necessary for them to take a more anthropological approach, spending a longer time living in the community and learning the local language. This would help the researcher to get a much more in depth picture of women's perceptions and feelings on more sensitive issues.

Examining more deeply the ways in which gender dynamics influence women's access to health services is another area in which further research should be carried out. This study focused solely on examining gender-related barriers to accessing care from the perspective of women. However, it is clear that men also play an important role in determining women's access to services. Gaining a better understanding of how the interrelationship and power dynamics between men and women influence health care utilization is therefore critical to designing more effective interventions that will engage both men and women in improving women's health.

\subsection{Conclusion}

The health status of a population can have a significant effect on what a nation and its people are able to achieve in terms of development. Ill health can interfere with a woman's ability to work, support her family, and contribute to the development of her country. At the same time, poverty exacerbates health problems by limiting the resources 
available to maintain good health. The health of poor, rural women in developing countries is particularly at risk. They have fewer economic options, are less connected via both road networks and information systems, and there are more limitations on women due to gender roles and norms. Women also face health risks specific to their reproductive role.

Improving access to health for women in Sierra Leone is a long-term process. There is much work that needs to be done to strengthen all areas of the health system, and to improve the general social and economic conditions in the country in order to reduce barriers to accessing care. The Government of Sierra Leone obviously recognizes the need to reduce barriers to access and has taken some important first steps in doing so. The policy responses outlined in this thesis would help to increase utilization of health services even further, resulting in better health for women in Sierra Leone. 


\section{APPENDIX 1: Map of Sierra Leone}

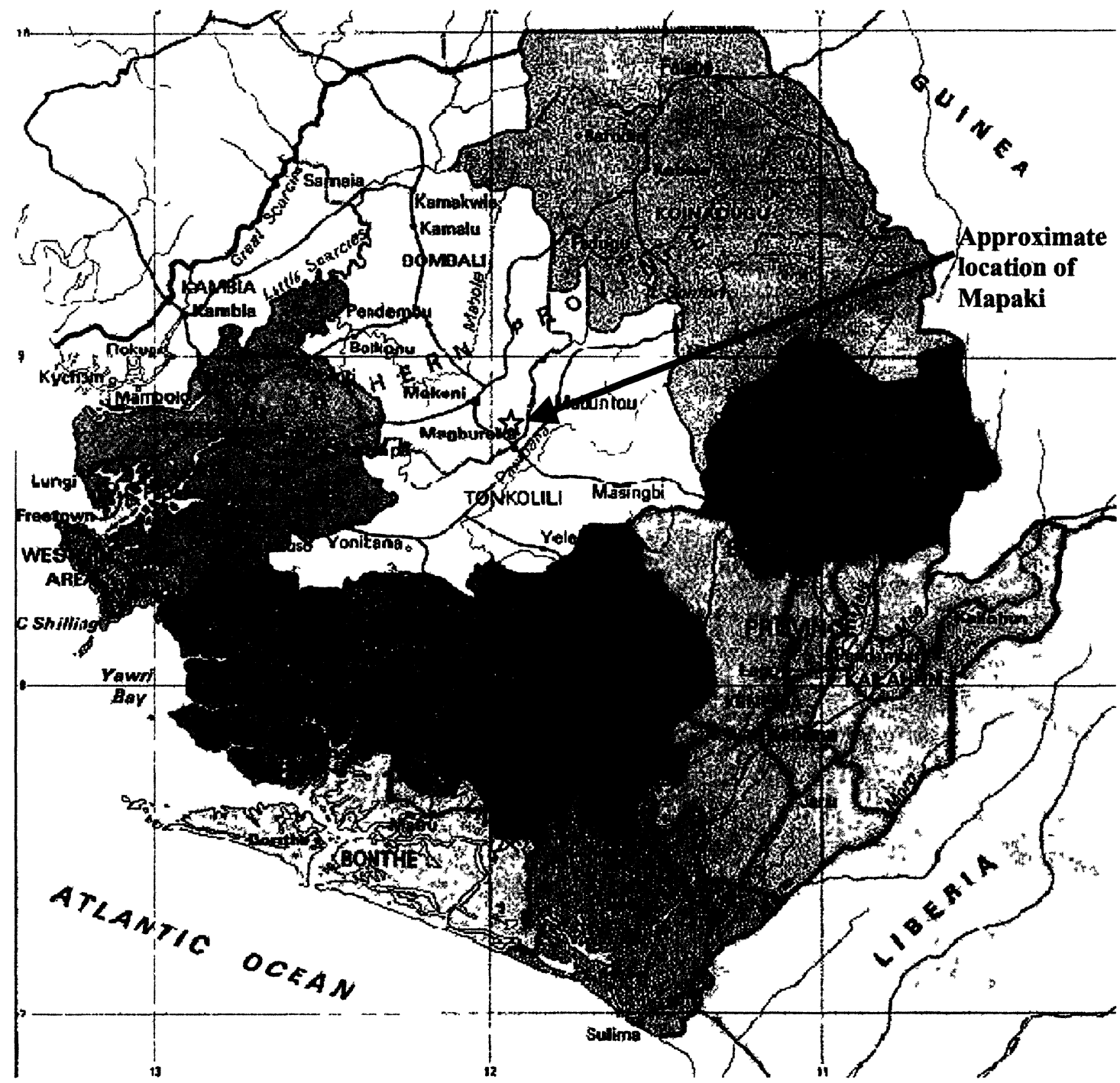




\section{APPENDIX 2: Consent Materials}

Below are the materials that were used to obtain consent, including the written and signed consent form for literate participants, and the oral consent script and signature page for illiterate participants.

\section{Carleton \\ U N I V E R S I T Y \\ Canada's Capital University}

1125 Colonel By Drive Ottawa, ON, Canada K1S 5B6

\section{CONSENT FORM}

Interviewees in "Barriers to accessing health care in Sierra Leone: Perceptions of rural women" Study

In signing this form I consent to participate in the study, "Barriers to accessing health care in Sierra Leone: Perceptions of rural women" being undertaken by Clare Levin, who is an M.A. student at the Norman Paterson School for International Affairs at Carleton University in Ottawa, Canada. Clare can be contacted at clevin@connect.carleton.ca, or by post at 2374 Clifton St., Halifax, NS, Canada, B3K 4V1.

In signing this form I agree to the following:

- I have read this form and the attached letter of information that provides an overview of the nature and purpose of this research project.

- I have had the opportunity to ask the researcher, Clare Levin, any questions and I have received satisfactory answers. I have received any additional information that I requested. - I understand that I may withdraw at any time from this study without any penalty, and I will inform the researcher if I wish to do so. If requested, all of my records associated with the study will be destroyed.

- I understand that this research project has been reviewed by and received ethics clearance through the Carleton University Research Ethics Committee.

- I understand that personal data that I provide will remain anonymous, will not be shared with other participants in the research, and that it will stored securely in the electronic and paper records of the researcher.

- I agree to participate in this study and will be interviewed by the researcher.

Research Participant

Researcher - Clare Levin 


\section{Oral Script}

My name is Clare Levin, and I am a student at Carleton University, in Ottawa, Canada, pursuing my Master's degree in International Affairs at the Norman Paterson School of International Affairs at Carleton. I am pleased to invite you to participate in the research project "Barriers to accessing health care in Sierra Leone: perceptions of rural women", which I am undertaking for my thesis. The research will be conducted by a principal researcher (myself) and will be supervised by a primary supervisor, Dr. Valerie Percival, and a second advisor, Dr. James Ron, both professors at the Norman Paterson School of International Affairs at Carleton University.

This research project will look at how women in the community of Mapaki, Sierra Leone access health care, and what barriers to accessing health care exist for this group. I hope that my research will increase our understanding of the factors that prevent women from seeking health care, and how those factors might be changed so that women can improve their health.

I will be interviewing people from the Mapaki area about this topic. I hope that you are willing to participate in an interview with me to contribute to this research. Your participation would take the form of a semi-structured interview, taking about 60-90 minutes. With your permission, I will record the interview. Anything you say during the interview will remain anonymous and you will not be named in any of the final research documents produced. There are no indirect or direct benefits to your participation, nor are there any risks. Your individual access to health care services will not be affected as a result of your participation, and you will not receive any additional services as a result of your participation.

The information collected during your interview will be used for research purposes only and will be kept anonymous. It will not be shared with any other participants in the research. It will only be seen by myself, my supervisors (Dr. Percival and Dr. Ron) and the translator (if required). All data, including recordings of interviews, will be stored in a locked (for paper files) or password-protected (for electronic files) area at all times. You may choose not to answer any question asked during the interview, and you can withdraw from the study or stop the interview at any time. If you decide to withdraw from the study, you can request that all of the information you have provided be destroyed. If you agree to participate, you will be asked to sign a consent form that says you are willing to take part in the research.

Once my research is finished, I will provide electronic copies to the Centre for Development and Peace Education (cdpeace), to community leaders in Mapaki, and to anyone else with an email address who requests a copy. Community leaders and cdpeace will share the results with the community.

This project was reviewed and received ethics clearance from the Carleton University Research Ethics Committee. Participants with concerns or questions about their 
involvement in the study may contact the ethics committee chair. The chair's name and contact information can be provided to you on request.

Questions specific to the research may be directed to myself, principal researcher, or to my research supervisor, Professor Valerie Percival. Contact information for both people can be provided to you on request.

\section{ORAL CONSENT}

Do you consent to voluntarily participating in this research project?

Do you agree to the interview being audio-recorded?

$\overline{\text { Signature of person obtaining consent - Clare Levin }}$ 


\section{APPENDIX 3: Sample Interview Questions}

The main interview questions were developed based on the theoretical model of access to health care that I used to guide my literature review. ${ }^{293}$ Questions addressing each of the four identified components of access (geographic accessibility, financial accessibility, availability and acceptability) were included. Questions on aspects of Sierra Leone's health system (for example, access to health information and the effect of the conflict on health care) were also included. I developed a draft of the questions in Canada before leaving for Sierra Leone. I then refined and revised the questions after arriving in Sierra Leone and consulting with locals and other expatriates about my study.

Each interview was digitally recorded with the permission of the interview subject. I transcribed each interview as soon as possible after the interview was finished. I made field notes on the interview process and on my own observations and experiences, which have also helped to inform my final conclusions. Below are the questions asked in field work interviews in Sierra Leone, for both individual women respondents and key informant respondents.

\section{Individual interviews}

Demographic questions:

1. How old are you?

a. If participant is not aware of their exact age, an age range 20-30, 30-40, 40-50, etc. will be estimated.

2. What is your tribe and/or religion?

3. What is your work? How do you sustain yourself? How much money do you earn in a year? How easy is it for you to get money to buy things? Where do you get the money from?

4. Did you go to school? What level did you finish?

\footnotetext{
${ }^{293}$ See Figure 1, p. 6.
} 
5. Where do you live?

6. Who do you live with?

a. Do you have a husband/wife/partner?

b. Do you have children or other dependents?

Access to care:

7. How many times in the last year have you been sick? Did you get any help to get better? From where? How did you get medicine if needed?

a. If the person did not seek care at a clinic, ask why not?

b. How did you decide when/where to get treatment?

8. Have you been pregnant in the last year? Did you have any problems with your pregnancy? Where did you get care during the pregnancy and the birth? Did you have to pay?

a. If payment (official or unofficial) was required, ask how much and for what (e.g. service, drugs, bribe, gift, etc.).

b. How many times did you see a health provider during your pregnancy and after the birth?

9. Does anything stop you from going to a hospital or a clinic when you are sick?

a. What is the biggest barrier you face? What stops you from going to the hospital or clinic?

b. How are decisions about getting health care made in your family? Do you decide yourself about what kind of care you use? Who decides what to do when you are sick?

c. If you are sick, who would care for the house and children?

10. When was the last time went to the health clinic in Mapaki? How many times in the last year did you go to the clinic? Why did you go? Did you have to pay?

a. If payment (official or unofficial) was required, ask how much and for what (e.g. service, drugs, bribe, gift, etc.).

11. How often is the clinic in Mapaki open? Who runs it (government, private, NGO)? Who works there (doctor, nurse, community health worker, other)? What kinds of services can you get (medication, malaria check, prenatal/antenatal care, immunizations, xray)?

a. What do you think of the clinic - is it good or bad at helping you when you are sick?

12. When was the last time you saw a traditional healer? How many times in the last year did you see a traditional healer? Why did you go? Did you have to pay to see the traditional healer?

a. If payment (official or unofficial) was required, ask how much and for what (e.g. service, drugs, bribe, gift, etc.). 
b. What do you think of the traditional healers - are they good or bad at helping you when you are sick?

13. When was the last time you went to a hospital? How many times in the last year did you go to the hospital? Why did you go? Did you have to pay?

a. If payment (official or unofficial) was required, ask how much and for what (e.g. service, drugs, bribe, gift, etc.).

b. How would you get to the hospital? Are there costs associated with getting there?

c. What do you think of the hospital - is it good or bad at helping you when you are sick?

d. Would you be more likely to go to the hospital if it was closer? What about if it was free? Why or why not?

14. What is the most you have had to pay for care when you were sick? Did this cause a problem for you and your family? Why or why not?

15. Can you get help accessing medical care, such as help with the costs or with transportation? Who would help you?

16. Do you know of any health services that are offered for free? Have you ever received a service from a hospital or clinic for free?

17. Where do you get information about health?

18. Compared to men, do you think it is easier or harder for women to get care when they are sick? Why or why not?

a. Would you be comfortable with a male nurse? A male doctor? A male traditional healer?

19. What was health care like before the conflict? What is it like now? Are things better or worse?

Other:

20. Is there anything else you would like to share with me? Do you have any questions for me?

\section{Key Informant Interviews}

\section{Identification questions:}

1 . What is your role in the community?

a. If respondent works for a health care provider, ask: What organization do you work for? What kinds of health services do you provide? 
2. How long have you been in this role?

Health System:

3. What can you tell me about the health system in Sierra Leone?

4. What kinds of health services are provided by the government? NGOs? Traditional healers?

a. What role do you think the government should play in providing health care for people?

5. Very often fees are charged for different types of health care (hospitals, clinics and traditional healers). What can you tell me about these fees? Why are they charged? Are they official or non-official fees?

a. Is it common to pay informal fees (e.g. a gift or bribe) to health providers?

6. Are there many home births? Who performs them in Mapaki?

a. How many times would a woman who was pregnant usually see a health provider during her pregnancy and after the birth?

Access to care:

7. What do you think are the key factors that prevent women in Mapaki from seeking medical care? Which, in your opinion, is most important?

a. If required, prompt about geographic accessibility, financial accessibility, acceptability, availability.

b. Ask about the roles of men and women in making decisions about health care in a family.

8. Are you aware of resources or supports provided in Mapaki or by the national or local governments to help people access care? If so, what are they?

9. How far do people travel to get health services? How do patients usually get there?

10. Do women normally pay for health services? How does this affect women's decisions about accessing health care?

a. In your experience, how do people find the money to pay for services?

b. If respondent works for a health care provider, ask: Do you provide any fee exemptions? Are you aware of any?

c. Why do you think existing exemptions from fees are not honoured?

11. What happens to women who can not afford to pay the fees for health care?

12. What do you think of the quality of health care available to women living in Mapaki? 
a. What can you tell me about the availability of staff, medications, supplies and equipment in the clinics? What about the skills and training of the staff?

b. How do you think the quality of health services offered in clinics and hospitals affects decisions about whether or not to seek care?

c. Is there a difference in the quality of health care in urban vs. rural areas?

13. Where do people get their information about health? Can you comment on the general level of knowledge about health care among women in Mapaki?

a. Does your organization/Do you carry out any campaigns/programs around health education?

14. Are you familiar with any spiritual or cultural practices that affect people's decisions about seeking health care? If so, please tell me about those.

15. Do you think there is a difference in ability to access health care between men and women? Why or why not?

a. Ask here about the roles of men and women in making decisions about health care in a family if not discussed above.

16. What was health care like before the conflict? What is it like now? Are things better or worse?

17. Is there anything else you would like to share with me? Do you have any questions for me? 


\section{APPENDIX 4: Coding Structure}

Below is an outline of the coding structure used to code participant responses.

\begin{tabular}{|c|c|}
\hline Code Name & Description \\
\hline Available health services & $\begin{array}{l}\text { Discussion of the types of health services that are available at particular } \\
\text { health facilities. }\end{array}$ \\
\hline $\begin{array}{l}\text { General hospital } \\
\text { services }\end{array}$ & Services in any hospital \\
\hline $\begin{array}{l}\text { Makeni government } \\
\text { hospital }\end{array}$ & Services at the Makeni government hospital \\
\hline Mapaki clinic & Services at the Mapaki clinic \\
\hline Pépé doctors & Services provided by Pépé doctors \\
\hline Barriers to care & $\begin{array}{l}\text { Comments related to any one of the barriers to health care identified in } \\
\text { the theoretical model. }\end{array}$ \\
\hline Acceptability & Comments related to acceptability. \\
\hline Availability & Comments related to availability. \\
\hline Financial & Comments related to financial accessibility. \\
\hline $\begin{array}{l}\text { Financial - payment } \\
\text { strategies }\end{array}$ & $\begin{array}{l}\text { Comments about payment strategies used by patients to pay costs (direct } \\
\text { and indirect) of health care. }\end{array}$ \\
\hline Geography & Comments related to geographic accessibility. \\
\hline $\begin{array}{l}\text { Geography - } \\
\text { transportation costs }\end{array}$ & Comments about transportation costs in accessing health care. \\
\hline Cultural practices & $\begin{array}{l}\text { Discussion about cultural practices that relate to health and access to } \\
\text { health care. }\end{array}$ \\
\hline Gender roles & Discussion of gender roles and/or how they impact health and health care. \\
\hline Health care costs & Discussion about the costs of any type of health care (formal or informal). \\
\hline Fee exemptions & Discussion about fee exemptions. \\
\hline $\begin{array}{l}\text { Fees for traditional } \\
\text { healers }\end{array}$ & $\begin{array}{l}\text { Discussion about fees paid to traditional healers or the cost of care from } \\
\text { traditional healers. }\end{array}$ \\
\hline Formal fees & Comments about official fees paid in the formal health care system. \\
\hline Free services & Discussion of any free health services received or known about. \\
\hline Hospital fees & Comments about the costs of care in hospitals. \\
\hline Informal fees & Comments about informal fees paid for health care. \\
\hline In-kind fees & Discussion about any in-kind fees paid for health care. \\
\hline Mapaki clinic fees & Reference to any type of fees paid at the Mapaki clinic. \\
\hline Health decision-making & Discussion about how decisions on health care are made within families. \\
\hline Health information & Reference to health information. \\
\hline Level & $\begin{array}{l}\text { Comments about the level of health information (respondent or within the } \\
\text { general population). }\end{array}$ \\
\hline Sources & Discussion about where respondents get health information. \\
\hline Health system & Discussion about any aspect of Sierra Leone's health system. \\
\hline Corruption & $\begin{array}{l}\text { Comments about corruption in the health system (direct or indirect } \\
\text { reference). }\end{array}$ \\
\hline Financing & Comments about how the health system is financed, level of financing. \\
\hline Functioning & Comments about how the health system does or doesn't function. \\
\hline Income & $\begin{array}{l}\text { Reference to how participants earned cash income, or how much they } \\
\text { earned. }\end{array}$ \\
\hline NGOs & Discussion about the role of NGOs in providing health services. \\
\hline Polygyny & Discussion of the effects of polygyny on health. \\
\hline
\end{tabular}




\begin{tabular}{|c|c|}
\hline Pregnancy & Comments related to pregnancy. \\
\hline Care during & $\begin{array}{l}\text { Comments about the care pregnant women receive or that respondents } \\
\text { who were pregnant received. }\end{array}$ \\
\hline Complications & $\begin{array}{l}\text { Discussion of any complications during a pregnancy and how they were } \\
\text { treated. }\end{array}$ \\
\hline Costs & $\begin{array}{l}\text { Comments about how the costs associated with being pregnant and } \\
\text { delivering a baby. }\end{array}$ \\
\hline Delivery & Comments about delivery of a baby. \\
\hline TBAs & $\begin{array}{l}\text { Discussion of the role or use of Traditional Birth Attendants (TBAs) } \\
\text { during pregnancy and birth. }\end{array}$ \\
\hline Quality & Comments referring to the quality of health services. \\
\hline Questions & Responses to specific interview questions. \\
\hline Barriers to access & $\begin{array}{l}\text { Q7 in the Key Informant interview: "What do you think are the key } \\
\text { factors that prevent women in Mapaki from seeking medical care? Which, } \\
\text { in your opinion, is most important?" } \\
\text { Q9 in the Ind interview: "Does anything stop you from going to a hospital } \\
\text { or a clinic when you are sick?" }\end{array}$ \\
\hline Biggest cost & $\begin{array}{l}\text { Responses to Ind. interview Q14: "What is the most you have had to pay } \\
\text { for care when you were sick? Did this cause a problem for you and your } \\
\text { family? Why or why not?" }\end{array}$ \\
\hline Community supports & $\begin{array}{l}\text { Responses to Ind. Interview Q15: "Can you get help accessing medical } \\
\text { care, such as help with the costs or with transportation? Who would help } \\
\text { you?" }\end{array}$ \\
\hline Free services & $\begin{array}{l}\text { Responses to Ind. Interview Q16, "Do you know of any health services } \\
\text { that are offered for free?" }\end{array}$ \\
\hline Traditional healers & $\begin{array}{l}\text { Discussion of the role of traditional healers, the work they do, the care } \\
\text { they provide, or experiences of seeing a traditional healer. }\end{array}$ \\
\hline Training & $\begin{array}{l}\text { References to the training health care workers receive or their level of } \\
\text { training, skill or knowledge. }\end{array}$ \\
\hline Use of health services & Discussion of health services participants have used. \\
\hline Hospital pregnancy & Respondent used a hospital for treatment when pregnant. \\
\hline Hospital sick & Respondent used a hospital for treatment when sick. \\
\hline $\begin{array}{l}\text { Mapaki clinic } \\
\text { pregnancy }\end{array}$ & Respondent used the clinic in Mapaki for treatment when pregnant. \\
\hline Mapaki clinic sick & Respondent used the clinic in Mapaki for treatment when sick. \\
\hline $\begin{array}{l}\text { Traditional healer } \\
\text { pregnancy }\end{array}$ & Respondent used a traditional healer for treatment when pregnant. \\
\hline $\begin{array}{l}\text { Traditional healer } \\
\text { sick }\end{array}$ & Respondent used a traditional healer for treatment when sick. \\
\hline War & $\begin{array}{l}\text { Comments about the war, the effect of the war on health services or on } \\
\text { health status. }\end{array}$ \\
\hline $\begin{array}{l}\text { Health now vs. } \\
\text { before }\end{array}$ & Comments comparing health care now vs. before the conflict. \\
\hline Women vs. men & $\begin{array}{l}\text { Discussion of differences between men and women in access to care, use } \\
\text { of care, and health problems. }\end{array}$ \\
\hline Access to care & $\begin{array}{l}\text { Discussion of differences between men and women in access to health } \\
\text { care. }\end{array}$ \\
\hline Health problems & $\begin{array}{l}\text { Discussion of differences between men and women in the health } \\
\text { problems they have. }\end{array}$ \\
\hline Use & cussio \\
\hline
\end{tabular}




\section{BIBLIOGRAPHY}

"Sierra Leone Doctors and Nurses Get Massive Pay Rise." http://news.bbc.co.uk/2/hi/africa/8591682.stm (accessed March 29, 2010).

"Sierra Leone Starts Free Care for Mothers and Children." http://news.bbc.co.uk/2/hi/8645968.stm (accessed April 28, 2010).

"Sierra Leone: Maternity Hospital Is "Last Resort"." http://www.irinnews.org/report.aspx?ReportId=77252 (accessed July 15, 2009).

Abraham, Arthur. "Dancing with the Chameleon: Sierra Leone and the Elusive Quest for Peace." Journal of Contemporary African Studies 19, no. 2 (July 2001): 205-28.

Adebajo, Adekeye. Building Peace in West Africa: Liberia, Sierra Leone and GuineaBissau. Boulder: Lynne Rienner Publishers Inc., 2001.

Akin, J. S. and P. Hutchinson. "Health-Care Facility Choice and the Phenomenon of Bypassing." Health Policy and Planning 14, no. 2 (June 1999): 135-51.

Alderman, Harold and Victor Lavy. "Household Responses to Public Health Services: Cost and Quality Tradeoffs." The World Bank Research Observer 11, no. 1 (February 1996): 3-22.

Amnesty International. "Maternal Death Rate in Sierra Leone Is A "Human Rights Emergency"." http://www.amnesty.org/en/news-and-updates/report/maternaldeath-rate-sierra-leone-quothuman-rights-emergencyquot-20090921 (accessed October 15, 2009).

Andaleeb, Syed Saad. "Service Quality Perceptions and Patient Satisfaction: A Study of Hospitals in a Developing Country." Social Science \& Medicine 52, no. 9 (May 2001): 1359-70.

Bhutta, Zulfiqar A. et al. "Countdown to 2015 Decade Report (2000-10): Taking Stock of Maternal, Newborn, and Child Survival." The Lancet 375, no. 9730 (June 5, 2010): 2032-44.

Campbell, Oona M R and Wendy J Graham. "Strategies for Reducing Maternal Mortality: Getting on with What Works." The Lancet 368, no. 9543: 1284-99.

Center for Pharmaceutical Management. "Defining and Measuring Access to Essential Drugs, Vaccines, and Health Commodities." Paper presented at the WHO-MSH Consultative Meeting, Strategies for Enhancing Access to Medicines Program, Ferney-Voltaire, France, December 11-13, 2000. 
Cham, Mamady, Johanne Sundby, and Siri Vangen. "Maternal Mortality in the Rural Gambia, a Qualitative Study on Access to Emergency Obstetric Care." Reproductive Health 2, no. 3 (May 4, 2005), http://www.reproductive-healthjournal.com/content/2/1/3 (accessed June 15, 2010).

Davies, Philip and Guy Carrin. "Risk-Pooling - Necessary but Not Sufficient?" Bulletin of the World Health Organization 79, no. 7: 587.

Department for International Development (DFID). Working Together for Better Health. Department for International Development (DFID), 2007. http://www.dfid.gov.uk/Documents/publications/health-strategy07.pdf (accessed June 18, 2009).

Editorial. "Gender Equity Is the Key to Maternal and Child Health." The Lancet 375, no. 9730 (June 5, 2010): 1939.

Ekman, Björn. "Community-Based Health Insurance in Low-Income Countries: A Systematic Review of the Evidence." Health Policy and Planning 19, no. 5 (2004): 249-70.

Fabricant, Stephen J., Clifford W. Kamara, and Anne Mills. "Why the Poor Pay More: Household Curative Expenditures in Rural Sierra Leone." The International Journal of Health Planning and Management 14, no. 3 (July 1999): 179-99.

Fofanah, Mohamed. "Bold Plan for Maternal Health." http://www.ipsnews.net/africa/nota.asp?idnews=51279 (accessed May 1, 2010).

Fryatt, Robert, Anne Mills, and Anders Nordstrom. "Financing of Health Systems to Achieve the Health Millennium Development Goals in Low-Income Countries." The Lancet 375, no. 9712 (January 30, 2010): 419-26.

Gil-Lacruz, Marta and Ana I. Gil-Lacruz. "Health Perception and Health Care Access: Sex Differences in Behaviors and Attitudes." The American Journal of Economics and Sociology 69, no. 2: 783-801.

Gottret, Pablo and George Schieber. Health Financing Revisited: A Practitioner's Guide. Washington, D.C.: The International Bank for Reconstruction and Development/The World Bank, 2006.

Government of Sierra Leone. An Agenda for Change: Second Poverty Reduction Strategy (PRSP II), 2008-2012. Freetown, Sierra Leone, 2008.

- Free Healthcare Services for Pregnant and Lactating Women and Young Children in Sierra Leone. Freetown, Sierra Leone: Government of Sierra Leone, November 2009. 
http://www.sierraleoneconference2009.org/docs/free services framewk_nov09.p df (accessed November 29, 2009).

Sierra Leone Integrated Household Survey (SLIHS) 2003/04: Final Statistical Report. Freetown: Government of Sierra Leone, November 2007.

http://www.statistics.sl/SLIHS_REPORT.pdf (accessed January 13, 2010).

Government of Sierra Leone, European Commission, and UK Department for International Development. Sierra Leone - European Community Country Strategy Paper and National Indicative Programme for the Period 2008-2013. European Commission, December 9, 2007. http://ec.europa.eu/development/icenter/repository/scanned_sl_csp10_en.pdf (accessed August 13, 2009).

Hanlon, Joseph. "Is the International Community Helping to Recreate the Preconditions for War in Sierra Leone?" The Round Table 94, no. 381 (September 2005): 45972 .

Hardeman, Wim et al. "Access to Health Care for All? User Fees Plus a Health Equity Fund in Sotnikum, Cambodia." Health Policy and Planning 19, no. 1 (January 2004): 22-32.

Hardiman, Margaret G. W. and J. O. Midgley. "Planning and the Health of Mothers and Children in the Rural Areas of Sierra Leone." Journal of Tropical Pediatrics 27, no. 2 (April 1981): 83-87.

Hirsch, John L. Sierra Leone: Diamonds and the Struggle for Democracy. Boulder: Lynne Rienner Publishers Inc., 2001.

Hjortsberg, Catharina. "Why Do the Sick Not Utilise Health Care? The Case of Zambia." Health Economics 12, no. 9 (July 2003): 755-70.

Hogan, Margaret C et al. "Maternal Mortality for 181 Countries, 1980-2008: A Systematic Analysis of Progress Towards Millennium Development Goal 5." The Lancet 375, no. 9726 (April 12, 2010): 1609-23.

International Crisis Group. Sierra Leone: A New Era of Reform? 31 July 2008. http://www.crisisgroup.org/library/documents/africa/west_africa/143_sierra_leone a_new_era_of_reform.pdf (accessed January 29, 2009).

Kamara, Joseph A.L. et al. 2004 Population and Housing Census: Analytical Report on the Mortality and Disability Status of the Population. Freetown, Sierra Leone: Statistics Sierra Leone, November 2006. http://www.statistics.sl $/ 2004 \% 20$ Pop.\%20\&\%20Hou.\%20Census\%20Analytical $\% 20$ Reports $/ 2004 \% 20$ Population $\% 20$ and $\% 20$ Housing $\% 20$ Census $\% 20$ Report $\% 20$ on\%20Morbidity\%20and\%20Mortality.pdf (accessed August 13, 2009). 
Konteh, Richard. "Socio-Economic and Other Variables Affecting Maternal Mortality in Sierra Leone." Community Development Journal 32, no. 1 (January 1997): 49-64.

Lavy, Victor et al. "Quality of Health Care, Survival and Health Outcomes in Ghana." Journal of Health Economics 15, no. 3 (June 1996): 333-57.

Lehmann, Uta and David Sanders. Community Health Workers: What Do We Know About Them? The State of the Evidence on Programmes, Activities, Costs and Impact on Health Outcomes of Using Community Health Workers. Geneva: WHO, Evidence and Information for Policy, Department of Human Resources for Health, January 2007. http://www.who.int/hrh/documents/community health_workers.pdf (accessed July 1, 2010).

Leigh, B. et al. "Improving Emergency Obstetric Care at a District Hospital, Makeni, Sierra Leone." International Journal of Gynecology \& Obstetrics 59, no. Suppl. 2 (November 1997): S55-S65.

Litvack, Jennie I. and Claude Bodart. "User Fees Plus Quality Equals Improved Access to Health Care: Results of a Field Experiment in Cameroon." Social Science \& Medicine 37, no. 3 (August 1993): 369-83.

McIntyre, Diane et al. "What Are the Economic Consequences for Households of Illness and of Paying for Health Care in Low- and Middle-Income Country Contexts?" Social Science \& Medicine 62, no. 4: 858-65.

Médecins Sans Frontières. Access to Healthcare in Post-War Sierra Leone: Summary of a 2005 Survey in Four Districts: Kambia, Tonkolili, Bombali, Bo. January 2006. http://www.msf.org/source/countries/africa/sleone/2006/Sierra_Leone_survey_2005_summary.pdf (accessed June 15, 2009).

Ministry of Health and Sanitation for the Republic of Sierra Leone. Basic Package of Essential Health Services (BPEHS). Freetown, Sierra Leone, March 2010.

- Health Interventions to Reduce under-Fives and Maternal Mortality Rates. Freetown, Sierra Leone, March 2006.

_ . "List of Health Registered NGOs in Sierra Leone 2007." http://www.health.sl/drwebsite/uploads/health_2007.xls (accessed January 19, 2010).

- National Health Policy. Freetown, Sierra Leone: Republic of Sierra Leone, 2002. http://www.health.sl/drwebsite/uploads/national_health_policy.doc (accessed August 13, 2009). 
- National Health Sector Strategic Plan (NHSSP), 2010 - 2015, Draft. Freetown, Sierra Leone, October 2009.

Mwabu, Germano, Martha Ainsworth, and Andrew Nyamete. "Quality of Medical Care and Choice of Medical Treatment in Kenya: An Empirical Analysis." Journal of Human Resources 28, (Fall 1993): 838-62.

Nabyonga, J. et al. "Abolition of Cost-Sharing Is Pro-Poor: Evidence from Uganda." Health Policy and Planning 20, no. 2 (March 2005): 100-08.

National Democratic Institute. Final Report on Sierra Leone's 2007 Elections. 2008. http://www.ndi.org/files/NDI_Final_Report on_2007_Sierra_Leone_Elections.pd f (accessed March 26, 2009).

O'Donnell, Owen. "Access to Health Care in Developing Countries: Breaking Down Demand Side Barriers." Cadernos Saúde Pública / Reports in Public Health 23, no. 12 (December 2007): 2820-28-34.

Office of the Prime Minister of Canada. "Canada's G8 Priorities." http://pm.gc.ca/eng/media.asp?id=3093 (accessed March 28, 2010).

Penchansky, Roy and J. William Thomas. "The Concept of Access: Definition and Relationship to Consumer Satisfaction " Medical Care 19, no. 2 (February 1981): $127-40$.

Peters, David H. et al. "Poverty and Access to Health Care in Developing Countries." Annals of the New York Academy of Sciences 1136, no. Reducing the Impact of Poverty on Health and Human Development: Scientific Approaches (June 2008): $161-71$.

Roberts, Marc J. et al. Getting Health Reform Right: A Guide to Improving Performance and Equity. Oxford: Oxford University Press, 2004.

Samb, Badara. "Reforming Country Health Systems for Women's Health." The Lancet 375, no. 9712 (January 30, 2010): 354-55.

Smith, Peter C. and Sopie N. Witter. Risk Pooling in Health Care Financing: The Implications for Health System Performance. Washington, DC: The International Bank for Reconstruction and Development / The World Bank, September 2004. http://www.heart-intl.net/HEART/061508/RiskPoolinginHealth.pdf (accessed July 2, 2010).

Statistics Sierra Leone and ICF Macro. Sierra Leone Demographic and Health Survey 2008. Calverton, Maryland, USA: Statistics Sierra Leone and ICF Macro, July 2009. 
The World Bank Group. "Mobile Cellular Subscriptions (Per 100 People)." World Development Indicators, http://ddpext.worldbank.org.proxy.library.carleton.ca/ext/DDPQQ/report.do?method=show

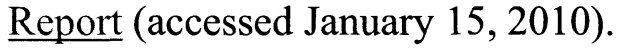

- . "Sierra Leone Country Data Profile." http://ddpext.worldbank.org/ext/ddpreports/ViewSharedReport?\&CF=\&REPORT ID $=914$ 7\&REQUEST TYPE=VIEWADVANCED (accessed January 15, 2010).

Thomas, Armand, Veronica M. MacCormack, and Peter S. Bangura. 2004 Population and Housing Census: Analytical Report on Population Size and Distribution Age and Sex Structure. Freetown, Sierra Leone: Statistics Sierra Leone, November 2006.

http://www.statistics.sl $/ 2004 \% 20$ Pop. $\% 20 \& \% 20$ Hou. $\% 20$ Census $\% 20$ Analytical $\% 20$ Reports $/ 2004 \% 20$ Census $\% 20$ Report $\% 20$ on $\% 20$ Population $\% 20$ Size $\% 20$ Age $\% 20$ and $\% 20$ Sex $\% 20$ Structure.pdf (accessed August 13, 2009).

Thomas, J. William and Roy Penchansky. "Relating Satisfaction with Access to Utilization of Services." Medical Care 22, no. 6 (June 1984): 553-68.

Tian, Lichun et al. "Women's Status, Institutional Barriers and Reproductive Health Care: A Case Study in Yunnan, China." Health Policy 84, no. 2-3 (December 2007): 284-97.

Ulin, Priscilla R., Elizabeth T. Robinson, and Elizabeth T. Tolley. Qualitative Methods in Public Health: A Field Guide for Applied Research. San Francisco, CA: JosseyBass, 2005.

United Nations. "Human Development Report 2009 - HDI Rankings." Statistics - Human Development Reports (UNDP), http://hdr.undp.org/en/statistics/ (accessed January 18, 2010).

United Nations Millennium Project. "Chapter 12: Strategies for Countries Affected by Conflict." In Investing in Development: A Practical Plan to Achieve the Millennium Development Goals, 183-90. London: Earthscan, 2005.

van Gurp, Gerald. "Asset-Based Needs Assessment: Paki Masabong and Gbonkolenken Chiefdoms: Northern Province, Sierra Leone." 2009.

Vlassoff, Carol. "Gender Inequalities in Health in the Third World: Uncharted Ground." Social Science \& Medicine 39, no. 9 (November 1994): 1249-59.

Wilkinson, David et al. "Effect of Removing User Fees on Attendance for Curative and Preventive Primary Health Care Services in Rural South Africa." Bulletin of the World Health Organization 79, no. 7 (July 2001): 665-71. 
Wong, Emelita L. et al. "Accessibility, Quality of Care and Prenatal Care Use in the Philippines." Social Science \& Medicine 24, no. 11 (1987): 927-44.

World Health Organization. Country Health System Fact Sheet 2006 - Sierra Leone. 2006. http://www.afro.who.int/home/countries/fact sheets/sierraleone.pdf (accessed July 1, 2009).

- Everybody's Business: Strengthening Health Systems to Improve Health Outcomes: WHO's Framework for Action. Geneva: World Health Organization, 2007. http://www.who.int/healthsystems/strategy/everybodys business.pdf (accessed June 26, 2010).

—. "What Is a Health System?" http://www.who.int/features/qa/28/en/ (accessed January 16, 2010).

-WHO Country Cooperation Strategy: Sierra Leone, 2004-2007. 2004. http://www.who.int/countryfocus/cooperation_strategy/ccs_sle en.pdf (accessed August 14, 2009).

—_. "WHO Statistical Information System (WHOSIS)." http://www.who.int/whosis/ (accessed August 13, 2009).

Yates, Rob. International Experiences in Removing User Fees for Health Services Implications for Mozambique. London: DFID Health Resource Centre, June 2006. http://www.dfidhealthrc.org/publications/health_sector_financing/06Yates01.pdf (accessed July 1, 2009).

Zack-Williams, A.B. "International Intervention and Struggle for Democracy." In The Quest for Sustainable Development \& Peace: The 2007 Sierra Leone Elections, edited by A.B. Zack-Williams, 14-36. Stockholm: Nordiska Afrikainstitutet, 2008.

Zack-Williams, A.B. and Osman Gbla. "The Conduct of the Elections: Challenges of Peacebuilding and Democratisation." In The Quest for Sustainable Development \& Peace: The 2007 Sierra Leone Elections, edited by A.B. Zack-Williams, 14-36. Stockholm: Nordiska Afrikainstitutet, 2008. 